RAFAEL BATEZINI

ESTUDO PRELIMINAR DE CONCRETOS PERMEÁVEIS COMO REVESTIMENTO DE PAVIMENTOS PARA ÁREAS DE VEÍCULOS LEVES 
RAFAEL BATEZINI

Engenheiro Civil, Universidade de Passo Fundo, 2009

\section{ESTUDO PRELIMINAR DE CONCRETOS PERMEÁVEIS COMO REVESTIMENTO DE PAVIMENTOS PARA ÁREAS DE VEÍCULOS LEVES}

Dissertação apresentada à Escola

Politécnica da Universidade de São Paulo como requisito para obtenção do título de Mestre em Engenharia

Área de Concentração: Engenharia de Transportes - Infraestrutura de Transportes

Orientador: Prof. Dr. José Tadeu Balbo 
Este exemplar foi revisado e alterado em relação à versão original, sob responsabilidade única do autor e com a anuência de seu orientador.

São Paulo, 09 de janeiro de 2013.

Assinatura do autor

Assinatura do orientador

FICHA CATALOGRÁFICA

Batezini, Rafael

Estudo preliminar de concretos permeáveis como revesti mento de pavimentos para áreas de veículos leves / R. Batezini. -- ed.rev. -- São Paulo, 2013.

p.133

Dissertação (Mestrado) - Escola Politécnica da Universidade de São Paulo. Departamento de Engenharia de Transportes.

1. Transportes 2. Pavimentação de concreto 3. Veículos leves sobre pneus 4. Concretos permeáveis I. Universidade de São Paulo. Escola Politécnica. Departamento de Engenharia de Transportes II. t. 


\section{AGRADECIMENTOS}

Primeiramente, gostaria de agradecer aos meus pais, Nadir e Evani, e irmãos, André e João Batista, pelo incentivo que se estendeu desde o início da minha etapa estudantil até os dias atuais.

Aos meus sobrinhos, Enzo, Kaynã e Vicente (In Memoriam) por me mostrarem o sentido da vida.

Ao meu orientador, Prof. Dr. José Tadeu Balbo, por ter se dedicado e se empenhado durante todo o meu mestrado. Foram de extrema valia todos os conselhos, conversas e discussões, pelo seu apoio e confiança e, acima de tudo, por acreditar no meu potencial.

Ao Laboratório de Construção Civil do PCC e seus funcionários, em especial o Sr. Adílson.

Ao Laboratório de Tecnologia da Pavimentação da EPUSP, em especial ao Dr. Edson de Moura.

À Holcim Brasil S/A, eng. José Wanderlei de Abreu e toda a sua equipe, em especial Donizete, Fernando, Chico e Márcio; por disponibilizarem materiais, infraestrutura e mão de obra para a realização das moldagens.

À minha banca de qualificação, Prof. Dr. Antonio Domingues Figueiredo e a Dra. Dirce Carregã Balzan, pelos conselhos e válidas considerações feitas na etapa de qualificação.

Ao CNPQ pela bolsa de mestrado.

Ao Prof. Dr. Carlos Yukio Suzuki, à engenheira Angela e ao engenheiro Caio por ajudarem a sanar várias das dúvidas que tive ao longo do meu mestrado.

Aos meus colegas de laboratório, Virgínia, Ester, Bruno e Lúcio pelos auxílios em vários momentos de necessidade.

À minha noiva Ana Patrícia pelo apoio em todos os momentos desde que cheguei a São Paulo para iniciar o mestrado. 
Aos meus amigos de longa data, Abel, Afonso, Renan, Thomaz, entre outros, os quais eu considero como irmãos e me auxiliaram de inúmeras maneiras ao longo de toda a minha vida.

Aos antigos companheiros de república, Ciro, Leonardo e Paula, que me auxiliaram na minha adaptação às novas mudanças no início do meu mestrado. 
Se exponha aos seus medos mais profundos. Depois disso, o medo não terá poder algum e o medo da liberdade encolhe e desaparece. Você é livre.

(Jim Morrison) 


\section{RESUMO}

Esta pesquisa teve por finalidade estudar concretos permeáveis para uso como camada de revestimento de pavimentos em áreas de veículos leves, por meio da realização de ensaios laboratoriais de caracterização mecânica e hidráulica para três diferentes misturas com variação do diâmetro máximo de agregados graúdos. Além disso, o estudo procurou interpretar o comportamento desse material quando solicitado por cargas de veículos, a partir de análises numéricas utilizando o software EverFE para análise de placas de concreto por elementos finitos.

A caracterização mecânica foi realizada com base em ensaios de resistência à tração na flexão, tração indireta por compressão diametral, compressão, módulo de elasticidade estático e módulo de elasticidade dinâmico por equipamento ultrassônico. Para determinação da condutividade hidráulica foi utilizado um permeâmetro de carga constante. As análises mecanicistas envolveram estudos de placas de concreto permeável solicitadas por um eixo simples de rodas duplas com carga de $80 \mathrm{kN}$ e por um eixo simples de roda simples com carga de $22 \mathrm{kN}$, simulando, nesse caso, um veículo utilitário leve.

O material estudado apresentou para um índice de vazios de aproximadamente 0,25 , valores de condutividade hidráulica na ordem de $0,14 \mathrm{~cm} / \mathrm{s}$, aproximadamente, caracterizando um material com boa drenabilidade. Com relação às características mecânicas, apresentou resistência à tração na flexão de aproximadamente $2,1 \mathrm{MPa}$ e módulo de elasticidade estático na ordem de $15.000 \mathrm{MPa}$, se aproximando da metade dos valores normalmente observados em concretos convencionais de uso corrente na pavimentação. Por meio da realização das análises mecanicistas, foi possível avaliar que o material estudado apresenta resistência suficiente para ser utilizado como revestimento de pavimentos para áreas de veículos leves.

PALAVRAS CHAVE: concreto permeável, resistência, permeabilidade, análises mecanicistas 


\begin{abstract}
The main goal of this research was to study the pervious concrete material as the surface layer for light traffic pavement by carrying out a laboratorial analysis in order to better understand the mechanical and hydraulic behavior of three different coarse aggregate gradation mixtures. Besides that, it was applied a Finite Element Analysis in order to identify the pervious concrete behavior when loaded by different vehicle loads by using the EverFE Software
\end{abstract}

The mechanical characterization was developed by evaluating the tests results of flexural strength, split tensile strength, compressive strength, Young's Modulus and the non-destructive ultrasonic test. The hydraulic conductivity was measured using a constant head permeameter. In order to carry out the mechanistic analysis, it was considered a pervious concrete slab loaded by both an $80 \mathrm{kN}$ dual wheel axle, and, to simulate a light vehicle, a $22 \mathrm{kN}$ single wheel axle.

The studied material has shown, considering the void ratio of 0,25 , values of hydraulic conductivity around $0,14 \mathrm{~cm} / \mathrm{s}$, characterizing a material with good drenability characteristics. Besides that, it presented a flexural strength of $2,1 \mathrm{MPa}$ and Young's Modulus of 15.000 MPa, reaching the half of the values commonly used in regular concretes for pavements. By using the mechanistic analysis, it was possible to assess that this specific studied pervious concrete has enough strength to be used as the surface layer of pavements loaded by lightweight vehicles.

KEY WORDS: pervious concrete, strength, permeability, mechanistic analysis 


\section{LISTA DE ILUSTRAÇÕES}

Figura 1.1: a) Relação entre área permeável e a densidade populacional baseada em dados obtidos nas cidades de São Paulo, Curitiba e Porto Alegre. b) Relação entre crescimento populacional e número de eventos de cheia em Belo Horizonte.

Figura 1.2: Porcentagem de áreas impermeabilizadas com relação aos diferentes tipos de uso e ocupação do solo.

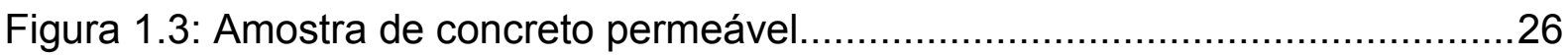

Figura 1.4: Curvas granulométricas típicas de misturas de concreto permeável ......29

Figura 1.5: Permeâmetro de carga variável utilizado para medir a condutividade hidráulica de amostras de concreto permeável

Figura 1.6: Relação entre o índice de vazios e a condutividade hidráulica do concreto permeável.

Figura 1.7: (a): Fissuras paralelas e verticais através da pasta e da ZT; (b) e (c): Fissuras paralelas à superfície que propagaram através do agregado e da pasta. (escala: $1 / 0,8 \mathrm{~mm}$ ).

Figura 1.8: Resistência à compressão (dividido por 10) e resistência à tração na flexão em função da variação do índice de vazios

Figura 1.9: Efeito da energia de compactação na resistência à compressão em corpos de prova rompidos aos 7 dias.

Figura 1.10: Efeito da energia de compactação na relação entre a resistência à compressão e resistência à tração por compressão diametral.

Figura 1.11: Efeito da energia de compactação na variação da massa unitária em função do índice de vazios .

Figura 1.12: Efeito do látex na permeabilidade do concreto permeável.

Figura 1.13: Efeito do látex na resistência à tração por compressão diametral do concreto permeável

Figura 1.14: Variação da resistência à fadiga em função das diferentes relações entre tensão máxima e tensão resistente e relações entre tensão máxima de carregamento e tensão mínima de descarregamento

Figura 1.15: Valores máximos e mínimos da evolução de deformação total durante os testes 
Figura 1.16: Relação entre o módulo de elasticidade e a resistência à compressão de amostras de concreto permeável .

Figura 1.17: Diferença entre superfícies de pavimento de concreto permeável e pavimento asfáltico impermeável após a ocorrência da precipitação

Figura 1.18: Comparação entre a profundidade de congelamento entre os pavimentos permeáveis e o pavimento de referência

Figura 1.19: Procedimento de lançamento do concreto permeável

Figura 1.20: Passagem de rolo de metal transversal sobre a lona para retenção de umidade.

Figura 1.21: Rolo utilizado para fazer as juntas no concreto permeável 59

Figura 1.22: Rolo utilizado para fazer as juntas no concreto permeável 60

Figura 1.23: Lona plástica utilizada para proteção do concreto permeável contra a perda precoce de água

Figura 2.1: Curva granulométrica da brita 0

Figura 2.2: Peneiras utilizadas para separação das frações dos agregados .

Figura 2.3: Diferenciação entre os diâmetros dos agregados (Esquerda - 4,75 mm;

Direita $-6,3 \mathrm{~mm}$ )

Figura 2.4: Mistura dos componentes do concreto permeável. 69

Figura 2.5: Determinação da massa específica aparente no estado fresco... 69

Figura 2.6: Teste visual para controle da mistura 71

Figura 2.7: Procedimento de compactação de corpos de prova cilíndricos 72

Figura 2.8: Procedimento de vibração dos corpos de prova prismáticos .72

Figura 2.9: Corpos de prova prismáticos na câmara úmida .72

Figura 2.10: Corpos de prova cilíndricos na câmara úmida .72

Figura 2.11: Detalhe da estrutura aberta do concreto permeável no estado fresco..73

Figura 2.12: Corpos de prova desmoldados .73

Figura 2.13: Diferença entre os corpos de prova cilíndricos moldados para a mistura M1 (esquerda) e M2 (direita). 73

Figura 2.14: Procedimento de medição das amostras 75

Figura 2.15: Ensaio de resistência à tração na flexão. .77 
Figura 2.16: Ensaio de resistência à tração na flexão .77

Figura 2.17: Montagem do ensaio de tração por compressão diametral 78

Figura 2.18: Amostra após ruptura 78

Figura 2.19: Ensaio de compressão uniaxial. 79

Figura 2.20: Fissuras observadas após ruptura da amostra em compressão 80

Figura 2.21: Posicionamento do LVDT para obtenção da flecha durante o ensaio de resistência a tração na flexão

Figura 2.22: Equipamento para medida, por pulso de onda, do módulo de elasticidade dinâmico .83

Figura 2.23: Permeâmetro de carga constante 84

Figura 2.24: Procedimento de corte dos corpos de prova 85

Figura 2.25: Corpo de prova envolto pela membrana flexível 86

Figura 2.26: Procedimento de obtenção do peso seco 87

Figura 2.27: Procedimento de obtenção do peso submerso 88

Figura 3.1: Índice de vazios em função da massa específica aparente seca. 100

Figura 3.2: Resistência à tração na flexão em função do módulo de elasticidade estático

Figura 3.3: Módulo de elasticidade estático em função do módulo de elasticidade dinâmico 102

Figura 3.4: Comparação entre o módulo de elasticidade estático em função do índice de vazios 103

Figura 3.5: Módulo de elasticidade dinâmico em função da massa específica aparente seca. 104

Figura 3.6: Módulo de elasticidade dinâmico em função do índice de vazios 104

Figura 3.7: Comparação da variação da resistência à tração na flexão média em função do índice de vazios médio 105

Figura 3.8: Comparação da variação da resistência à tração por compressão diametral média em função do índice de vazios médio 106

Figura 3.9: Comparação da variação da resistência à compressão média em função do índice de vazios médio 
Figura 3.10: Comparação da variação da condutividade hidráulica em função do índice de vazios médio.

Figura 4.1: Tela inicial do programa com dados da placa estudada

Figura 4.2: Eixo de $80 \mathrm{kN}$

Figura 4.3: Esquema do veículo utilitário

Figura 4.4: Eixo de $22 \mathrm{kN}$

Figura 4.5: Malha de elementos finitos

Figura 4.6: Tensões máximas de tração em função da variação das espessuras da placa.

Figura 4.7: Variação da RT em função da espessura da placa.

Figura 4.8: Variação da RT em função da espessura das placas de concreto permeável

Figura 4.9: Distribuição das tensões no topo da placa em função da solicitação do eixo de $80 \mathrm{kN}$

Figura 4.10: Distribuição das tensões no fundo da placa em função da solicitação do eixo de $80 \mathrm{kN}$

Figura 4.11: Distribuição das tensões no fundo da placa em função da solicitação do eixo de $22 \mathrm{kN}$

Figura 4.12: Deformação gerada em função da solicitação do eixo de $80 \mathrm{kN}$ 120

Figura 4.13: Deformação gerada em função da solicitação do eixo de $22 \mathrm{kN}$ 120 


\section{LISTA DE TABELAS}

Tabela 1.1: Consumos e proporções típicas utilizadas nas misturas de concreto

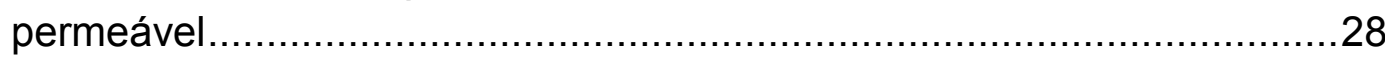

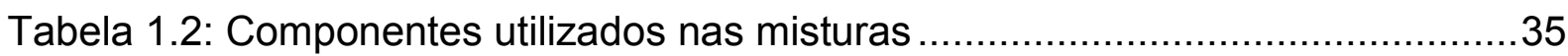

Tabela 1.3: Resumo das fissuras subsuperficiais das amostras de concreto

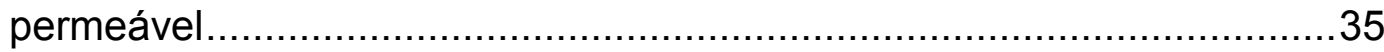

Tabela 1.4: Resultado das medidas de ruído em concreto permeável.......................37

Tabela 1.5: Propriedades de concretos permeáveis ...........................................4

Tabela 2.1: Características do agregado utilizado nas moldagens dos corpos de prova

Tabela 2.2: Características do cimento utilizado nas moldagens dos corpos de prova .65

Tabela 2.3: Proporções de agregados utilizados nas moldagens ...........................66

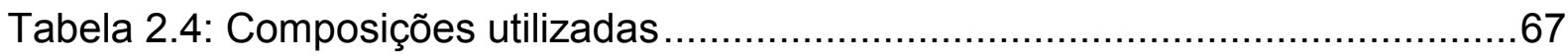

Tabela 2.5: Massas específicas aparentes no estado fresco obtidas durante $o$ procedimento de controle das misturas .............................................. 70

Tabela 2.6: Quantidade de corpos de prova ensaiados .......................................75

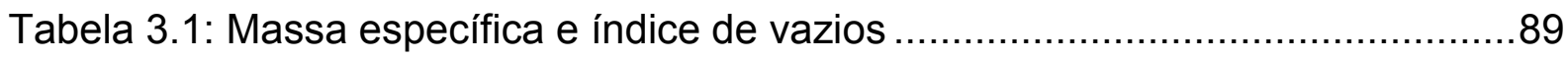

Tabela 3.2: Análise estatística dos resultados de massa específica e índice de vazios 90

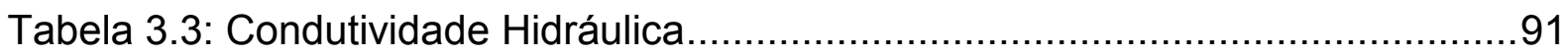

Tabela 3.4: Análise estatística dos resultados de condutividade hidráulica ..............91

Tabela 3.5: Módulo de elasticidade dinâmico.........................................................93

Tabela 3.6: Análise estatística do resultados do módulo de elasticidade dinâmico ..93

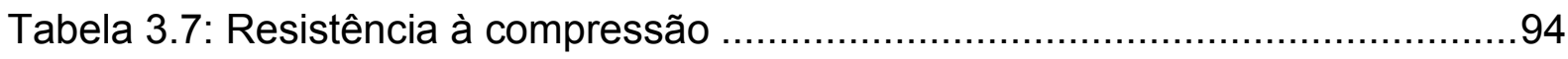

Tabela 3.8: Resistência à tração na flexão e módulo de elasticidade estático..........95

Tabela 3.9: Análise estatística dos resultados de resistência à tração na flexão e módulo de elasticidade dinâmico.......................................................95

Tabela 3.10: Módulo de elasticidade estático segundo a equação de Goede (2009) 
Tabela 3.11: Resistência à tração indireta por compressão diametral . .99

Tabela 3.12: Análise estatística do resultados da resistência à tração indireta.........99

Tabela 4.1: Parâmetros de resistência utilizados nas análises mecanicistas. 113 


\section{LISTA DE ABREVIATURAS E SIGLAS}

a/c Relação água - cimento

ABNT Associação Brasileira de Normas Técnicas

$\mathrm{ACl} \quad$ American Concrete Institute

ACPA American Concrete Pavement Association

ASTM American Society for Testing and Materials

BMPs Best Management Practices

CA Concreto asfáltico

CCP Concreto de cimento Portland

CP Corpo de prova

cV Coeficiente de variação

EPA Environmental Protection Agency (U.S.)

EPUSP Escola Politécnica da Universidade de São Paulo

EUA Estados Unidos da América

FHWA Federal Highway Administration

LMP Laboratório de Mecânica dos Pavimentos (Escola Politécnica da

Universidade de São Paulo)

LVDT Linear variable differential transformer

n/a Não avaliado

NBR Norma Brasileira Registrada

PCA Portland Cement Association

PCC Departamento de Engenharia de Construção Civil da Escola Politécnica da Universidade de São Paulo

RT Relação entre tensão atuante e tensão resistente

USP Universidade de São Paulo

ZT Zona de transição 


\section{LISTA DE SÍMBOLOS}

$\begin{array}{ll}k & \text { Condutividade hidráulica } \\ \sigma_{\max } & \text { Tensão máxima aplicada } \\ f_{c} & \text { Resistência à compressão } \\ f_{c t, f} & \text { Resistência à tração na flexão } \\ f_{c t, s p} & \text { Resistência à tração por compressão diametral } \\ E & \text { Módulo de elasticidade estático } \\ E_{d} & \text { Módulo de elasticidade dinâmico } \\ \rho_{c} & \text { Massa unitária do concreto } \\ F_{u} & \text { Carga de ruptura } \\ V_{r} & \text { Índice de vazios } \\ W_{1} & \text { Peso submerso } \\ W_{2} & \text { Peso seco } \\ v & \text { Coeficiente de Poisson } \\ V & \text { Velocidade } \\ \mu & \text { Média } \\ \sigma & \text { Desvio padrão }\end{array}$




\section{SUMÁRIO}

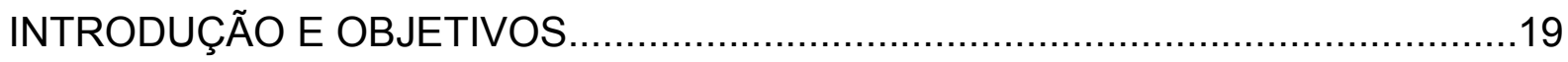

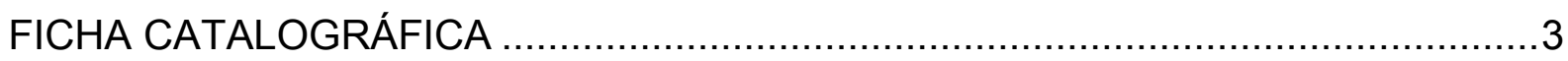

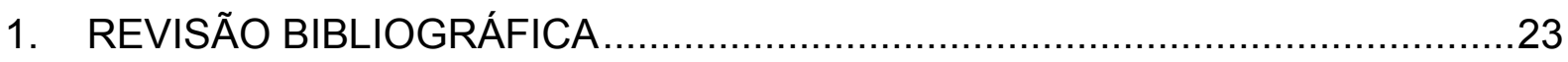

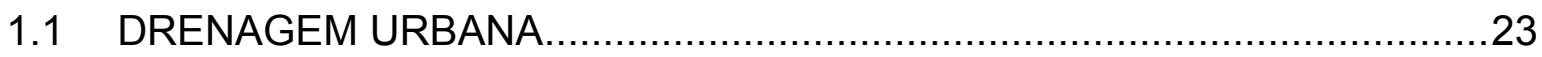

1.2 CONCRETO PERMEÁVEL PARA PAVIMENTAÇÃO - CARACTERÍSTICAS

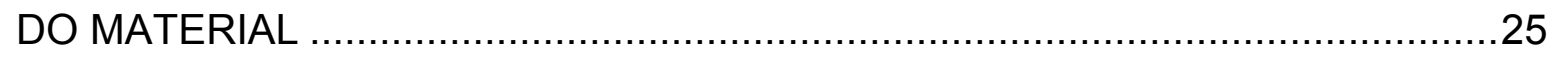

1.2.1 Materiais Utilizados na Composição do Concreto Permeável ...............27

1.2.2 Principais Características do Concreto Permeável no Estado Fresco....30

1.2.3 Características do Concreto Permeável no Estado Endurecido .............30

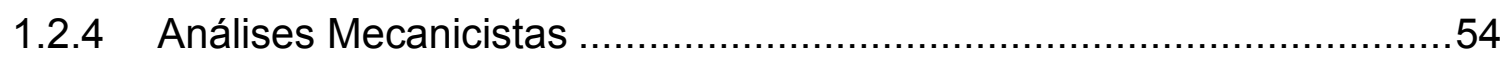

1.2.5 Métodos de Construção de Revestimentos de Concreto Permeáveis...54

1.2.6 Dimensionamento e Projeto Estrutural .......................................61

2. METODOLOGIA DA PESQUISA EM LABORATÓRIO ................................63

2.1 CARACTERIZAÇÃO DOS MATERIAIS E DOSAGEM $\ldots \ldots \ldots \ldots \ldots \ldots \ldots \ldots \ldots \ldots \ldots . \ldots . \ldots \ldots$

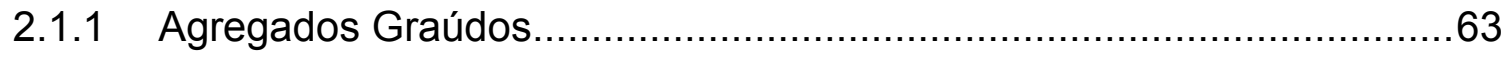

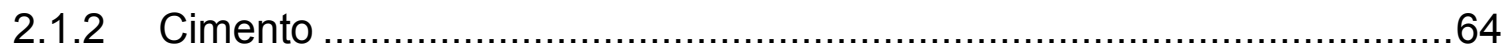

2.2 DESCRIÇÃO DOS CONCRETOS PERMEÁVEIS CONCRETOS

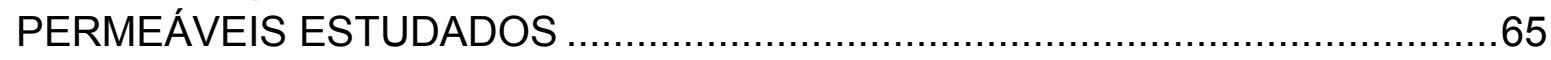

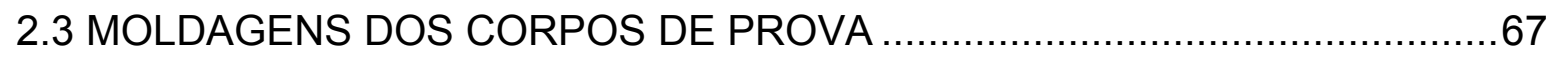

2.4 DIMENSÕES E QUANTIDADE DOS CORPOS DE PROVA MOLDADOS .....74

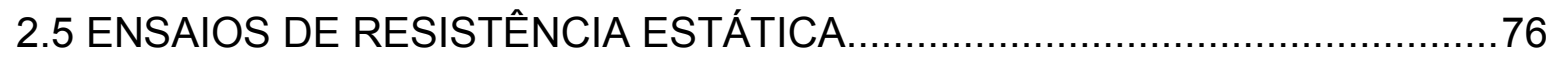

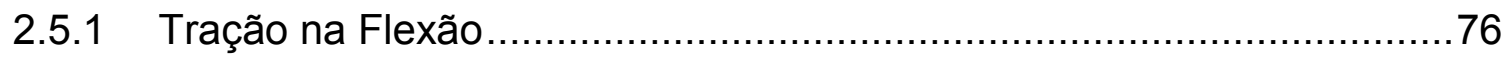

2.5.2 Tração Indireta por Compressão Diametral (Ensaio Brasileiro) .............77

2.5.3 Compressão Uniaxial............................................................ 78

2.6 MÓDULO DE ELASTICIDADE ESTÁTICO …........................................ 80

2.7 MÓDULO DE ELASTICIDADE DINÂMICO $\ldots \ldots \ldots \ldots \ldots \ldots \ldots \ldots \ldots \ldots \ldots \ldots \ldots \ldots . . \ldots 2$ 
2.8 ENSAIOS DE PERMEABILIDADE .84

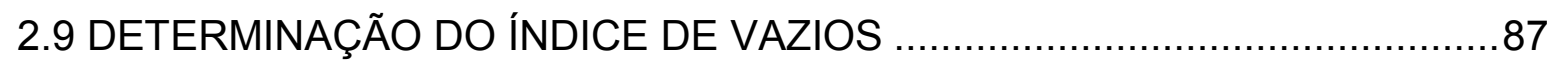

3. APRESENTAÇÃO E DISCUSSÃO DOS RESULTADOS …..............................89

3.1 MASSA ESPECÍFICA APARENTE SECA E ÍNDICE DE VAZIOS ..................89

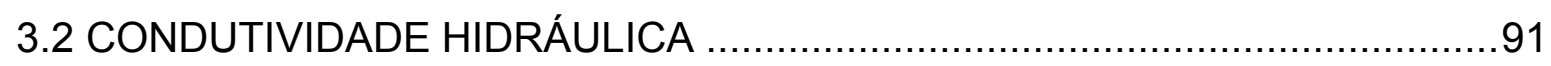

3.3 MÓDULO DE ELASTICIDADE DINÂMICO ...............................................92

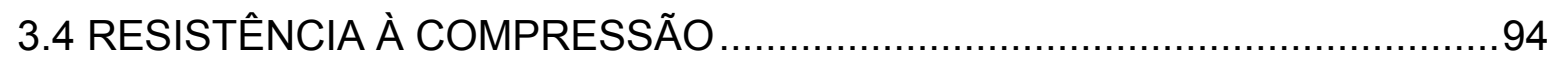

3.5 RESISTÊNCIA À TRAÇÃO NA FLEXÃO E MÓDULO DE ELASTICIDADE

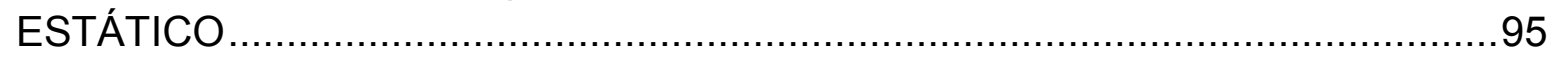

3.6 RESISTÊNCIA À TRAÇÃO INDIRETA POR COMPRESSÃO DIAMETRAL ...98

3.7 RELAÇÕES ENTRE OS PARÂMETROS .....................................................99

3.7.1 Índice de Vazios X Massa Específica Aparente Seca ..........................99

3.7.2 Resistência à Tração na Flexão X Módulo de Elasticidade Estático ...100

3.7.3 Módulo de Elasticidade Estático X Módulo de Elasticidade Dinâmico.101

3.7.4 Módulo de Elasticidade Estático X Índice de Vazios ….......................102

3.7.5 Módulo de Elasticidade Dinâmico X Massa Específica Aparente Seca e

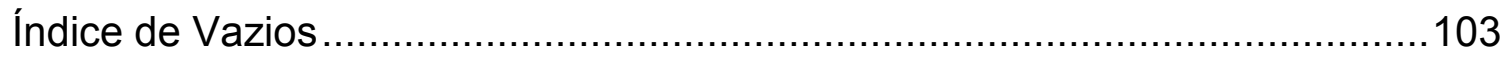

3.7.6 Resistência à Tração na Flexão X Índice de Vazios.............................104

3.7.7 Resistência à Tração Indireta por Compressão Diametral X Índice de Vazios 106

3.7.8 Resistência à Compressão X Índice de Vazios ..................................106

3.7.9 Condutividade Hidráulica X Índice de Vazios ....................................108

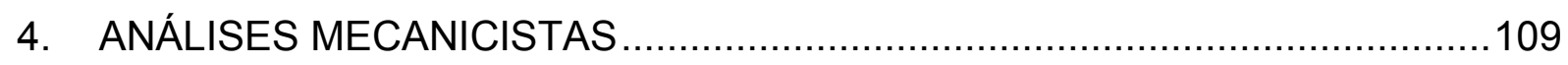

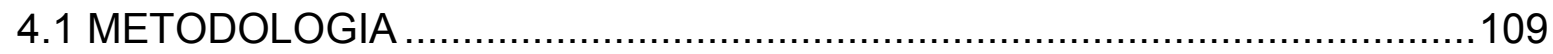

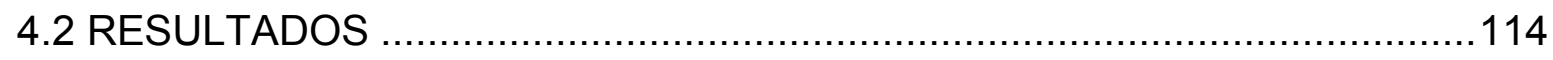

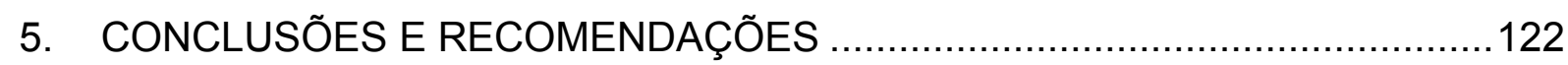

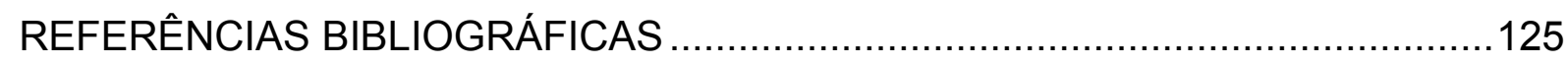




\section{INTRODUÇÃO E OBJETIVOS}

Um dos principais impactos que o desenvolvimento urbano acelerado provoca nos processos hidrológicos está ligado ao crescimento de áreas com superfícies impermeáveis que, juntamente com a ocupação indevida das margens de rios e córregos, aumenta em grande escala a probabilidade de ocorrência de picos de cheias, agravando assim os problemas relativos às enchentes dos rios e inundações nas cidades. Tais ocorrências são consequências diretas da explosão demográfica aliada à falta de planejamento de uso e ocupação do solo urbano por parte dos governantes.

Além disso, a condição de superfícies impermeáveis possui estreita relação com as alterações na qualidade das águas. Os poluentes e sedimentos que ficam depositados sobre tais superfícies acabam sendo transportados aos corpos d'água pelas águas das chuvas. Outros problemas, como erosão e assoreamento de rios, também podem ser causados, em parte, pela impermeabilização das superfícies, que gera escoamentos com maior volume e velocidade do que o escoamento em superfícies naturais (ESTEVES, 2006).

Nos últimos anos, um conceito de controle hidrológico alternativo aos convencionais tem conquistado espaço no cenário da drenagem urbana brasileira. As Best Management Practices (BMPs) são técnicas que tem como princípio básico evitar a transferência dos problemas de montante para jusante, por meio do controle do escoamento na bacia, mais próximo de sua fonte, e não no curso d'água. Este conceito foi desenvolvido nos Estados Unidos da América (EUA) pela Environmental Protection Agency (EPA) nos anos 80 e é baseado no planejamento do controle de águas pluviais em escala de bacia e no uso de estruturas físicas para armazenamento e infiltração do escoamento (reservatórios, trincheiras de infiltração, pavimentos permeáveis), na tentativa de compensar os efeitos da urbanização acelerada (McCUEN, 1989; URBONAS e STAHRE, 1993; SCHUELER, 1987). 
Porém, é comum a ocorrência de resistência à aplicação das BMPs no Brasil por parte dos projetistas, uma vez que ainda existe pouca divulgação, pouca quantidade de obras executadas, oposição natural a inovações, além da escassez de normatização específica nacional sobre o assunto. No entanto, a experiência tem mostrado que o seu uso é mais eficiente, barato e, principalmente, colabora para solucionar o problema mais próximo de sua origem, sem afetar as outras regiões (TUCCI e GEZ, 1995). Uma das exceções utilizadas que caracterizam este sistema são os reservatórios de amortecimento de cheias (piscinões), que se tornaram técnica frequente na cidade de São Paulo.

Pavimento permeável é uma estrutura que permite a passagem de água e ar através de suas camadas. É um equipamento urbano de infiltração que absorve parte ou a totalidade do escoamento através de uma superfície permeável para dentro de um reservatório de brita, com graduação uniforme, construída sobre o subleito. A água, quando captada pelo pavimento, pode ser conduzida para um reservatório e deste para um ponto de captação específico, ou simplesmente ser absorvida pelo subsolo, dependendo de sua capacidade permeável. A sub-base e a base dos pavimentos permeáveis, constituídas de agregados com pouca quantidade de finos, atuam como um recipiente de coleta d'água, permitindo que o líquido seja estocado nos vazios dessas camadas.

Para o correto dimensionamento da espessura das camadas de um pavimento permeável deve-se levar em consideração $\circ$ volume de tráfego, tipo de carregamento, número de solicitações e outros fatores de natureza mecânica, bem como as premissas hidráulicas de tempo de armazenamento, tempo de retenção e condutividade hidráulica, permitindo a implantação de um pavimento permeável que atenda simultaneamente às necessidades técnicas concernentes à infraestrutura de transportes e à drenagem urbana, tendo em vista as questões de sustentabilidade. (VIRGILIIS, 2009).

Existem três tipos genéricos de pavimentos permeáveis: pavimento de concreto asfáltico poroso; pavimento de concreto permeável; e pavimento de blocos de concreto intertravados permeável. 
$\mathrm{Na}$ atualidade brasileira pouco se desenvolveu no campo de utilização do concreto permeável, bem como com relação ao seu desempenho em longo prazo, sendo que o número de publicações encontradas sobre este tema é escasso. Então, considerando-se as vantagens ambientais e econômicas possíveis relativas à utilização deste material como revestimento de pavimentos para tráfego de veículos leves frente aos demais materiais disponíveis, verifica-se a importância de realizar um estudo mais detalhado sobre o assunto. Tal importância está relacionada com a capacidade que este tipo de estrutura permeável possui de reduzir a necessidade de sistemas de gestão de águas pluviais e também de lagoas de captação, diminuindo potencialmente o custo de instalações relativas à drenagem dos pavimentos, auxiliando de maneira mais eficaz com a redução da impermeabilização e, consequentemente, com a ocorrência de enchentes nas cidades.

Assim, devido à escassez de pesquisas em nível nacional que considerem questões relativas aos tipos de materiais constituintes de concretos permeáveis, bem como 0 comportamento mecânico deste material frente aos seus requisitos de permeabilidade, o presente trabalho teve como objetivo analisar estruturalmente possíveis aplicações de pavimentos de concreto permeáveis para condições de tráfego e traços de concreto específicos.

Nesse contexto, os principais objetivos do trabalho foram:

- Revisar e analisar criticamente a literatura existente sobre o tema, principalmente em locais onde esse tipo de estrutura é utilizado com maior frequência, como é o caso dos EUA;

- Determinar as principais características mecânicas de três traços de concreto permeável, que foram sua resistência à compressão simples, resistência à tração por compressão diametral, resistência à tração na flexão, seu módulo de elasticidade estático em tração na flexão e seu módulo de elasticidade dinâmico por equipamento ultrassônico;

- Determinar as características de índice de vazios e permeabilidade das diferentes misturas; 
- Realizar análises mecanicistas por meio do software de elementos finitos EverFe versão 2.24 para verificação das respostas estruturais teóricas de placas de concreto permeável, visando sua aplicação em pavimentos.

A apresentação da pesquisa realizada foi sistematizada nos seguintes capítulos:

No capítulo 1 foi realizada uma revisão da literatura existente sobre o tema pavimentos permeáveis com foco principalmente em revestimentos de concretos permeáveis discutindo suas principais características e alguns resultados já obtidos por diversos autores. No capítulo 2 está apresentada a metodologia empregada para atingir os objetivos propostos, descrevendo detalhadamente a moldagem das amostras no laboratório e a realização dos ensaios. No capítulo 3 foi realizada a apresentação e discussão dos resultados obtidos nos ensaios laboratoriais, comparando as três misturas estudadas bem como com resultados de pesquisas já realizadas. Por fim, no capítulo 4 estão apresentadas as análises mecanicistas, descrevendo os conceitos e parâmetros considerados, a metodologia empregada para resolução das análises, e os resultados obtidos. 


\section{REVISÃO BIBLIOGRÁFICA}

\subsection{DRENAGEM URBANA}

O processo de urbanização no Brasil ocorreu de maneira rápida e desordenada ao longo do século $X X$, influenciado pela grande migração da população que trocou o meio rural pelas novas oportunidades oferecidas pelas cidades. A falta de planejamento urbano e o crescimento acelerado trouxeram algumas consequências para esses centros urbanos, tais como: problemas de saneamento básico, enchentes e inundações devido à impermeabilização do solo, poluição ambiental, elevação dos níveis de ruído, entre outros.

Na Figura 1.1a é apresentada a evolução das áreas impermeáveis em função da variação da densidade urbana baseada em dados obtidos nas cidades de São Paulo, Curitiba e Porto Alegre. Na Figura 1.1b está apresentada a relação entre o crescimento populacional e o aumento das ocorrências de inundações na cidade de Belo Horizonte (TUCCI, 2003).

Ferguson (2005) apresenta dados obtidos a partir de medições realizadas nas áreas de Chesapeak Bay (CAPIELLA e BROWN, 2001) e Puget Sound nos EUA, referente à proporção de solo coberto por estruturas construídas em distritos urbanos, relacionando as áreas impermeáveis com diferentes tipos de uso e ocupação do solo (Figura 1.2). As porções escura e branca das barras representam respectivamente as áreas pavimentadas e as áreas de cobertura das edificações.

Ressalta-se que, no caso das informações apresentadas na Figura 1.1, tratam-se de resultados específicos de evolução da população e das áreas impermeáveis para as cidades citadas, sendo estes valores variáveis dependendo do local e tipo de clima considerado, uma vez que cada região possui suas próprias equações de chuva, as quais podem conformar condições hidrológicas muito diferentes. 

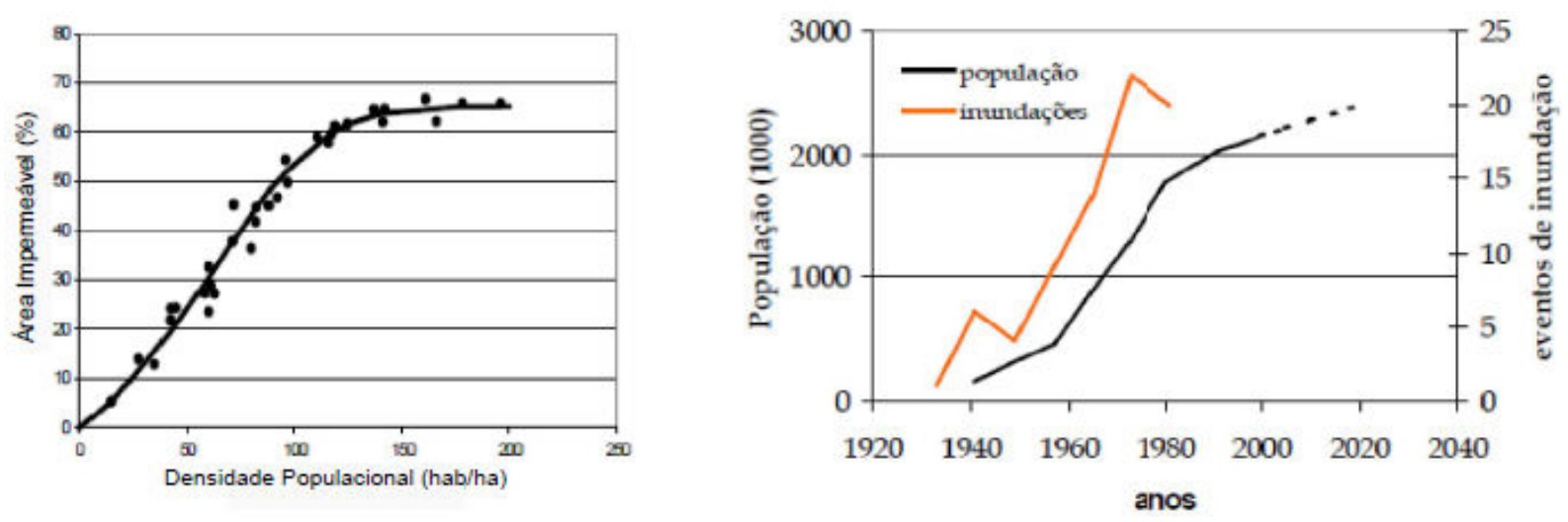

Figura 1.1: a) Relação entre área permeável e a densidade populacional baseada em dados obtidos nas cidades de São Paulo, Curitiba e Porto Alegre. b) Relação entre crescimento populacional e número de eventos de cheia em Belo Horizonte.

(Adaptado de: TUCCI, 2003)

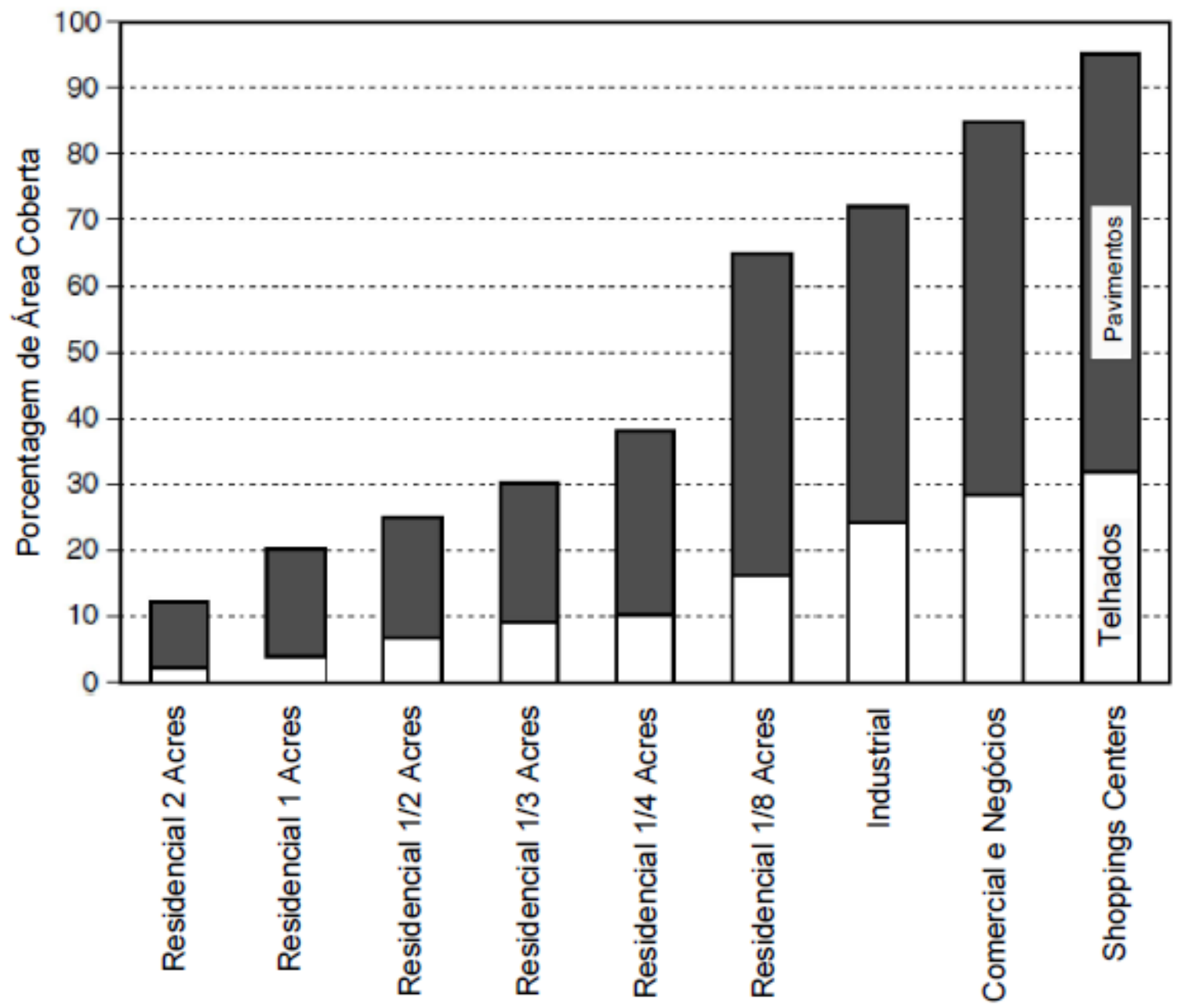

Figura 1.2: Porcentagem de áreas impermeabilizadas com relação aos diferentes tipos de uso e ocupação do solo.

(Adaptado de: FERGUSON, 2006) 
Ao analisar a Figura 1.2, observa-se que para todos os tipos de uso e ocupação do solo as taxas de impermeabilização devido às áreas pavimentadas representam cerca de $65 \%$ da área total impermeabilizada, restando cerca de 35\% para as áreas de cobertura das edificações. Além disso, pode-se observar que as áreas industriais, de negócios e comércio, bem como de shopping centers, representam os casos mais críticos de impermeabilização, possuindo em média cerca de $80 \%$ da área com algum tipo de cobertura.

\subsection{CONCRETO PERMEÁVEL PARA PAVIMENTAÇÃO - CARACTERÍSTICAS DO MATERIAL}

O pavimento permeável é caracterizado por possuir elevada porosidade e boa drenabilidade, dependendo da sua composição. Devido a essa capacidade de deixar a água infiltrar através de sua estrutura porosa, a utilização dessas estruturas, quando corretamente projetadas e implantadas, pode influenciar significativamente nas vazões de pico que ocorrem durante eventos de chuva em determinado local.

O concreto permeável (Figura 1.3) é um material composto por ligante hidráulico, material britado de graduação uniforme, água e pouca ou nenhuma quantidade de agregado miúdo. Adicionalmente, pode-se utilizar uma combinação de diferentes tipos de adições e aditivos que possuem a finalidade de atribuir ao concreto melhor desempenho, durabilidade, resistência e trabalhabilidade.

Segundo Li (2009), o uso do concreto permeável teve início há mais de 150 anos, embora a sua real aplicação para as mais diversas finalidades somente veio a apresentar grande avanço há pouco mais de 20 anos, principalmente nos EUA. Recentemente, as pesquisas sobre o comportamento mecânico e hidráulico desse tipo de material se tornaram atrativas, uma vez que o concreto permeável pode apresentar bom desempenho e durabilidade quando utilizado como revestimento de pavimentos em áreas de veículos leves, o que, aliado à sua capacidade drenante, permite o seu emprego como equipamento urbano de mitigação dos níveis de impermeabilização, intensificados pela urbanização das cidades. 


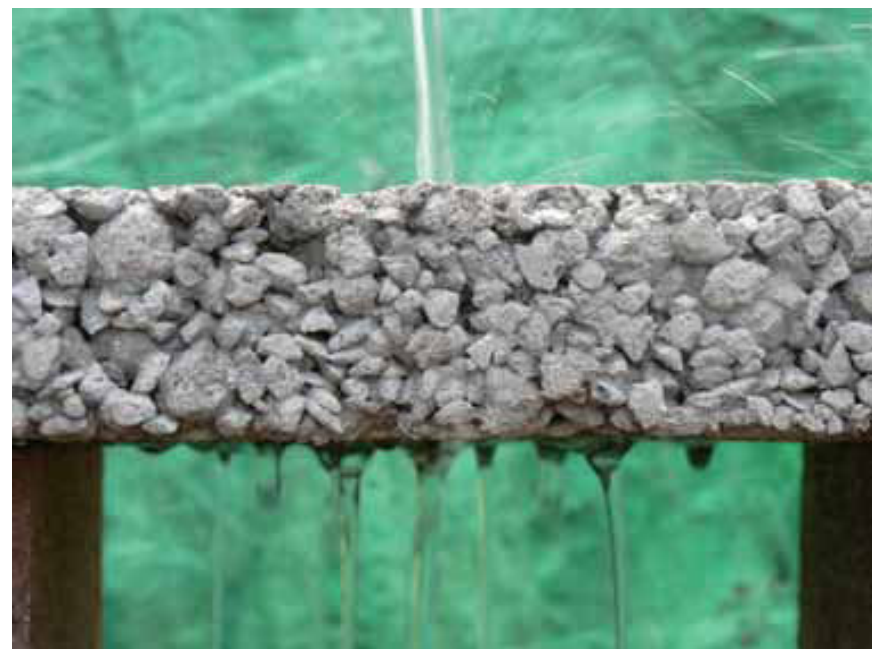

Figura 1.3: Amostra de concreto permeável (Fonte: http://www.ecodesenvolvimento.org)

Segundo Henderson et al. (2009), ao se reduzir a quantidade de agregado miúdo ou simplesmente eliminá-lo da mistura de concreto, o índice de vazios aumenta para valores entre 0,15 e 0,3. Dessa maneira, a água proveniente das precipitações irá percolar por meio dos poros da placa de concreto, diminuindo consideravelmente a quantidade de escoamento superficial das águas pluviais.

O revestimento em concreto permeável para uso em pavimentos é construído sobre base de pedra britada de granulometria descontínua, que serve de reservatório enquanto as águas provenientes de chuvas infiltram pelo revestimento, podendo requerer cuidados especiais com drenagem, caso o solo do subleito possua baixo coeficiente de permeabilidade.

Segundo Dellate e Clearly (2006), existem três tipos de concretos permeáveis que podem ser caracterizados pelo nível de resistência e drenabilidade. O primeiro, conhecido como concreto permeável hidráulico, é um material com baixa resistência mecânica e elevada permeabilidade, utilizado para aplicações não estruturais. 0 concreto permeável normal possui resistência e permeabilidade intermediárias, e pode ser utilizado para estacionamentos e calçadas, sendo representado por uma mistura sem adição de agregado miúdo. Por fim, existe o concreto permeável estrutural, que possui elevada resistência mecânica e baixa permeabilidade, sendo caracterizado pela adição de materiais de granulometria reduzida na mistura. Este 
tipo pode ser utilizado em estacionamentos, ruas e avenidas que possuam tráfego de veículos pesados.

As quantidades de água e de ligante hidráulico empregadas na composição do concreto permeável são cuidadosamente controladas com a finalidade de se obter uma pasta que forme uma capa espessa ao redor das partículas dos agregados. A mistura deve possuir pequena ou nula quantidade de agregado miúdo a fim de se obter um material de elevado índice de vazios, que, com auxílio da interconectividade dos seus vazios, apresentará boa drenabilidade.

Segundo Delatte et al. (2009), a condutividade hidráulica característica do concreto permeável varia normalmente entre 0,1 e $0,9 \mathrm{~cm} / \mathrm{s}$, embora este valor possa ser muito diferente, a depender principalmente da composição do concreto e da qualidade do processo executivo.

\subsubsection{Materiais Utilizados na Composição do Concreto Permeável}

O concreto permeável é produzido com os mesmos materiais utilizados na composição do concreto de cimento Portland convencional (CCP), com a diferença de que a quantidade de agregados miúdos é muito reduzida, ou, na grande maioria das vezes, nula ( $\mathrm{ACl}, 2006$; TENNIS et al., 2004). As proporções utilizadas nas misturas de concreto permeável são geralmente muito mais restritas com relação às misturas de $\mathrm{CCP}$, sendo que normalmente é necessário um controle visual rigoroso na sua produção para que se consigam obter as características desejadas no produto final (TENNIS et al,. 2004).

As proporções dos materiais variam dependendo dos tipos de insumos disponíveis no local de uso, sendo que o correto é sempre realizar experimentos e procedimentos de dosagem em laboratório, que servirão de subsídio para a melhor definição de tais proporções (dosagem racional). Na Tabela 1.1 são apresentadas faixas típicas de consumo e proporções de materiais utilizados nas misturas de concreto permeável. 
A relação cimento/agregado e o procedimento de compactação ou adensamento a ser utilizado na produção de concretos permeáveis são os dois fatores mais importantes da mistura, que afetam diretamente as características mecânicas do material (ACl, 2006).

Tabela 1.1: Consumos e proporções típicas utilizadas nas misturas de concreto permeável

\begin{tabular}{cc}
\hline Materiais & Consumo/proporção \\
\hline \hline Ligante hidráulico $\left(\mathrm{kg} / \mathrm{m}^{3}\right)$ & 270 a 415 \\
\hline Agregado graúdo $\left(\mathrm{kg} / \mathrm{m}^{3}\right)$ & 1.190 a 1.700 \\
\hline Relação água/cimento $(\mathrm{a} / \mathrm{c})$ em massa & 0,27 a 0,34 \\
\hline Relação cimento/agregado em massa & $1: 4$ a $1: 4,5$ \\
\hline Relação agreg. miúdo/agreg. graúdo em massa & 0 a $1: 1$ \\
\hline \hline
\end{tabular}

Os aditivos superplastificantes são também empregados com a finalidade de melhorar principalmente as características de trabalhabilidade e tempo de pega das misturas de concreto permeável.

\section{Aglomerantes}

O principal ligante hidráulico utilizado como aglomerante em concretos permeáveis é o cimento Portland. Além deste, materiais suplementares como cinza volante, escória granulada de alto forno moída e sílica ativa, são também empregados com a finalidade de melhorar as características mecânicas do produto final. Cabe lembrar que as proporções com que esses aditivos são incorporados à mistura devem ser cuidadosamente observadas, uma vez que se deve garantir que o produto final possua vazios suficientes e boa condutividade hidráulica, parâmetro esse de suma importância para o correto funcionamento do sistema de pavimento permeável como um todo. 


\section{Agregados}

As curvas granulométricas de agregados utilizadas nas misturas são normalmente do tipo uniforme (diâmetro único), em que o diâmetro máximo utilizado é de $19 \mathrm{~mm}$. Para as curvas descontínuas, com variação do diâmetro do agregado, são comumente utilizadas graduações variando de $19 \mathrm{~mm}$ a $4,8 \mathrm{~mm}, 9,5 \mathrm{~mm}$ a 2,4 $\mathrm{mm}$ e $9,5 \mathrm{~mm}$ a $1,2 \mathrm{~mm}$ (TENNIS et al., 2004).

Na Figura 1.4 são apresentadas três curvas granulométricas já empregadas na produção de concreto permeável, em que o diâmetro máximo de agregado utilizado é de $19 \mathrm{~mm}$ (LI, 2009).

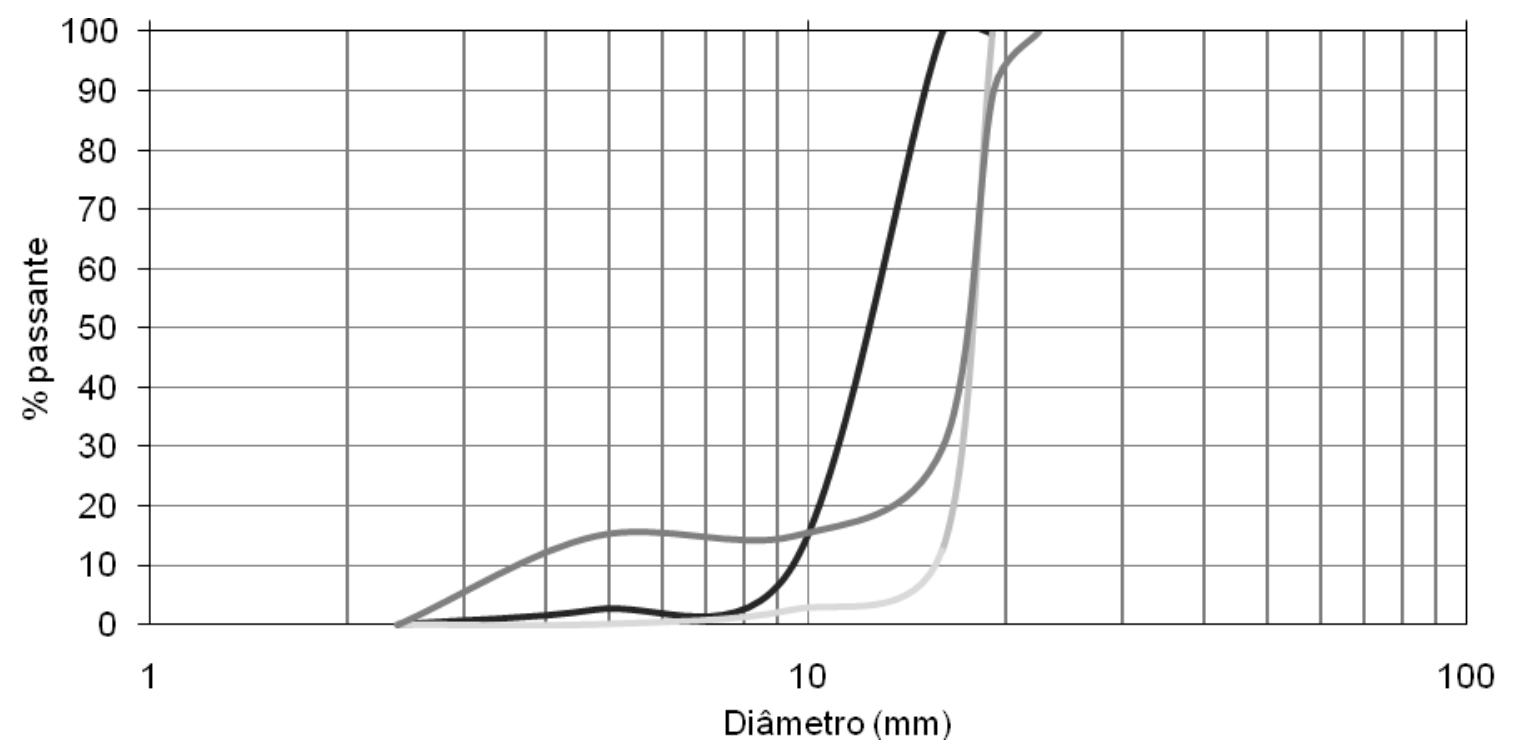

Figura 1.4: Curvas granulométricas típicas de misturas de concreto permeável (Adaptado de: Li, 2009)

\section{Aditivos}

Pela mesma razão que os aditivos químicos são empregados no CCP, são também incorporados nas misturas para produção de concreto permeável. Aditivos retardadores de pega são adicionados à mistura para controle do tempo de pega que, no caso do concreto permeável, ocorre muito rapidamente. Aditivos redutores de água também são utilizados, dependendo da relação a/c considerada (PERVIOUS CONCRETE PAVEMENT, 2011). 


\subsubsection{Principais Características do Concreto Permeável no Estado Fresco}

O concreto permeável no estado fresco é caracterizado por apresentar elevada consistência (baixa trabalhabilidade) quando comparado com o concreto convencional. $\mathrm{O}$ abatimento da mistura, normalmente, é menor que $20 \mathrm{~mm}(\mathrm{ACl}$, 2006; TENNIS et al., 2004). São raros os casos em que se emprega abatimento superior a $50 \mathrm{~mm}$.

Em função da sua baixa consistência, é incomum a utilização do ensaio de abatimento de tronco de cone como método de controle na produção de misturas de concreto permeável. Ensaios de massa unitária e controle visual são os métodos mais empregados nesse processo. A massa unitária desse material representa, em média, cerca de $70 \%$ da massa unitária de concretos convencionais (PERVIOUS CONCRETE PAVEMENT, 2011).

O tempo útil de trabalho do concreto permeável é geralmente menor quando comparado ao tempo do concreto convencional. O ACl (2008) sugere que o tempo útil de trabalho deve ser de no máximo 60 minutos após o material ser misturado com água. No caso de uso de aditivos retardadores esse tempo pode ser aumentado para cerca de 90 minutos, dependendo do tipo de aditivo e das condições climáticas locais.

Em função das suas características diferenciadas, os procedimentos padrão para produção de corpos de prova e realização de ensaios em laboratório utilizados para o concreto convencional não se aplicariam, sem prova prévia, para o concreto permeável. No Brasil, ainda não existem especificações ou métodos referentes ao estudo em laboratório deste tipo de material.

\subsubsection{Características do Concreto Permeável no Estado Endurecido}

\section{Massa Específica, Índice de Vazios e Textura}

O concreto permeável é caracterizado por apresentar uma textura superficial diferenciada quando comparado ao concreto convencional. Esta diferença está 
associada a pequena ou nula quantidade de agregados miúdos na sua composição, o que proporciona uma superfície mais rugosa, elevando o coeficiente de atrito. Este tipo de textura pode trazer benefícios relativos à segurança dos usuários, principalmente em períodos chuvosos ou em ocorrências de neve e gelo na pista, uma vez que, além do maior coeficiente de atrito atribuído à estrutura mais rugosa, a condição permeável do concreto pode ser bastante efetiva na diminuição dos riscos de hidroplanagem. Isso ocorre porque a água proveniente das intempéries percola pelo revestimento permeável do pavimento não permanecendo na sua superfície, o que evita a formação de poças d'água e diminui a ocorrência do fenômeno de spray.

A massa específica e o índice de vazios característicos do concreto permeável variam em função da proporção relativa de cada material constituinte da mistura, bem como do procedimento de compactação empregado. As massas específicas aparentes do concreto permeável no estado fresco variam de 1.300 a $2.000 \mathrm{~kg} / \mathrm{m}^{3}$ (TENNIS et al., 2004).

O valor de índice de vazios afeta diretamente as características de resistência mecânica do material no estado endurecido. O material é dito de baixa porosidade quando possui índice de vazios inferior a $15 \%$, enquanto que um índice de vazios superior a $30 \%$ caracteriza um material altamente poroso. Tennis et al. (2004) sugerem que se utilizem índices de vazios na ordem de $20 \%$ para garantir boas características de resistência e permeabilidade do concreto, simultaneamente.

\section{Permeabilidade}

Condutividade hidráulica (ou taxa de percolação ou coeficiente de permeabilidade) é um dos parâmetros mais importantes do concreto permeável e pode ser definida como a taxa de infiltração da água através de sua estrutura. Valores típicos de condutividade hidráulica de concretos permeáveis para revestimento de pavimentos variam entre $0,21 \mathrm{~cm} / \mathrm{s}$ e $0,54 \mathrm{~cm} / \mathrm{s}$ (TENNIS et al., 2004). Bean et al. (2007) determinaram valores de condutividade hidráulica em campo variando de $0,07 \mathrm{~cm} / \mathrm{s}$ a $0,77 \mathrm{~cm} / \mathrm{s}$. 
O parâmetro condutividade hidráulica pode ser medido em laboratório de diversas maneiras. Observa-se que até o momento, a grande maioria dos autores utilizam permeâmetros de carga variável em função da sua praticidade. Para este tipo de ensaio, a amostra cilíndrica é preparada tendo-se o cuidado de evitar perda de água pelas laterais do corpo de prova, sendo que todo o volume de água deverá percolar somente entre as faces superior e inferior do corpo de prova. Na Figura 1.5 é apresentado o permeâmetro desenvolvido por Schaefer et al. (2006) que é semelhante a todos os instrumentos desenvolvidos por outros autores que estudaram este material.

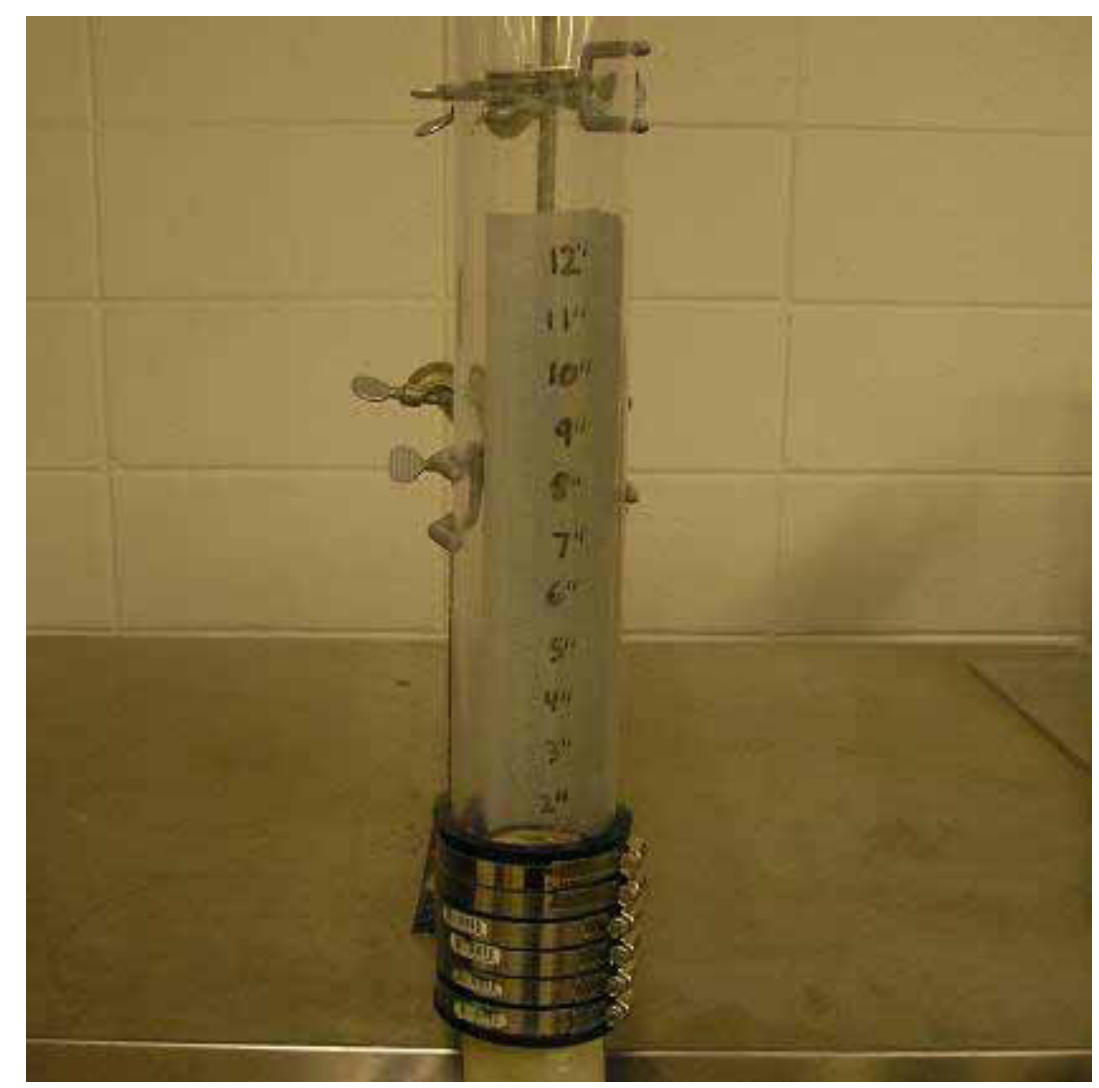

Figura 1.5: Permeâmetro de carga variável utilizado para medir a condutividade hidráulica de amostras de concreto permeável

(Fonte: SCHAEFER et al., 2006)

Segundo conceitos básicos de mecânica dos solos, sabe-se que para materiais com elevada permeabilidade $\left(\mathrm{k}>10^{-3} \mathrm{~cm} / \mathrm{s}\right)$ deve-se utilizar para determinação da condutividade hidráulica o ensaio de carga constante, onde a altura de coluna d'água não varia. Já os ensaios de carga variável devem aplicados aos materiais com nível de condutividade hidráulica muito baixo, uma vez que se tornaria inviável 
manter a carga constante para estes materiais, devido ao elevado tempo requerido para passagem da água pela sua estrutura. Além disso, para obtenção de valores reais de condutividade hidráulica de placas de concreto permeável, sugere-se a utilização de anéis de PVC apoiados sobre placas em pistas experimentais, reduzindo a ocorrência de discrepâncias nos resultados que possivelmente possam ocorrer devido às descontinuidades laterais características de corpos de prova de concreto permeável.

Um dos principais problemas existentes relativos à capacidade drenante desse tipo de revestimento é abordado por Henderson et al. (2009), e está relacionado com a selagem da superfície da camada de revestimento. Esse tipo de situação é comum quando há excesso de compactação da superfície durante as etapas do processo construtivo. Quando a superfície está selada, os vazios ficam entupidos e, consequentemente, toda a camada de revestimento se torna impermeável. Esta condição pode ser determinada por meio de uma avaliação visual de condição de superfície do pavimento acabado, quando se verifica a existência de poças d'água, por exemplo. A permeabilidade também pode ser alterada ao longo do tempo, geralmente decorrente da incrustação de partículas de areia ou solo nos poros do revestimento de concreto permeável (colmatação).

Segundo Kuang et al. (2007) a permeabilidade em pavimentos de concreto permeáveis tende a diminuir com o passar do tempo, sendo que procedimentos de manutenção e restauração da capacidade permeável devem ser executados com periodicidade máxima de seis meses. Ao se utilizar o sistema de limpeza de pavimento a vácuo, por exemplo, consegue-se recuperar mais de $95 \%$ da capacidade inicial de condutividade hidráulica do revestimento.

Schaefer et al. (2006) estudaram a variação da condutividade hidráulica de corpos de prova (CP) de concreto permeável em função do seu índice de vazios. Na Figura 1.6 são apresentados os resultados obtidos pelos autores. 


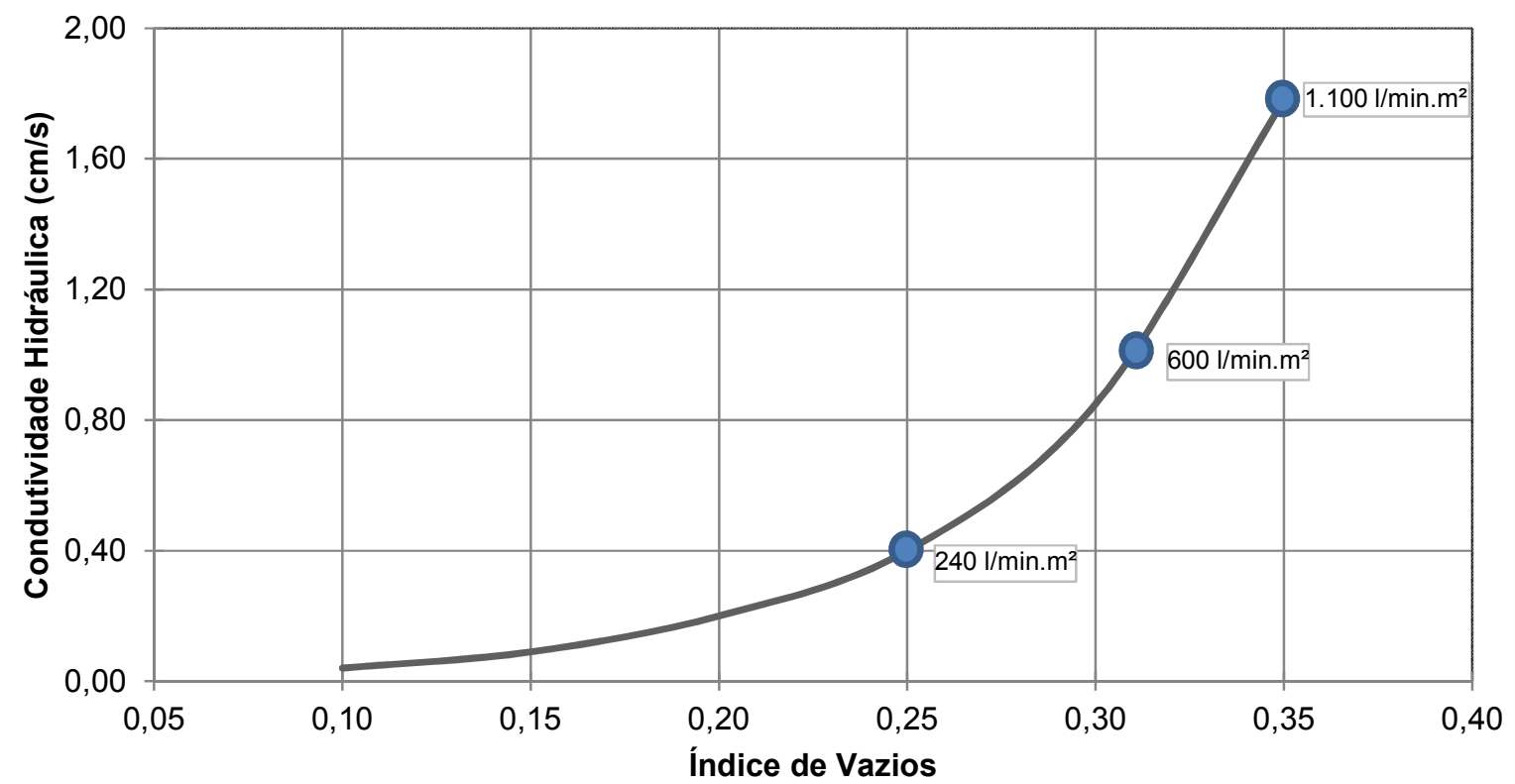

Figura 1.6: Relação entre o índice de vazios e a condutividade hidráulica do concreto permeável

(Adaptado de: SCHAEFER et al., 2006)

\section{Resistência e Durabilidade}

Vancura et al. (2011), realizaram análises microscópicas em corpos de prova de concreto permeável com a finalidade de determinar qual relação entre a microestrutura característica do material e a sua condição de durabilidade. Os corpos de prova utilizados na pesquisa foram obtidos de pistas com tempo de serviço variando entre 1 e 5 anos, localizadas no estado de Minnesota (EUA), que é uma região caracterizada por clima temperado com invernos rigorosos. Os concretos utilizados neste estudo possuem em sua composição três diferentes tipos de agregado - cascalho de rio; calcário dolomítico e granito britado. Na Tabela 1.2 são apresentados os demais componentes empregados nas misturas estudadas.

Os resultados mostraram que as fissuras se propagaram através da pasta $(P)$, do agregado $(A)$ e na zona de transição (ZT) entre a pasta e o agregado, sendo que a ocorrência das fissuras em um ou mais dos meios citados está atrelada principalmente ao tipo de agregado utilizado nas misturas. Na Tabela 1.3 estão resumidos quantitativamente os meios pelos quais as fissuras se propagaram nos corpos de prova analisados. 
Tabela 1.2: Componentes utilizados nas misturas

(Adaptado de: VANCURA et al., 2011)

\begin{tabular}{cc}
\hline \hline Materiais & Quantidade \\
\hline \hline Diâmetro máximo de agregado & $9,5 \mathrm{~mm}$ a $12,5 \mathrm{~mm}$ \\
\hline Areia & $7 \%$ (apenas em $1 / 4 \mathrm{dos}$ CPs) \\
\hline Ligante hidráulico (cimento Portland e/ou de escória) & $356 \mathrm{~kg} / \mathrm{m}^{3}$ \\
\hline Relação a/c & 0,27 a 0,30 \\
\hline \hline
\end{tabular}

Tabela 1.3: Resumo das fissuras subsuperficiais das amostras de concreto permeável (Adaptado de: VANCURA et al., 2011)

\begin{tabular}{|c|c|c|c|c|c|c|c|c|c|c|}
\hline \multirow{2}{*}{$\begin{array}{c}\text { Tipo de } \\
\text { agregado }\end{array}$} & \multirow{2}{*}{$\begin{array}{l}\text { Número de } \\
\text { estruturas }\end{array}$} & \multirow{2}{*}{$\begin{array}{l}\text { Número de } \\
\text { amostras }\end{array}$} & \multicolumn{8}{|c|}{ Número de amostras com fissura subsuperficial por meio específico } \\
\hline & & & Nenhuma & $\mathbf{P}$ & A & ZT & $P$ e A & P e ZT & A e ZT & $\begin{array}{c}\mathrm{P}, \mathrm{Ae} \\
\mathrm{ZT}\end{array}$ \\
\hline Calcário & 11 & 21 & 3 & 6 & 2 & 1 & 0 & 1 & 1 & 7 \\
\hline Cascalho & 5 & 8 & 1 & 1 & 0 & 0 & 0 & 3 & 0 & 3 \\
\hline Granito & 2 & 4 & 3 & 0 & 0 & 1 & 0 & 0 & 0 & 0 \\
\hline Total & 18 & 33 & 7 & 7 & 2 & 2 & 0 & 4 & 1 & 10 \\
\hline
\end{tabular}

Na Figura 1.7 são apresentadas imagens dos corpos de prova obtidas por meio do uso de um microscópio óptico, exemplificando os tipos de propagação de fissuras geradas. Observa-se nas imagens que o concreto permeável empregado apresenta grande concentração de pasta envolvendo os agregados e uma quantidade pequena de poros, sugerindo que a mistura estudada apresenta índice de vazios baixo.

Ainda nesta pesquisa foram avaliadas as quantidades de ar incorporado existentes em todos os corpos de prova. Foi verificado que nenhuma das 33 amostras estudadas apresentou a quantidade recomendada por norma, nem o espaçamento mínimo definido para as bolhas de ar incorporado. Isto ocorreu mesmo para os casos em que foi utilizado incorporador de ar adicionado às misturas do concreto permeável. Não foi comprovado se a quantidade de ar incorporado tem relação direta com a propagação das fissuras visualizadas nos corpos de prova. 


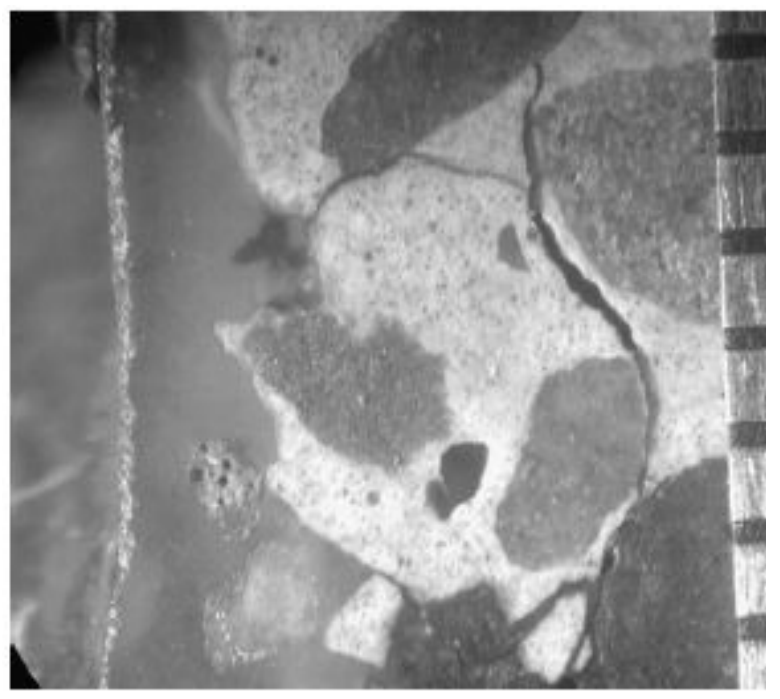

(a)

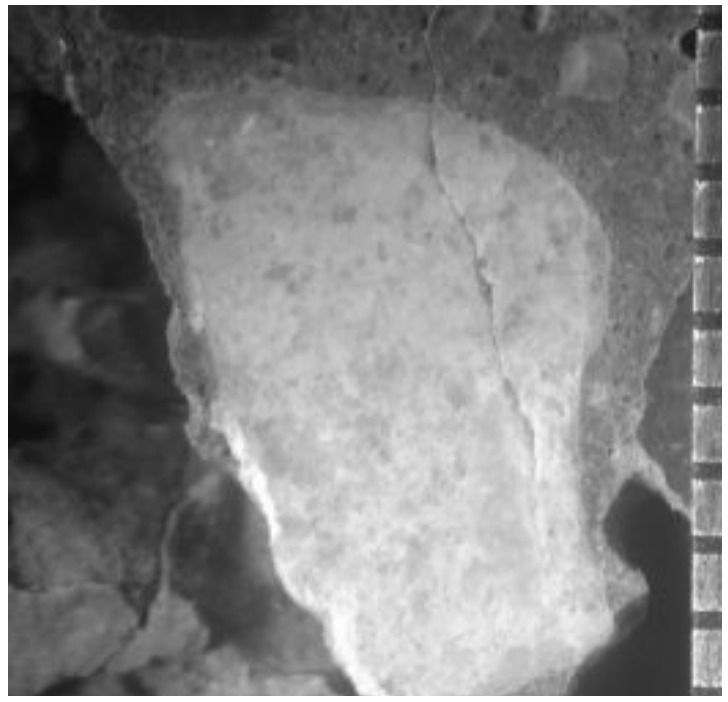

(b)

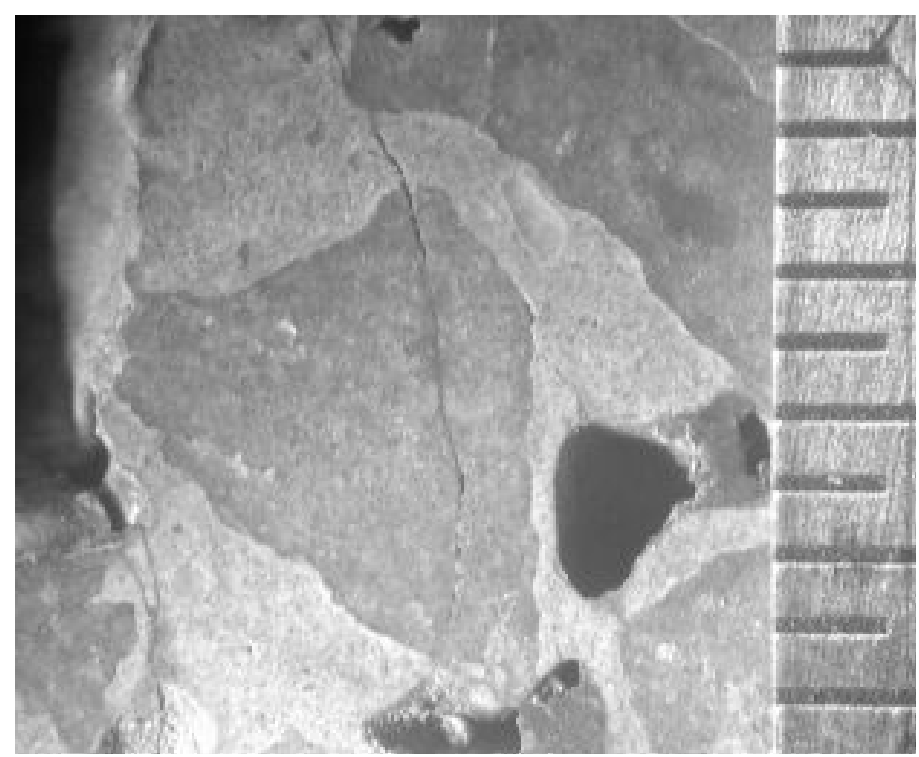

(C)

Figura 1.7: (a): Fissuras paralelas e verticais através da pasta e da ZT; (b) e (c): Fissuras paralelas à superfície que propagaram através do agregado e da pasta. (escala: $1 / 0,8 \mathrm{~mm}$ )

(Fonte: VANCURA et al., 2010)

\section{Redução de Ruído}

A estrutura aberta do concreto permeável promove uma diferença no tempo de chegada e de reflexão das ondas sonoras provenientes da movimentação dos veículos sobre o pavimento. Esta diferença diminui o nível da intensidade do ruído, fazendo com que o revestimento absorva parte do ruído gerado pelo tráfego (OLEK 
et al., 2003). Esta propriedade tem levado alguns pesquisadores a se interessarem pela criação de pavimentos mais silenciosos (KAJIO et al., 1998; OLEK et al., 2003).

Kajio et al. (1998) compararam os níveis de ruído gerados em pavimentos com revestimentos em concretos permeáveis contendo duas diferentes dimensões de agregados $(6,3 \mathrm{~mm}$ e $12,5 \mathrm{~mm})$ e pavimentos asfálticos densos, considerando diferentes velocidades de veículos sobre a pista. Na Tabela 1.4 estão apresentados resultados de medições do nível de ruído.

Observa-se que para ambos os diâmetros de agregados utilizados os níveis de ruído medidos foram de intensidade reduzida no pavimento de concreto permeável quando em comparação com o pavimento revestido com concreto asfáltico convencional. Além disso, nota-se que a variação do diâmetro máximo dos agregados influi muito pouco na propagação do ruído, uma vez que os resultados obtidos na pesquisa são muito semelhantes para estes dois casos.

Tabela 1.4: Resultado das medidas de ruído em concreto permeável (Adaptado de: KAJIO et al., 1998)

\begin{tabular}{|c|c|c|c|c|c|}
\hline \multirow{3}{*}{ Veículo } & \multirow{3}{*}{$\begin{array}{c}\text { Condição do } \\
\text { pavimento }\end{array}$} & \multirow{3}{*}{$\begin{array}{c}\text { Velocidade } \\
\text { (km/h) }\end{array}$} & \multicolumn{3}{|c|}{ Nível de ruído (dB) } \\
\hline & & & \multicolumn{2}{|c|}{$\begin{array}{l}\text { Concreto permeável } \\
\text { (ø máx em mm) }\end{array}$} & \multirow{2}{*}{$\begin{array}{c}\text { Revestimento } \\
\text { asfáltico }\end{array}$} \\
\hline & & & 6,3 & 12,5 & \\
\hline \multirow{6}{*}{ de Passeio } & \multirow{3}{*}{ Seco } & 40 & 65,8 & 66,6 & 72,3 \\
\hline & & 60 & 72,2 & 74,5 & 79,9 \\
\hline & & 75 & 75,1 & 77,9 & 82,5 \\
\hline & \multirow{3}{*}{ Molhado } & 40 & 66,8 & 68,1 & 70,6 \\
\hline & & 60 & 73,1 & 74,4 & 77,2 \\
\hline & & 75 & 75,9 & 77,8 & 80,4 \\
\hline \multirow{4}{*}{ Caminhão } & \multirow{2}{*}{ Seco } & 40 & 73,8 & 72,5 & 80,6 \\
\hline & & 60 & 82 & 81,0 & 86,5 \\
\hline & \multirow{2}{*}{ Molhado } & 40 & 74,8 & 76,1 & 78,6 \\
\hline & & 60 & 81,7 & 81,3 & 84,5 \\
\hline
\end{tabular}


Resistência à compressão, tração na flexão e módulo de elasticidade

A resistência mecânica, principalmente de tração na flexão, e as propriedades elásticas são características importantes para o comportamento estrutural do concreto permeável para uso como revestimento de pavimentos, sendo influenciadas por muitos fatores, com atenção especial ao índice de vazios da mistura. Porém, nas pesquisas disponíveis sobre o assunto é escassa a existência de resultados de ensaios de módulo de elasticidade e de resistência à tração na flexão uma vez que, em função das características irregulares normalmente observadas nos corpos de prova de concreto permeável, torna-se difícil a execução destes tipos de ensaios em laboratório. Dessa maneira, são mais comuns estudos de desempenho e comportamento referentes a resistência à compressão e às condições de permeabilidade das misturas.

Uma revisão de literatura realizada por Kevern et al. (2009) revela que as misturas para produção de concreto permeável eram basicamente compostas de agregado graúdo com distribuição granulométrica uniforme, apresentando elevada condutividade hidráulica (em média 0,6 cm/s). Todavia, como consequência de seu elevado índice de vazios, o material apresentava também baixas resistências à compressão (entre 6,7 MPa e 17,5 MPa). Consequentemente, no final dos anos 90, a EPA relatou que aproximadamente $75 \%$ dos sistemas de pavimentos porosos falharam no país, principalmente em função das baixas resistências dos pavimentos causadas pelo elevado índice de vazios ou por práticas inadequadas de construção.

Enquanto que nos EUA ocorriam tais problemas, este tipo de sistema estava sendo empregado no Japão, na Austrália e na Europa com maior sucesso, uma vez que as suas misturas de concreto permeável, exibiram resistências à compressão na ordem de $32 \mathrm{MPa}$, porém com uma permeabilidade menor se comparadas às misturas americanas (BEELDENS, 2001).

Verifica-se que nesse caso há uma necessidade de realizar estudos aprofundados para melhor entendimento do binômio resistência/permeabilidade, uma vez que o material deve ser resistente o suficiente para atender aos requisitos do tráfego atuante e ao mesmo tempo possuir permeabilidade suficiente para permitir a rápida 
percolação das águas das intempéries. Dessa maneira, deve-se garantir que no processo de dosagem as proporções utilizadas dos materiais, assim como os tipos de materiais empregados na composição do concreto permeável, sejam bem definidos.

Dellate et al. (2009) realizaram inspeções visuais além de diferentes tipos de ensaios laboratoriais em corpos de prova extraídos de pistas em 20 diferentes locais revestidos com concreto permeável nos EUA. Foi observado que a maioria dos revestimentos apresentou desagregação superficial com perda de agregados em pequena escala. Este tipo de problema é comum quando a ligação entre o agregado e o ligante é quebrada e o agregado é desalojado da matriz do concreto. Além disso, foi observado que seis das áreas estudadas apresentaram sinais de fissuração precoce.

$\mathrm{Na}$ etapa de testes laboratoriais realizadas na pesquisa, os resultados mostraram que em alguns casos existem diferenças no valor de índice de vazios entre as partes superior e inferior da espessura do revestimento permeável, sendo que o valor verificado na parte superior é muito menor que o índice de vazios da parte inferior. Tal condição é provavelmente decorrente do processo construtivo ou da colmatação dos vazios da superfície das placas de revestimento, problema comum em revestimentos de pavimentos permeáveis que não recebem devida manutenção periódica.

Com relação às resistências à compressão e à tração na flexão, foi determinado que ambas são inversamente proporcionais ao volume de vazios existente, ou seja, quanto maior o volume de vazios, menor será a resistência mecânica (Figura 1.8). 


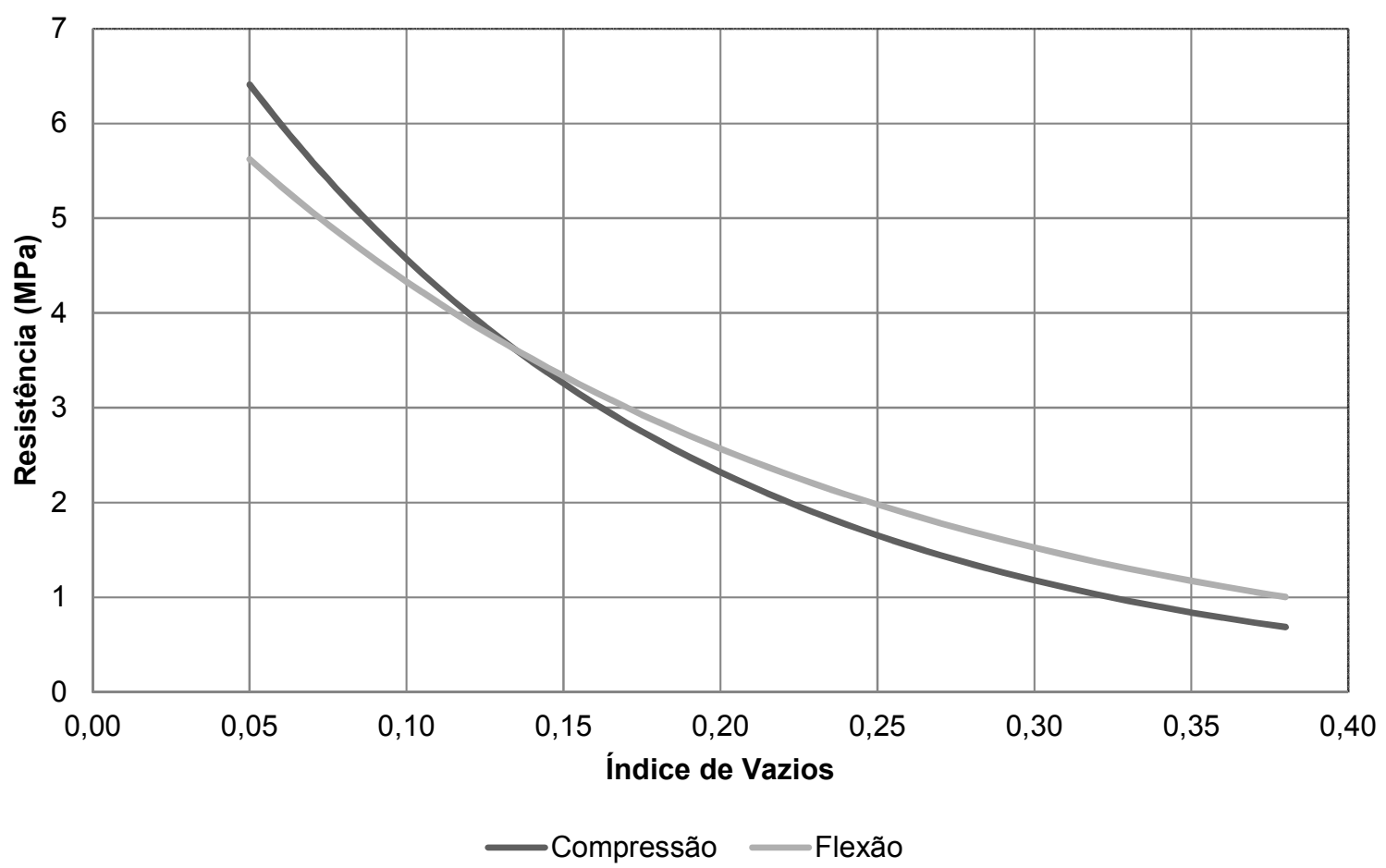

Figura 1.8: Resistência à compressão (dividido por 10) e resistência à tração na flexão em função da variação do índice de vazios

(adaptado de: DELATTE et al., 2009)

Schaefer et al. (2006) estudaram os efeitos da energia de compactação nas propriedades do concreto permeável. Os parâmetros estudados na pesquisa foram resistência à compressão, resistência à tração por compressão diametral, massa unitária e resistência a ciclos de gelo e degelo. As amostras foram confeccionadas no formato cilíndrico, empregando-se na sua compactação 25 golpes de um bastão de metal por camada, sendo que cada corpo de prova foi moldado em 3 camadas. Após a etapa de compactação, cada corpo de prova foi colocado em uma mesa vibratória pelo período de 5 segundos. Para produzir as energias de compactação diferentes, foram empregadas duas mesas vibratórias com amplitudes de vibração de $0,000127 \mathrm{~mm}$ e $0,0000864 \mathrm{~mm}$, que foram identificadas no estudo por energia de compactação regular e baixa, respectivamente. Nas Figuras 1.9, 1.10 e 1.11 estão apresentados os resultados obtidos neste estudo. 


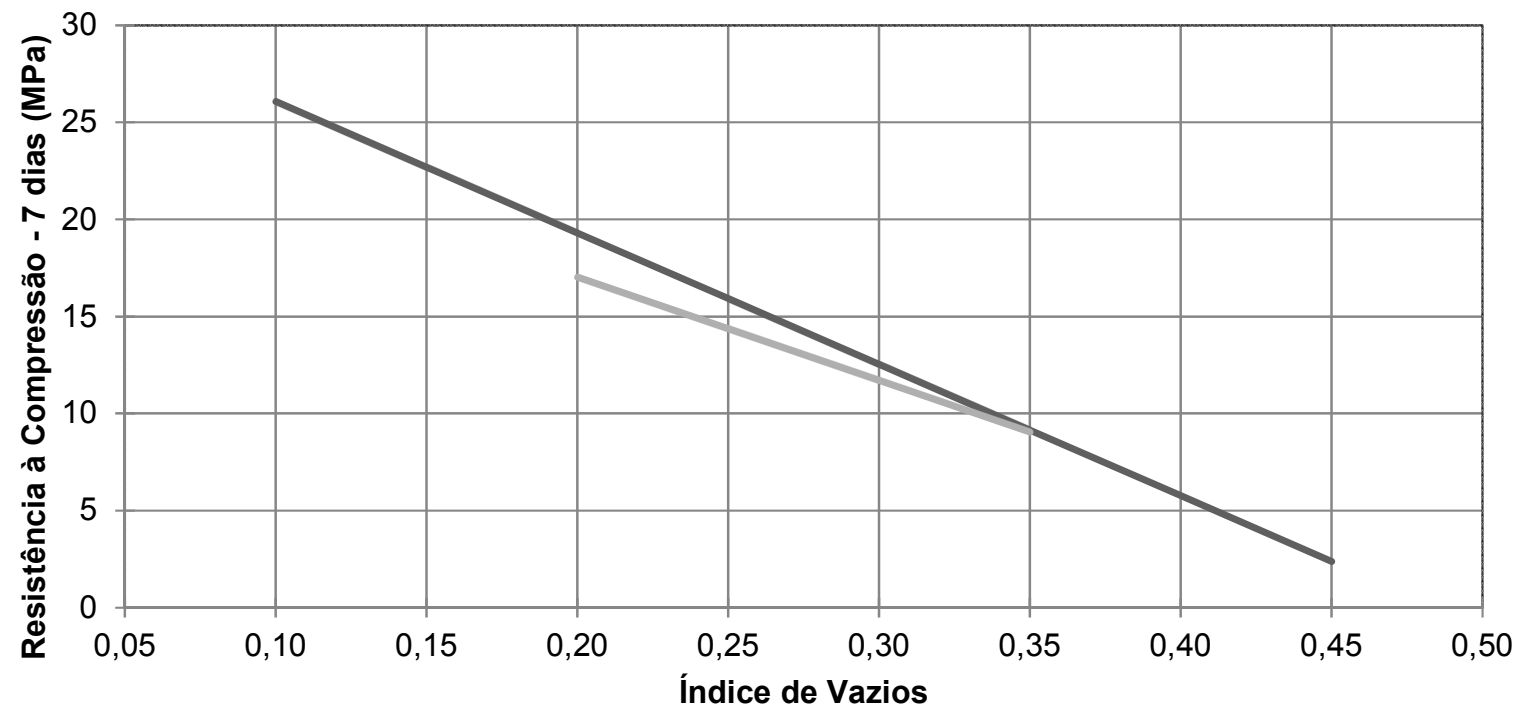

Energia Compac. Regular $\left(R^{2}=0,82\right) \quad$ Energia Compac. Baixa $\left(R^{2}=0,49\right)$

Figura 1.9: Efeito da energia de compactação na resistência à compressão em corpos de prova rompidos aos 7 dias

(adaptado de: SCHAEFER et al., 2006)

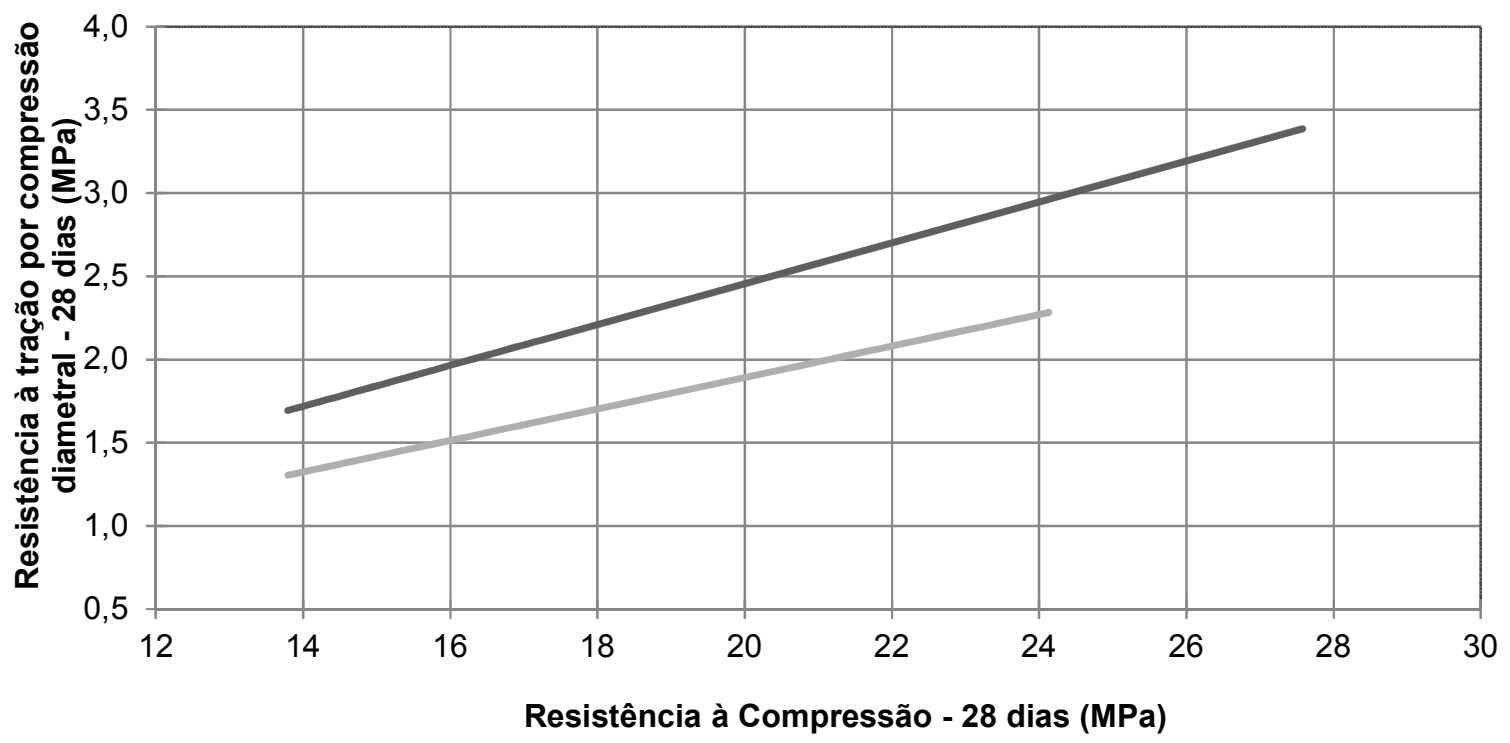

Energia Compac. Regular $\left(R^{2}=0,94\right) \quad$ Energia Compac. Baixa $\left(R^{2}=0,59\right)$

Figura 1.10: Efeito da energia de compactação na relação entre a resistência à compressão e resistência à tração por compressão diametral (adaptado de: SCHAEFER et al., 2006) 


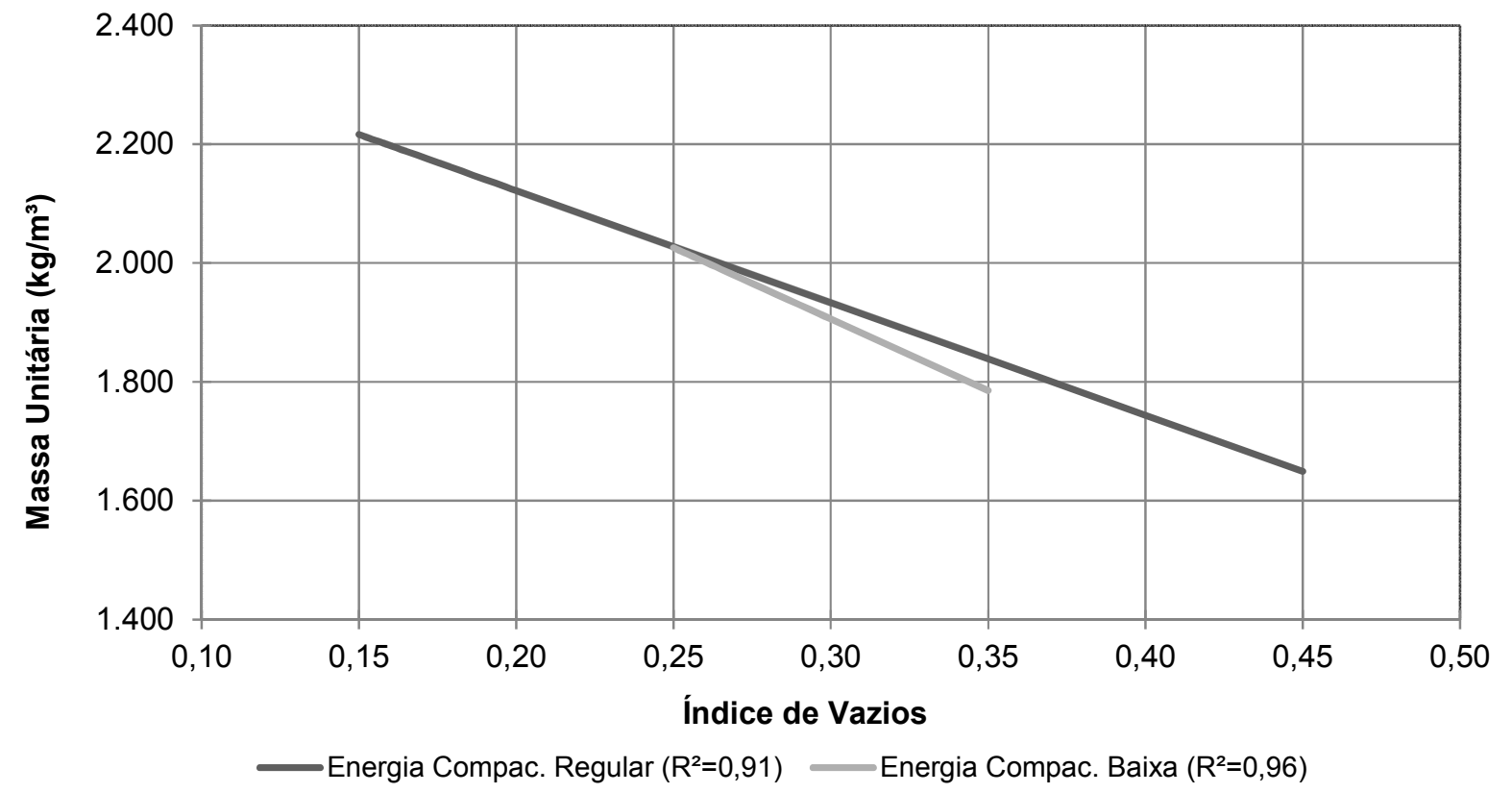

Figura 1.11: Efeito da energia de compactação na variação da massa unitária em função do índice de vazios

(adaptado de: SCHAEFER et al., 2006)

No geral, pode-se notar a partir da comparação entre os coeficientes de correlação apresentados nas diversas curvas, que os resultados obtidos para a energia de compactação regular se correlacionam melhor do que os resultados obtidos para energia de compactação baixa, podendo-se dizer que, para estes casos específicos, quanto menor a energia de compactação maior será a dispersão dos resultados. Além disso, observa-se na Figura 1.9 que a distância entre as curvas é mais acentuada para menores valores de índice de vazios, ou seja, quanto maior o índice de vazios, menor se torna a diferença na resistência, para as duas energias de compactação.

Huang et al. (2010) realizaram estudos referentes às condições de permeabilidade e resistência de misturas de concreto permeável com adição de fibras e látex. 0 trabalho teve como objetivo estudar o possível aumento da resistência do concreto sem diminuir a sua drenabilidade, com a finalidade de sua utilização em vias de tráfego pesado. Para tanto, além da utilização de agregado miúdo em pequenas quantidades, foram empregadas também fibras de polipropileno e látex como material de reforço na produção de diferentes misturas. Os resultados apresentados pelos autores indicam que não foi possível obter um concreto com níveis de permeabilidade e resistência aceitáveis para utilização em estradas caracterizadas 
por tráfego pesado, mesmo com a combinação de látex e areia na mistura. As Figuras 1.12 e 1.13 apresentam os resultados obtidos de condutividade hidráulica e resistência à tração por compressão diametral.

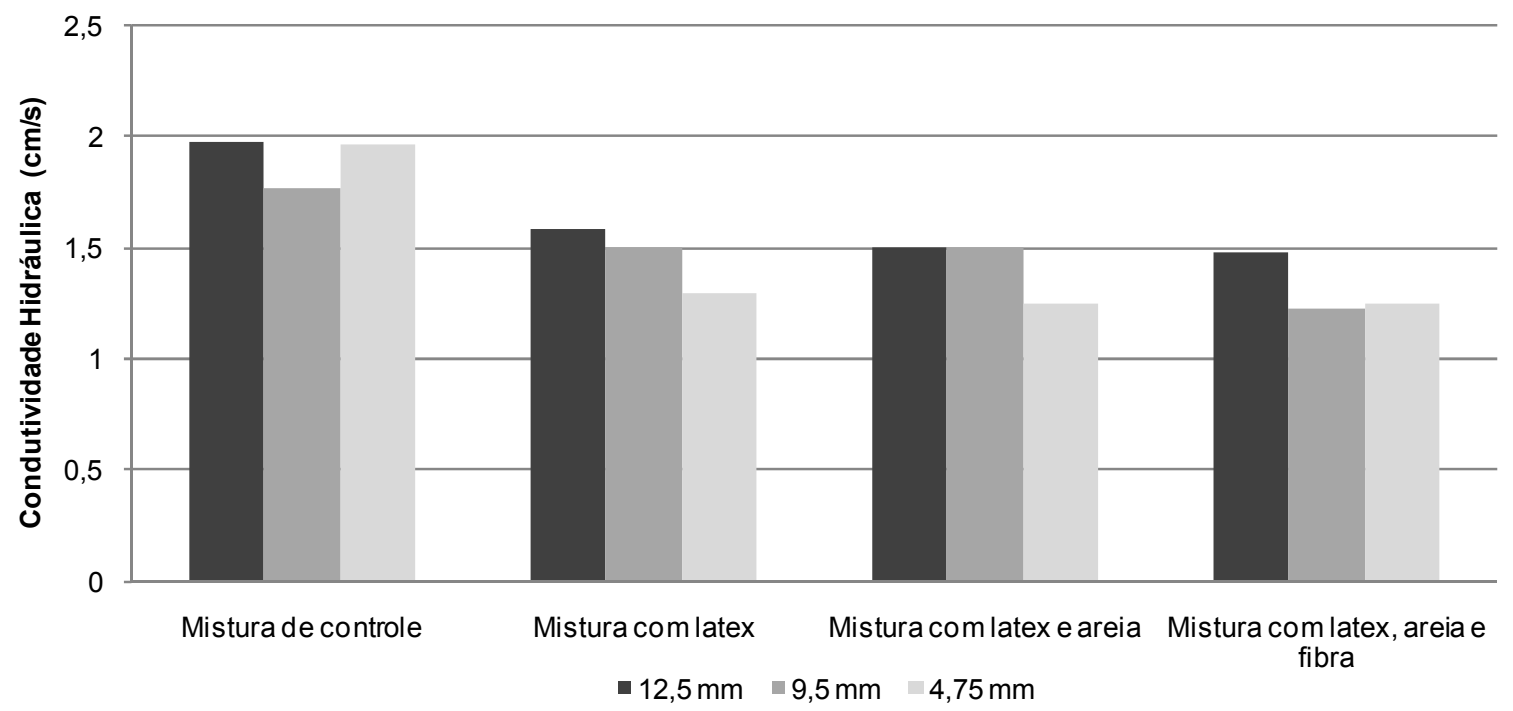

Figura 1.12: Efeito do látex na permeabilidade do concreto permeável (adaptado de: HUANG et al., 2010)

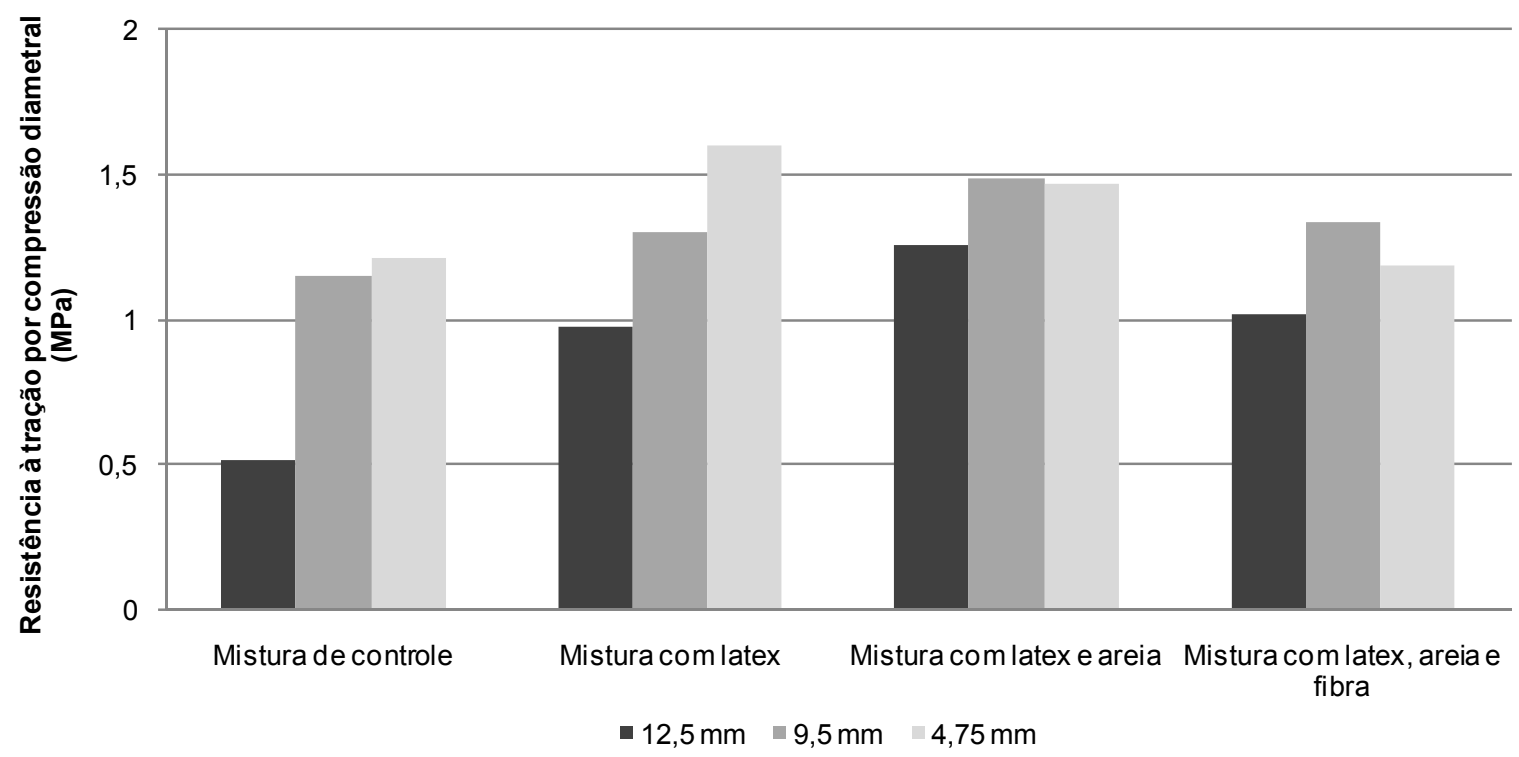

Figura 1.13: Efeito do látex na resistência à tração por compressão diametral do concreto permeável (adaptado de: HUANG et al., 2010)

Observa-se que, para todos os casos, a permeabilidade do concreto se manteve elevada, sendo que o menor valor encontrado foi de aproximadamente $1,25 \mathrm{~cm} / \mathrm{s}$ 
para a mistura com diâmetro máximo de agregado de 4,8 $\mathrm{mm}$ contendo látex e areia em sua composição. No caso da resistência foi verificado valor mais elevado para a mistura também com diâmetro máximo do agregado de $4,8 \mathrm{~mm}$, porém contendo somente o látex como adição. Nota-se ainda que a permeabilidade parece não variar em função do diâmetro máximo dos agregados utilizados, sendo que provavelmente o fator que mais influencia esse parâmetro é a interconectividade dos poros das misturas.

Cabe ressaltar que, mesmo que o concreto permeável com adições apresente resistências relativamente elevadas, que possam até se equiparar com a resistência de concretos convencionais, deve-se ter cautela com a sua utilização em vias de tráfego pesado, uma vez que, em função do seu elevado índice de vazios, este material pode apresentar características de tenacidade e resistência à fadiga insatisfatórias. Dessa maneira, verifica-se a importância da realização de estudos baseados em carregamentos dinâmicos para avaliar a resistência à fadiga e condições de tenacidade do concreto permeável, a fim de melhor caracterizar o seu comportamento quando solicitado continuamente pelo tráfego.

A Tabela 1.5 resume algumas das principais características dos concretos permeáveis estudados por diversos autores pesquisados na literatura.

Tabela 1.5: Propriedades de concretos permeáveis

\begin{tabular}{|c|c|c|c|c|c|c|}
\hline $\begin{array}{l}\text { Índice de } \\
\text { vazios }\end{array}$ & $\begin{array}{c}\text { Massa } \\
\text { unitária } \\
\left(\mathrm{kg} / \mathrm{m}^{3}\right)\end{array}$ & $\begin{array}{l}\text { Condutividade } \\
\text { Hidráulica }(\mathrm{cm} / \mathrm{s})\end{array}$ & $\begin{array}{l}\text { Consumo de } \\
\text { cimento } \\
\left(\mathbf{k g} / \mathrm{m}^{3}\right)\end{array}$ & $\begin{array}{c}\text { Resistência à } \\
\text { compressão - } 28 \\
\text { dias (MPa) }\end{array}$ & $\begin{array}{l}\text { Resistência à } \\
\text { tração na } \\
\text { flexão (MPa) }\end{array}$ & Referência \\
\hline 0,15 a 0,25 & $\begin{array}{c}1.600 \mathrm{a} \\
2.000\end{array}$ & 0,20 a 0,53 & 270 a 415 & 5,5 a 20,6 & 1,0 a 3,8 & Tennis et al., 2004 \\
\hline 0,15 a 0,35 & $\mathrm{n} / \mathrm{a}$ & $\mathrm{n} / \mathrm{a}$ & $\mathrm{n} / \mathrm{a}$ & $\mathrm{n} / \mathrm{a}$ & 2,5 a 3,9 & Olek et al., 2003 \\
\hline 0,19 & $\mathrm{n} / \mathrm{a}$ & $\mathrm{n} / \mathrm{a}$ & $\mathrm{n} / \mathrm{a}$ & 26,0 & 4,4 & Beeldens et al.,2003 \\
\hline 0,20 a 0,30 & $\begin{array}{c}1.890 \mathrm{a} \\
2.080\end{array}$ & $\mathrm{n} / \mathrm{a}$ & $\mathrm{n} / \mathrm{a}$ & 17,6 a 32,1 & 3,9 a 5,7 & Beeldens, 2001 \\
\hline 0,11 a 0,15 & $\mathrm{n} / \mathrm{a}$ & 0,03 a 0,18 & $\mathrm{n} / \mathrm{a}$ & $\mathrm{n} / \mathrm{a}$ & 4,2 a 7,5 & Kajio et al., 1998 \\
\hline $\mathrm{n} / \mathrm{a}$ & $\mathrm{n} / \mathrm{a}$ & $\mathrm{n} / \mathrm{a}$ & $\mathrm{n} / \mathrm{a}$ & 19,0 & $\mathrm{n} / \mathrm{a}$ & Tamai e Yoshida, 2003 \\
\hline 0,18 a 0,31 & $\mathrm{n} / \mathrm{a}$ & $\mathrm{n} / \mathrm{a}$ & $\mathrm{n} / \mathrm{a}$ & 11,0 a 25,0 & $\mathrm{n} / \mathrm{a}$ & Park e Tia, 2004 \\
\hline
\end{tabular}




\begin{tabular}{|c|c|c|c|c|c|c|}
\hline $\begin{array}{c}\text { Índice de } \\
\text { vazios }\end{array}$ & $\begin{array}{l}\text { Massa } \\
\text { unitária } \\
\left(\mathrm{kg} / \mathrm{m}^{3}\right)\end{array}$ & $\begin{array}{c}\text { Condutividade } \\
\text { Hidráulica (cm/s) }\end{array}$ & $\begin{array}{l}\text { Consumo de } \\
\text { cimento } \\
\left(\mathrm{kg} / \mathrm{m}^{3}\right)\end{array}$ & $\begin{array}{c}\text { Resistência à } \\
\text { compressão - } 28 \\
\text { dias (MPa) }\end{array}$ & $\begin{array}{c}\text { Resistência à } \\
\text { tração na } \\
\text { flexão (MPa) }\end{array}$ & Referência \\
\hline 0,15 a 0,25 & $\mathrm{n} / \mathrm{a}$ & $\mathrm{n} / \mathrm{a}$ & $\mathrm{n} / \mathrm{a}$ & 22,0 a 39,0 & $\mathrm{n} / \mathrm{a}$ & Chindaprasirt et al., 2008 \\
\hline $\mathrm{n} / \mathrm{a}$ & $\mathrm{n} / \mathrm{a}$ & $\mathrm{n} / \mathrm{a}$ & $\mathrm{n} / \mathrm{a}$ & 31,0 a 54,0 & $\mathrm{n} / \mathrm{a}$ & Zaharieva et al., 2003 \\
\hline $\mathrm{n} / \mathrm{a}$ & $\mathrm{n} / \mathrm{a}$ & $\mathrm{n} / \mathrm{a}$ & 275 a 350 & 14,0 a 27,0 & $\mathrm{n} / \mathrm{a}$ & Pindado et al., 1999 \\
\hline 0,03 a 0,29 & $\begin{array}{c}1.856 \mathrm{a} \\
2.227\end{array}$ & 0,003 a 0,22 & 344 & 7,5 a 18,8 & $\mathrm{n} / \mathrm{a}$ & Lee et al., 2009 \\
\hline 0,05 a 0,35 & $\mathrm{n} / \mathrm{a}$ & 0,01 a 1,00 & $\mathrm{n} / \mathrm{a}$ & 4,1 a 55,8 & $\mathrm{n} / \mathrm{a}$ & Delatte et al., 2009 \\
\hline $\mathrm{n} / \mathrm{a}$ & $\mathrm{n} / \mathrm{a}$ & 0,70 a 1,60 & 295 a 352 & 4,5 a 14,5 & $\mathrm{n} / \mathrm{a}$ & Huang et al., 2010 \\
\hline $\mathrm{n} / \mathrm{a}$ & $\begin{array}{c}1.835 \mathrm{a} \\
2.392\end{array}$ & 0,01 a 0,92 & $\mathrm{n} / \mathrm{a}$ & 10,5 a 32,8 & $\mathrm{n} / \mathrm{a}$ & Henderson et al., 2009 \\
\hline
\end{tabular}

Fadiga

Estudos de resistência à fadiga têm sido extensivamente realizados para materiais de pavimentação convencionais, tais como o CCP e o concreto asfáltico. No caso do concreto permeável é rara a existência de estudos que apresentem o seu desempenho quando submetido a carregamentos cíclicos. Segundo Klaiber e Lee (1982), para o caso do CCP, a vida de fadiga diminui com o aumento da quantidade de poros ou vazios na estrutura.

Pindado et al. (1999) avaliaram os efeitos da incorporação de sílica ativa e polímero em misturas de concreto permeável para verificar a resposta do material à fadiga em compressão. Na pesquisa foram empregadas diferentes proporções de agregados graúdo e miúdo, bem como aditivos superplastificantes. Com relação aos ligantes empregados, já que instituições da Alemanha, Holanda e Espanha participaram da pesquisa, foram escolhidos ligantes hidráulicos provenientes desses três países. Além disso, os corpos de prova utilizados foram moldados nestes três países e não seguiram metodologias equivalentes de compactação das misturas nem mesmo de cura dos corpos de prova.

Para os testes de fadiga foram utilizadas relações entre tensões máximas e mínimas de carregamento e descarregamento na ordem de 0,05, 0,20 e 0,50 (amplitude de carga), bem como frequência de carregamento de $10 \mathrm{~Hz}$ e $15 \mathrm{~Hz}$. As relações entre 
a tensão máxima atuante ( $\left.\sigma_{\text {máx }}\right)$ e a tensão resistente à compressão $\left(f_{c}\right)$ do concreto variaram entre 0,60 e $0,95(\mathrm{RT})$.

Os autores determinaram que as relações de tensões máximas e mínimas de carregamento e descarregamento influenciam na vida útil de fadiga à compressão do material. Os resultados mostram que quanto menor a diferença entre estas tensões, menor será a vida de fadiga do material (Figura 1.14).

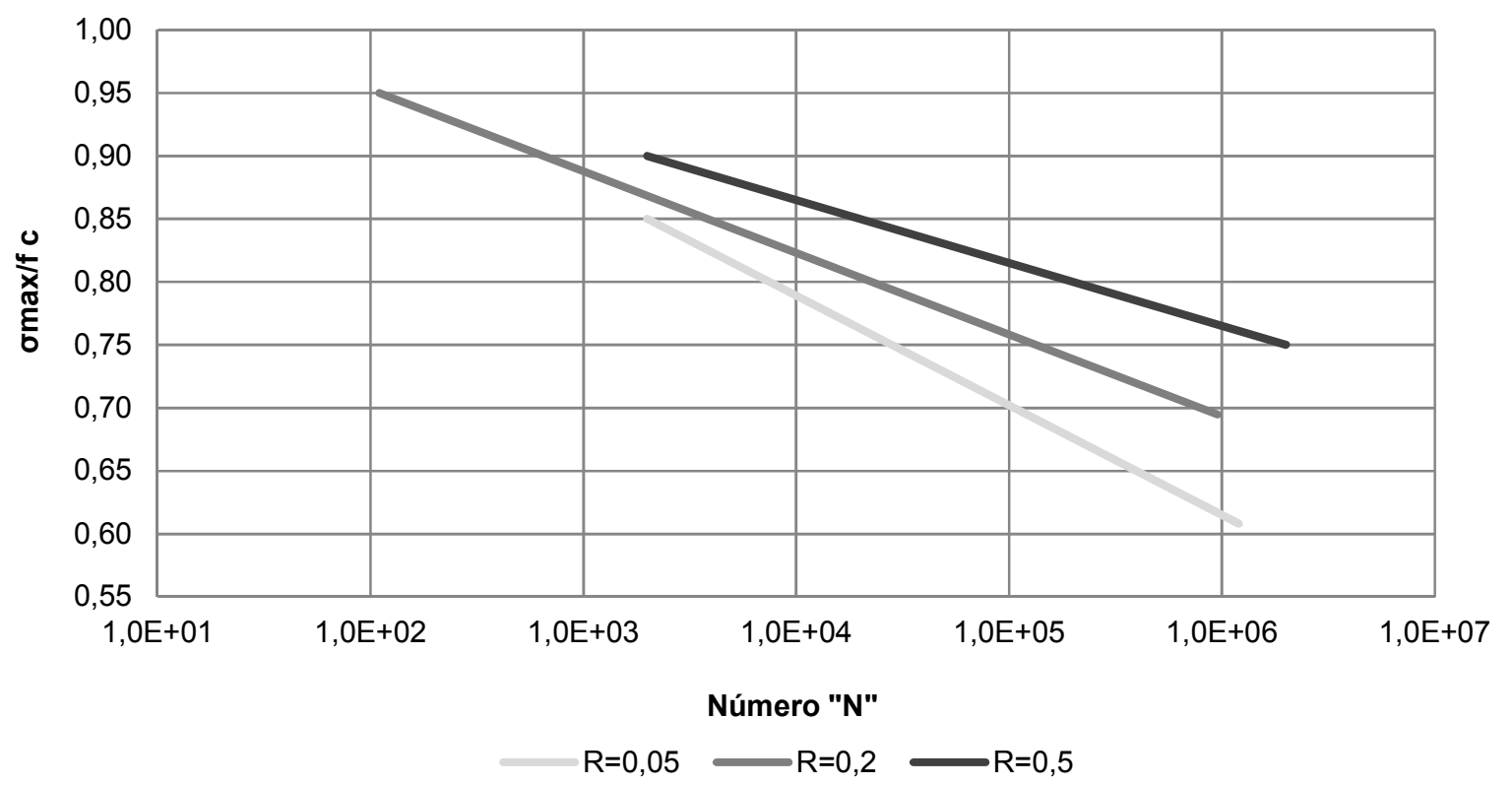

Figura 1.14: Variação da resistência à fadiga em função das diferentes relações entre tensão máxima e tensão resistente e relações entre tensão máxima de carregamento e tensão mínima de descarregamento (adaptado de: PINDADO et al., 1999)

Os resultados

As misturas com incorporação de polímeros apresentaram maior resistência à fadiga quando comparadas às misturas sem adições ou com adição de sílica ativa. Isso ocorreu provavelmente porque quando um polímero é adicionado a uma mistura de concreto permeável ele tende a aumentar a ductilidade do material endurecido que, consequentemente, impõe uma diminuição da taxa de evolução de dano causado pelos carregamentos cíclicos.

Com relação à propagação das fissuras e evolução de danos em concretos convencionais, estudos indicam que o nível de frequência do carregamento 
influencia muito nos resultados de ensaios de fadiga. Em testes utilizando frequências variando de 1 a $10 \mathrm{~Hz}$, Cervo (2004) mostrou que, para concretos convencionais, quanto menor a frequência de aplicação de cargas, menor será a resistência à fadiga do material.

Segundo Balbo (2009), a frequência das cargas aplicadas em pista nas situações reais é muito reduzida, tornando os resultados obtidos a partir do ensaio de resistência à fadiga com elevadas frequências de carregamento (acima de $10 \mathrm{~Hz}$ ), superestimados. Este fato se dá em função da diminuição da nucleação das fissuras, uma vez que com elevadas frequências de carregamento, as fissuras não possuem tempo suficiente para se desenvolverem e se interconectarem no interior da matriz do material, aumentando assim a sua vida útil. Dessa maneira, pode-se considerar que devido à elevada faixa de variação de frequência utilizada nos testes (entre 10 e $15 \mathrm{~Hz}$ ), os resultados obtidos por Pindado et al. (1999) podem estar superestimados com relação ao que o material realmente apresentaria em pista.

Cabe ressaltar que resultados de ensaios de fadiga em compressão pouco contribuem para a caracterização de um modelo em que se deseje avaliar o comportamento à fadiga de placas de concreto permeável para uso em pavimentos, uma vez que estas são solicitadas à tração na flexão e o comportamento a fadiga de um mesmo material à compressão e à tração na flexão são muito diferentes.

Pindado et al. (1999) avaliaram também o comportamento do material com relação à evolução de deformações para uma das misturas, considerando a RT na ordem de 0,65 e aplicação de 555.992 ciclos de carregamento. A partir dos resultados, identificaram a presença de 3 estágios distintos de evolução das deformações, como normalmente é visto em concretos convencionais (KIM e KIM, 1996). Em um primeiro estágio, as deformações cresceram rapidamente até atingir os $5 \%$ da vida de fadiga. Em seguida, entre $5 \%$ e $95 \%$ da vida de fadiga, as deformações mantiveram um crescimento estável com uma taxa mais reduzida. Por fim, a partir dos $95 \%$ de vida, as deformações tornaram a crescer rapidamente, até a ruptura das amostras (Figura 1.15). 


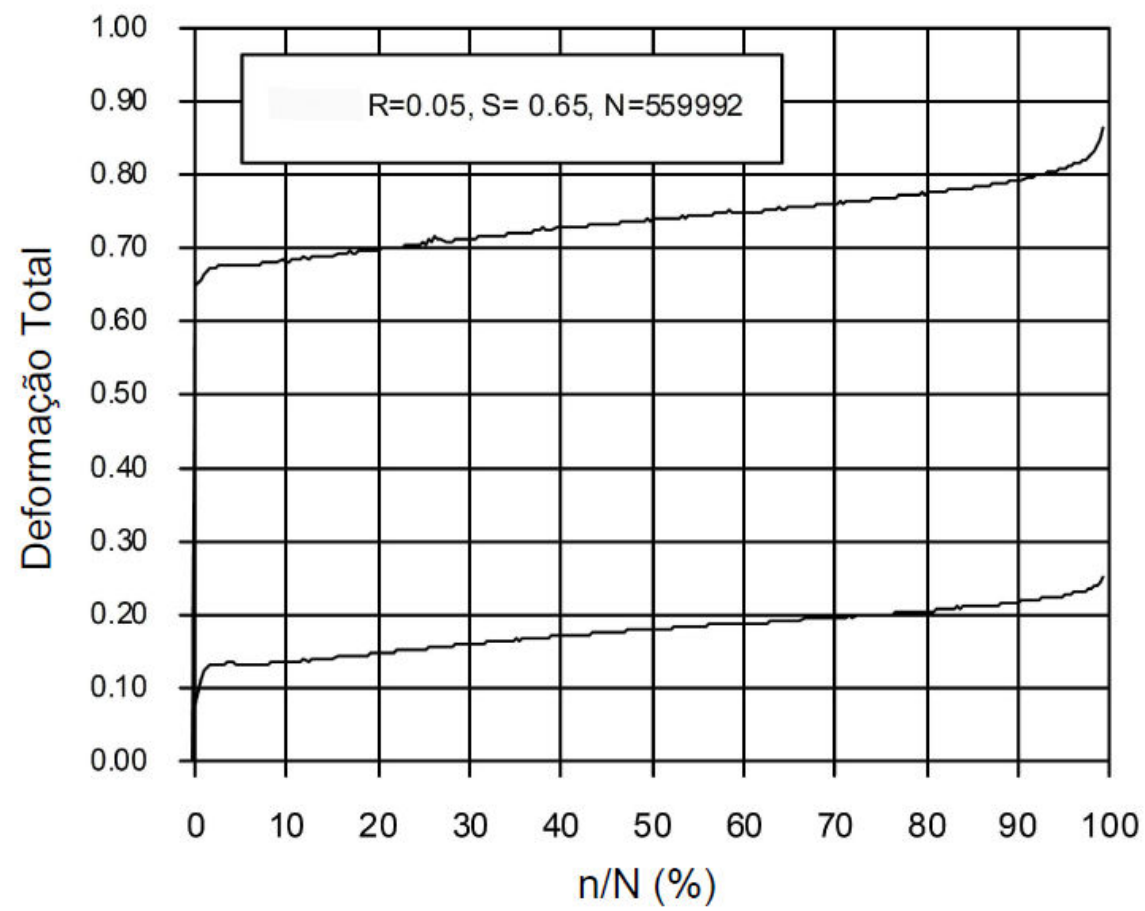

Figura 1.15: Valores máximos e mínimos da evolução de deformação total durante os testes (adaptado de: PINDADO et al., 1999)

Módulo de elasticidade e Coeficiente de Poisson

Goede (2009) determinou o módulo de elasticidade estático e o coeficiente de Poisson em ensaios de compressão em amostras cilíndricas de concreto permeável moldados com agregado de diâmetro único de $12,5 \mathrm{~mm}$ e relação a/c variando de 0,27 a 0,28 . Obteve como resultados valores de módulo de elasticidade variando entre 12.100 MPa e 15.100 MPa, menores, portanto, que os valores comumente encontrados para concretos convencionais. Essa constatação já era esperada devido à grande diferença de índice de vazios existente entre estes dois materiais, pelo fato de que a quantidade de vazios influencia diretamente no módulo de elasticidade.

Para concretos convencionais a $\mathrm{ACl}$ (2008) sugere que o módulo de elasticidade seja calculado a partir da equação (1) (GOEDE, 2009).

$$
E=33 \cdot \rho_{c}^{1,5} \cdot \sqrt{f_{c}}
$$


onde:

$$
\begin{aligned}
& E=\text { Módulo de Elasticidade; } \\
& \rho_{c}=\text { Massa Unitária do Concreto; } \\
& f_{c}=\text { Resistência à Compressão do Concreto. }
\end{aligned}
$$

Para o concreto permeável Ghafoori e Dutta (1995) experimentalmente desenvolveram uma equação similar (equação (2)) para determinação do módulo de elasticidade (GOEDE, 2009).

$$
E=32,88 \cdot \rho_{c}^{1,5} \cdot \sqrt{f_{c}}
$$

Observa-se que a variação da constante 32,88, determinada por Ghafoori e Dutta (1995) para concreto permeável, é muito próxima da constante "33" preconizada pela $\mathrm{ACl}$ (2008) para concretos convencionais.

A equação (3) foi determinada por Goede (2009). Pode-se notar que o valor da constante é maior que as constantes contidas nas equações preexistentes.

$$
E=39,1 \cdot \rho_{c}^{1,5} \cdot \sqrt{f_{c}}
$$

Na Figura 1.16 é apresentada uma curva de relação entre o módulo de elasticidade e a resistência à compressão dos corpos de prova, determinados em laboratório por Goede (2009).

Quanto ao coeficiente de Poisson, o autor determinou valores variando de 0,14 a 0,34 , sendo que a média obtida foi de 0,22. Estes resultados são similares, porém apresentam maior variabilidade do que os resultados obtidos por Ghafoori e Dutta (1995), que concluíram que o coeficiente de Poisson do concreto permeável é similar ao do concreto convencional, variando de 0,15 a 0,20. 


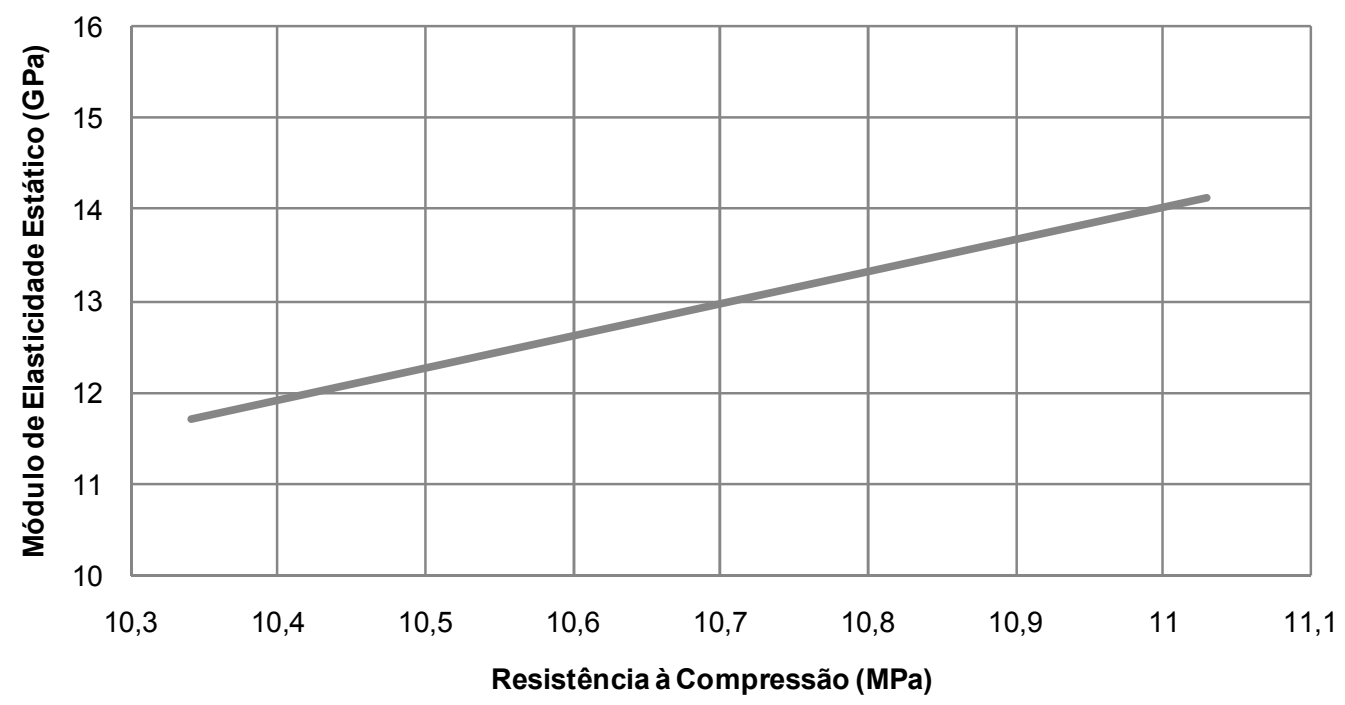

Figura 1.16: Relação entre o módulo de elasticidade e a resistência à compressão de amostras de concreto permeável

(adaptado de: GOEDE, 2009)

\section{Temperatura e Clima}

Evidências sugerem que, em épocas de nevascas nos países de clima temperado, a neve depositada sobre revestimentos de concreto permeável é removida do local com maior velocidade em comparação aos revestimentos convencionais de pavimentos, uma vez que a sua elevada porosidade auxilia no fenômeno de descongelamento.

De acordo com Henderson (2008), os vazios existentes em uma estrutura de concreto permeável podem se apresentar como um local passível de congelamento e expansão da água, o que poderia acarretar uma posterior perda de agregados devida a possíveis rupturas da estrutura interna do concreto. Todavia, em função da sua elevada capacidade permeável, o concreto faz com que a existência de umidade na camada de revestimento seja mínima, uma vez que a água das intempéries tende a percolar rapidamente pelo revestimento permeável e fica armazenada nas camadas subjacentes, diminuindo os riscos de ruptura da estrutura interna do revestimento por congelamento da água.

Além disso, pode ser considerada como benefício adicional, a estrutura aberta característica do concreto permeável, que possui capacidade de diminuir com 
maiores velocidades as quantidades de gelo, neve e lama existentes na superfície dos pavimentos. Nos países de clima temperado, onde é comum a existência de ciclos de gelo e degelo, há um grande número de estudos caracterizando este mecanismo.

Os pavimentos permeáveis permanecem com aparência praticamente inalterada após a ocorrência de intempéries, ao contrário do que ocorre com os pavimentos impermeáveis, que apresentam aparência úmida por mais tempo. Esta característica comprova a questão do ganho relativo de segurança dos usuários devido à redução na quantidade de água sobre a superfície. Isso pode ser observado na Figura 1.17.

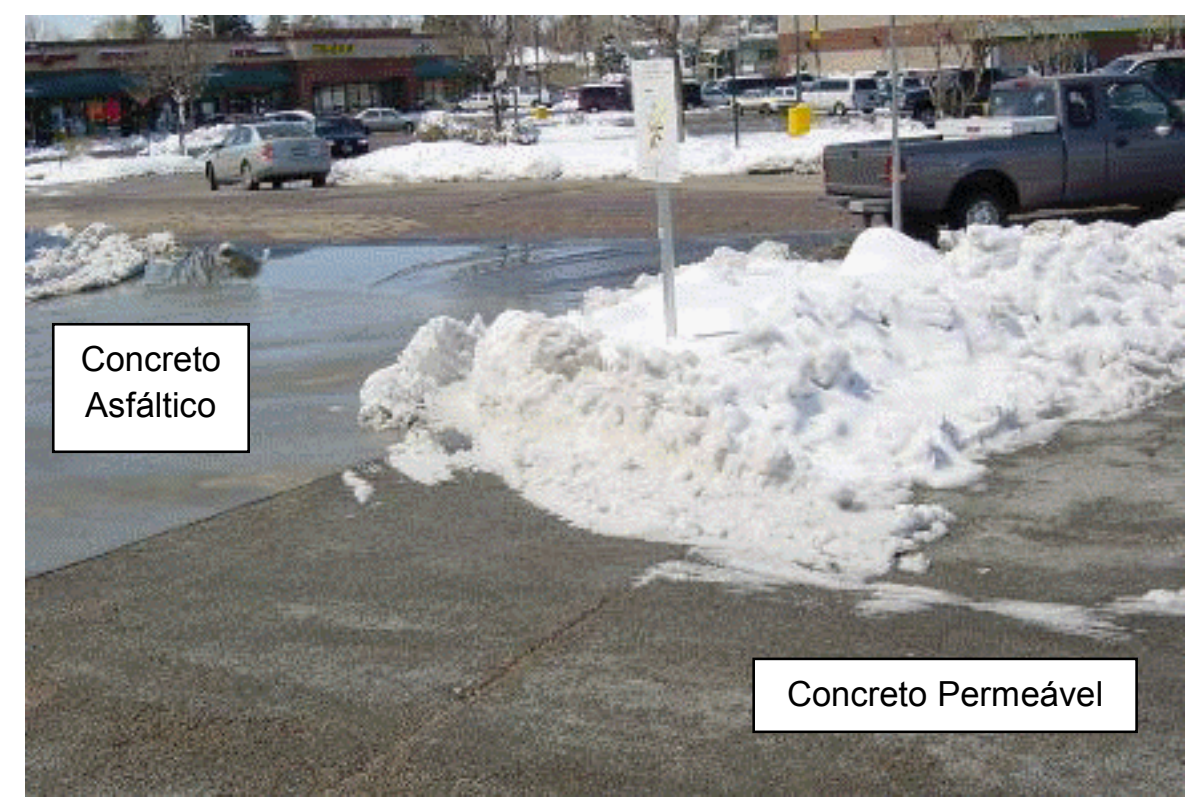

Figura 1.17: Diferença entre superfícies de pavimento de concreto permeável e pavimento asfáltico impermeável após a ocorrência da precipitação (Fonte: www.perviouspavement.org)

Houle et al. (2009) apresentam resultados de um estudo realizado comparando revestimentos de concreto asfáltico poroso e revestimentos de concreto permeável no que diz respeito à capacidade de infiltração, profundidade de congelamento, condições de temperatura e resistência à derrapagem. Para realização desta pesquisa foram construídas pistas experimentais em seis estacionamentos na Universidade de New Hampshire (Stormwater Center), nos EUA.

Os autores observaram que o pavimento de concreto asfáltico poroso apresentou um descongelamento total das camadas cerca de quatro semanas antes do 
pavimento revestido com concreto permeável. Isso pode ser explicado pelo fato de o revestimento asfáltico apresentar uma coloração escura, e, por consequência, baixa refletância, o que gera uma maior absorção de energia solar com relação ao pavimento com revestimento de concreto, o qual possui uma coloração clara, refletindo grande parte da luz que incide sobre ele. Na Figura 1.18 são apresentados os resultados dos experimentos considerando a profundidade de congelamento variando ao longo do tempo em áreas revestidas com asfalto poroso, concreto permeável e pavimento impermeável de referência.

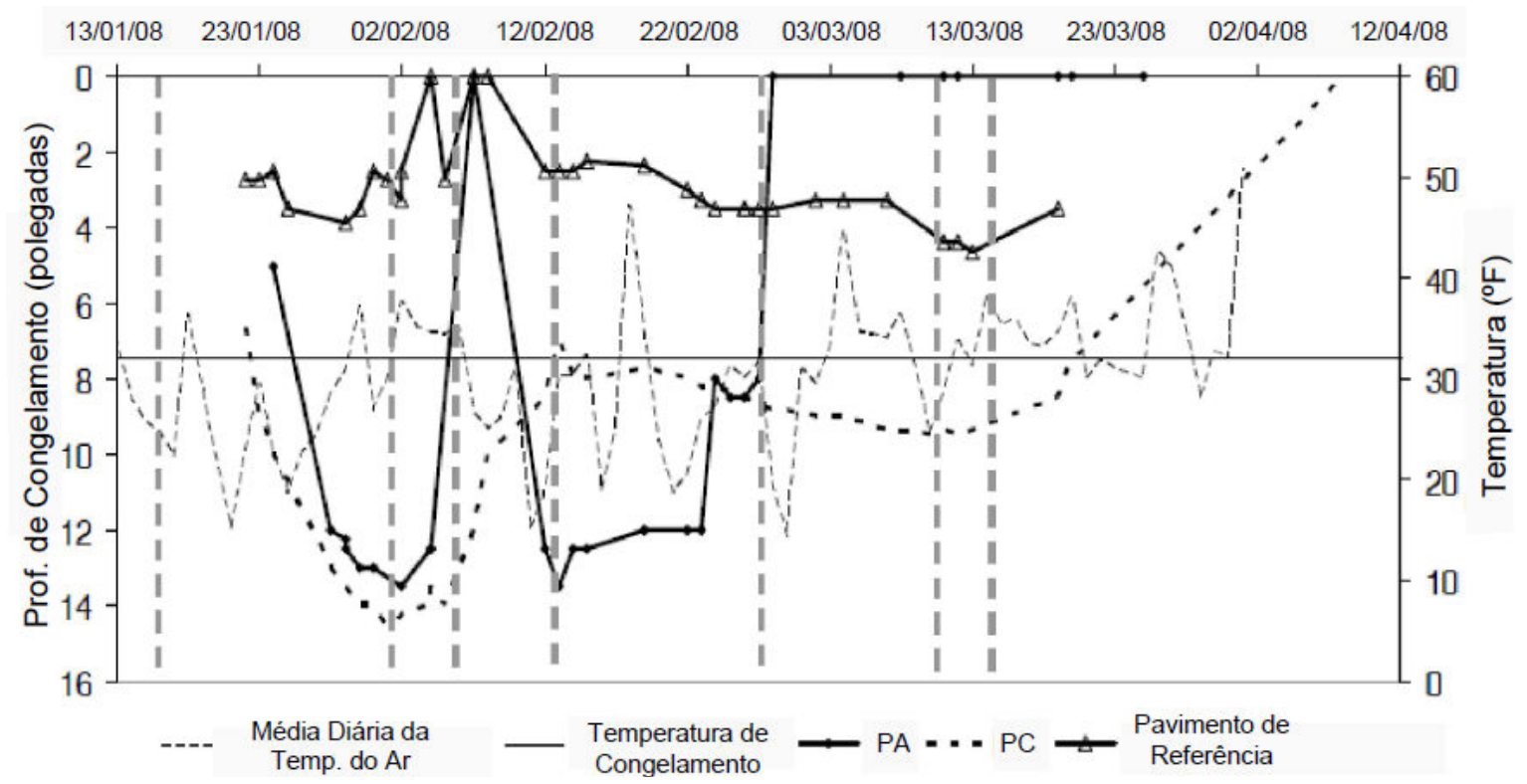

Figura 1.18: Comparação entre a profundidade de congelamento entre os pavimentos permeáveis e o pavimento de referência

(Fonte: HOULE et al., 2009)

Pode-se notar que para ambos os pavimentos permeáveis existe uma redução da profundidade de congelamento após um determinado evento de chuva, sendo mais expressiva no pavimento de asfalto poroso. Este fenômeno pode ser verificado para 6 dos 7 eventos de chuva, os quais estão representados pelas linhas verticais tracejadas na Figura 1.18. Além disso, observou-se que o revestimento de concreto permeável apresentou temperatura $6^{\circ} \mathrm{C}$ inferior, em média, àquela do revestimento asfáltico, quando submetido às mesmas condições climáticas. Quanto à resistência à derrapagem foi observado que o revestimento de asfalto poroso resultou em melhores respostas. Tal situação foi verificada tanto para condição seca quanto para condição de existência de neve na superfície das pistas. 
Kevern et al. (2009) estudaram a variação de temperatura em uma estrutura de pavimento com revestimento de concreto permeável. Para realização da pesquisa foi construída uma pista experimental em um estacionamento localizado no campus da lowa State University (EUA). Em metade de sua área empregou-se revestimento de concreto convencional e na outra metade foi utilizado concreto permeável como material de revestimento. Os resultados mostraram que a base granular da estrutura permeável dificulta a formação de camadas de gelo. Foi observado também que nos casos em que ocorreu exposição direta de ambos os revestimentos à luz do sol, a temperatura se mostrou mais elevada para o revestimento de concreto permeável.

Pindado et al. (1999) avaliaram a variação da temperatura de amostras de concreto permeável durante ensaios de fadiga. Os autores concluíram que a temperatura interna do concreto aumenta durante a aplicação dos ciclos de carga. Esse aumento se apresentou maior do que aqueles registrados nos concretos convencionais. Ainda, a distribuição de temperatura não se mostrou constante ao longo da altura do corpo de prova, sendo que os maiores valores foram medidos no centro das amostras. Por fim, os autores sugerem que, para se evitar efeitos indesejados em função do aumento de temperatura em ensaios de fadiga, deve-se realizar ensaios com menores frequências de aplicação de carga.

\section{Características de Interesse Ambiental}

O sistema de pavimento de concreto permeável tem potencial de controle hidrológico e químico de partículas das águas pluviais. Kuang et al. (2007) estudaram a capacidade de remoção de partículas existentes nas águas das chuvas quando estas percolam por um sistema de pavimento permeável. Foi determinado que o valor total de fósforo existente no efluente teve uma redução de mais de $80 \%$ com relação ao valor determinado para a água antes de entrar no sistema. O mesmo ocorreu quanto à turbidez do efluente, onde foram observadas reduções variando de $50 \%$ a $90 \%$.

Estudos referentes às questões de utilização de pavimentos revestidos com concreto permeável para fins de urbanização foram realizados por Volder et al. 
(2009). O estudo teve como objetivo comparar e avaliar a capacidade desse tipo de sistema frente aos sistemas tradicionais de pavimentação, de diminuir, ou até mesmo de extinguir a necessidade de retirada de árvores em locais onde serão construídas novas estruturas de pavimento. Porém, ao término dos estudos os autores concluíram que a utilização de revestimentos de concreto permeável em pavimentos não gera nenhum benefício adicional que garanta o crescimento ou a sobrevivência de árvores preexistentes.

\subsubsection{Análises Mecanicistas}

Alam et al. (2011) simularam painéis de concreto permeável submetidos a carregamentos por eixo tandem de rodas duplas a partir de análises por elementos finitos. Foram consideradas posições das rodas no canto, centro e na borda das placas. As tensões críticas obtidas foram comparadas com resultados de resistência à tração na flexão (2 MPa) e compressão (21,3 MPa) em amostras retiradas de pistas experimentais, considerando diferentes espessuras de concreto permeável. $O$ estudo mostrou que os painéis de concreto permeável projetados apresentam resistências suficientes para suportar as cargas utilizadas no estudo.

Os autores estudaram ainda o desempenho do material em longo prazo quando sujeitos a carregamentos cíclicos, comparando as tensões críticas de tração na flexão para várias espessuras de pavimento com dados de Índice de Condição do Pavimento obtidos em campo, refletindo o desempenho do pavimento de aproximadamente 131.000 ciclos de um eixo simples de roda dupla de $80 \mathrm{kN}$. Para este particular campo de aplicação, foi determinado que para carregamentos cíclicos a espessura necessária da camada de concreto permeável foi de $30 \%$ a $40 \%$ maior quando comparada com a condição de carregamento estático.

\subsubsection{Métodos de Construção de Revestimentos de Concreto Permeáveis}

A seguir estão descritos os principais procedimentos comumente utilizados na execução de pavimentos com revestimento em concreto permeável, com ênfase nos procedimentos para preparação do subleito, mistura dos componentes, transporte 
para obra, distribuição e consolidação do material nas formas, confecção de juntas e cura.

Cabe ressaltar que todos os procedimentos de dosagem, controle tecnológico em obra e produção do concreto permeável para utilização como revestimento de pavimentos possuem ainda um elevado grau de empirismo, uma vez que as definições das metodologias e técnicas para realização desses serviços, em especial com relação à dosagem e ao controle tecnológico, ainda estão em fase de estudo e de adaptação.

\section{Preparação do Subleito}

Um dos critérios chave para execução de pavimentos permeáveis é a uniformidade do subleito. Como no caso dos pavimentos convencionais, todas as irregularidades existentes devem ser retiradas procedendo-se com a compactação do solo. Sugerese que o grau de compactação do subleito varie de $90 \%$ a $95 \%$ com relação ao peso específico aparente seco teórico de laboratório. Entretanto, deve-se considerar que com o aumento do peso específico do subleito, existe uma tendência de decréscimo de sua permeabilidade, situação esta possivelmente desfavorável, uma vez que o solo precisa apresentar um coeficiente de permeabilidade elevado para que o sistema de pavimento permeável seja funcional e efetivo (isso se o sistema projetado depender da infiltração total da água no solo).

Uma vez que o concreto permeável contém baixa relação a/c e elevado índice de vazios, deve-se tomar cuidado para que o pavimento não perca água prematuramente. Dessa maneira, o subleito necessita estar pré-umedecido (evitando excesso de água) para que a água da superfície inferior do concreto não seja removida rapidamente de sua estrutura, prejudicando o processo de hidratação do cimento (consideração para quando o concreto for apoiado diretamente sobre o subleito). Este procedimento é considerado importante quando da execução de pavimentos convencionais, porém é ainda mais importante para o caso do concreto permeável, uma vez que este possui índice de vazios elevado, facilitando a fuga da água através de sua estrutura porosa, o que pode causar redução de sua resistência mecânica e durabilidade. 


\section{Procedimento de Mistura}

As propriedades especiais do concreto permeável requerem relativo controle das proporções dos materiais a serem utilizados na mistura. Em particular, a quantidade de água a ser utilizada é limitada em uma estreita faixa, com a finalidade de garantir as suas características de resistência e permeabilidade. Além disso, a pouca quantidade de água serve para prevenir que a pasta solte dos agregados, evitando a obstrução dos poros do concreto.

\section{Transporte}

Uma vez que o concreto permeável possui pouca quantidade de água em sua mistura deve-se tomar cuidado especial com relação ao seu de transporte à obra, quando este for industrializado. Assim, o material deve ser completamente descarregado em no máximo uma hora após o início da mistura dos seus componentes (evitar alterações bruscas de consistência). O uso de retardadores de pega pode elevar esse tempo. Deve-se ainda ter cuidado redobrado com relação ao tempo útil para utilização da mistura quando o local de aplicação do concreto seja caracterizado por temperatura ambiente e velocidade do vento elevadas.

\section{Lançamento e Consolidação}

O método mais comum para lançamento do concreto permeável em pista é manual, com instalação de formas laterais. Este tipo de material, em função de não poder ser bombeado, é inicialmente descarregado por um caminhão, sendo que nesse caso é necessário o planejamento dos acessos à pista para os caminhões. Na sequência o material é espalhado manualmente no interior das formas.

Como método de controle, cada carga do concreto permeável deve ser inspecionada visualmente para verificação da sua consistência e da condição de cobertura dos agregados. O controle da massa unitária da mistura se faz necessário para este tipo de material, uma vez que o ensaio de abatimento de tronco de cone, normalmente utilizado como método de controle de concretos convencionais, não é empregável 
neste caso, dado a reduzida relação a/c comumente presente nas misturas de concreto permeável.

Para a compactação do concreto permeável têm-se dois métodos mais comuns utilizados na prática atual. No primeiro método, uma placa espaçadora de 2,5 a 5,0 $\mathrm{cm}$ é colocada no topo das formas e o concreto é então nivelado com auxílio de uma régua vibratória como pode ser observado na Figura 1.19. Em seguida, a placa é removida e a superfície é compactada com auxílio de um rolo de metal leve. O rolo de metal é também utilizado para finalizar a superfície na direção transversal ao pavimento (Figura 1.20). O peso do rolo pode variar, mas comumente são utilizados rolos com peso de $68 \mathrm{~kg}$ por metro linear, produzindo uma pressão de 0,07 $\mathrm{MPa}$, sugerida pela Carolinas Ready Mixed Concrete Association (CRMCA, 2003).

O segundo método de compactação é a partir do uso de uma placa compactadora vibratória que normalmente é utilizada apenas para misturas contendo agregados de elevada angularidade (YOUNGS, 2005).

De maneira similar ao concreto convencional, as juntas são induzidas para controle de fissuração por retração, definindo a localização da ocorrência dessas fissuras na estrutura.

Enquanto a maioria dos pavimentos permeáveis em uso na atualidade foi executada com a existência de juntas para controle de fissuração do revestimento, algumas estruturas de estacionamentos construídas na Califórnia foram executadas sem a utilização das juntas (YOUNGS, 2005). 


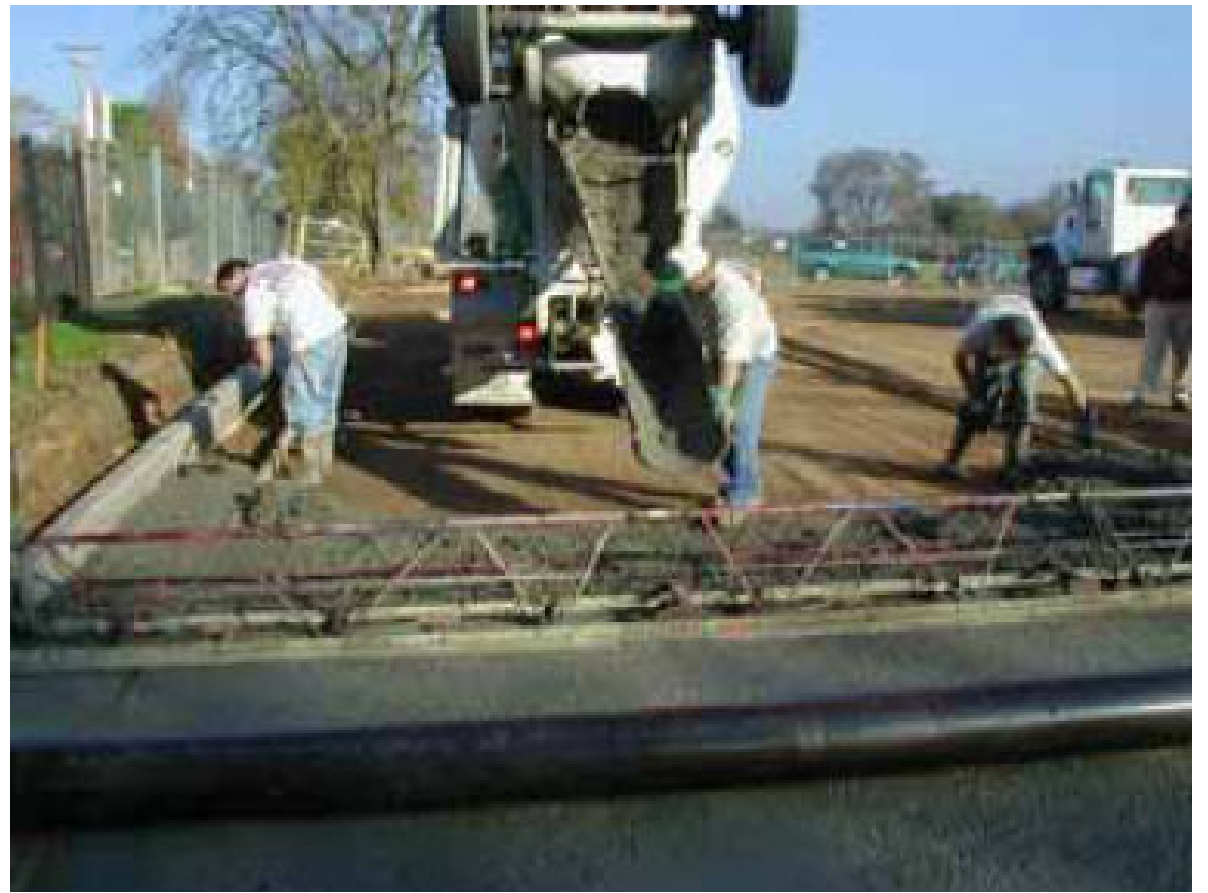

Figura 1.19: Procedimento de lançamento do concreto permeável (Fonte: YOUNGS, 2005.)

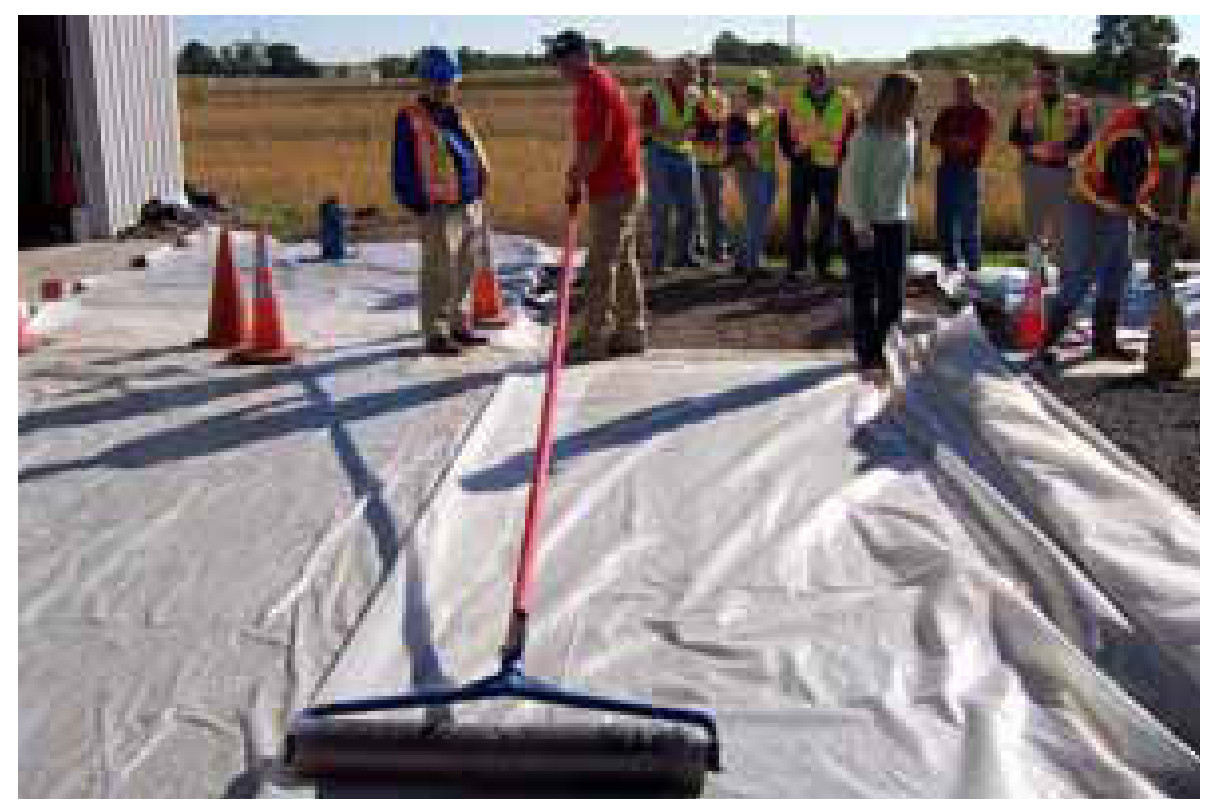

Figura 1.20: Passagem de rolo de metal transversal sobre a lona para retenção de umidade (Fonte: YOUNGS, 2005.)

Uma vez que o concreto permeável retrai menos que o concreto convencional, espaçamentos maiores entre as juntas são usualmente utilizados. A National Ready Mixed Concrete Association (NRMCA, 2004) recomenda que os comprimentos de placa máximos não ultrapassem seis metros, embora Tennis et al. (2004) afirmem 
que espaçamentos inferiores a treze metros já são suficientes para prevenção de trincas de retração.

As juntas podem ser executadas tanto pelo procedimento de corte das placas quanto pelo posicionamento de formas previamente ao lançamento do concreto. Dentre as duas opções, a utilização de formas é o método preferido, uma vez que com a realização dos serviços de corte das placas é possível a ocorrência de quebras nas juntas (esborcinamento). O corte das placas normalmente é realizado com auxílio de um equipamento conhecido como "cortador de pizza" (pizza cutter), que é uma espécie de rolo equipado com um disco metálico na sua região central, como pode ser observado nas Figuras 1.21 e 1.22. Este corte é elaborado previamente ao início de pega (corte verde).

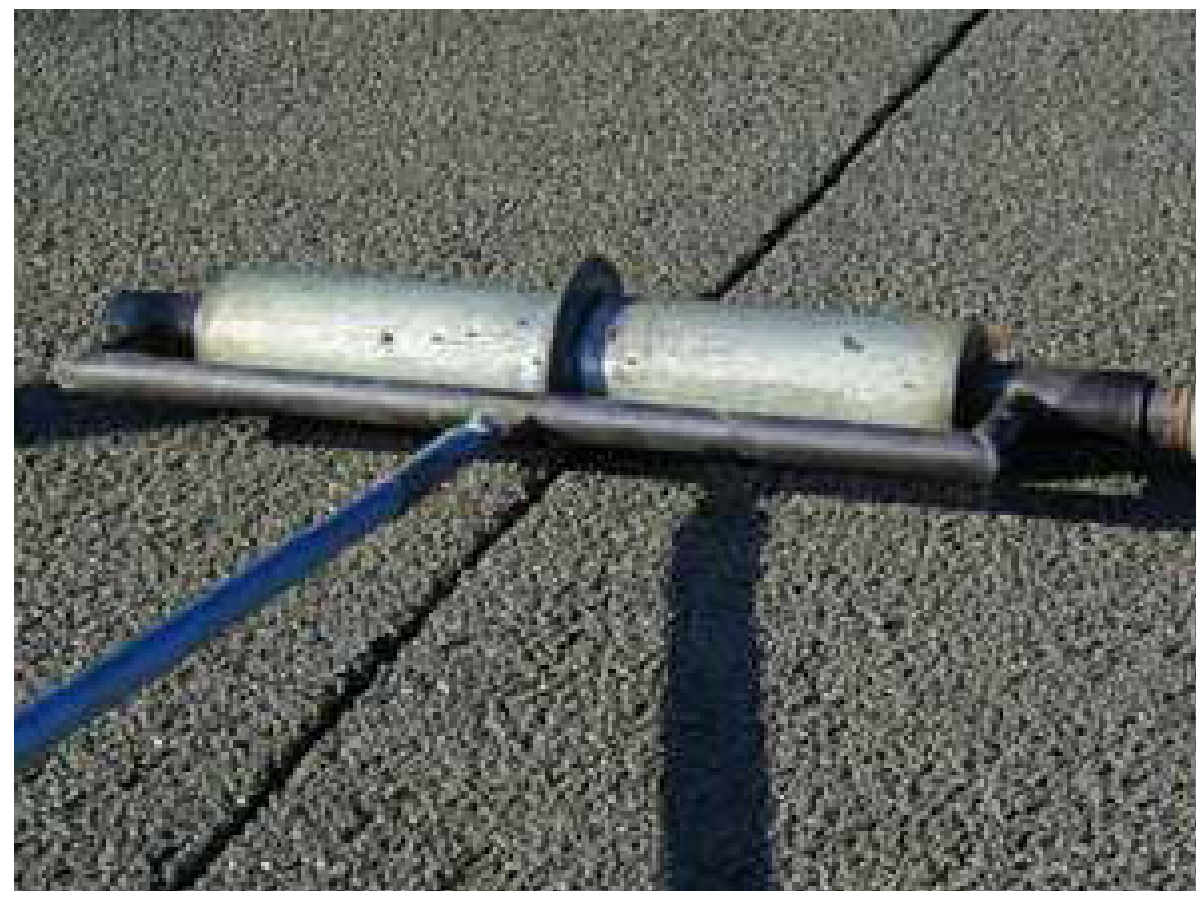

Figura 1.21: Rolo utilizado para fazer as juntas no concreto permeável (Fonte: Youngs, 2005.) 


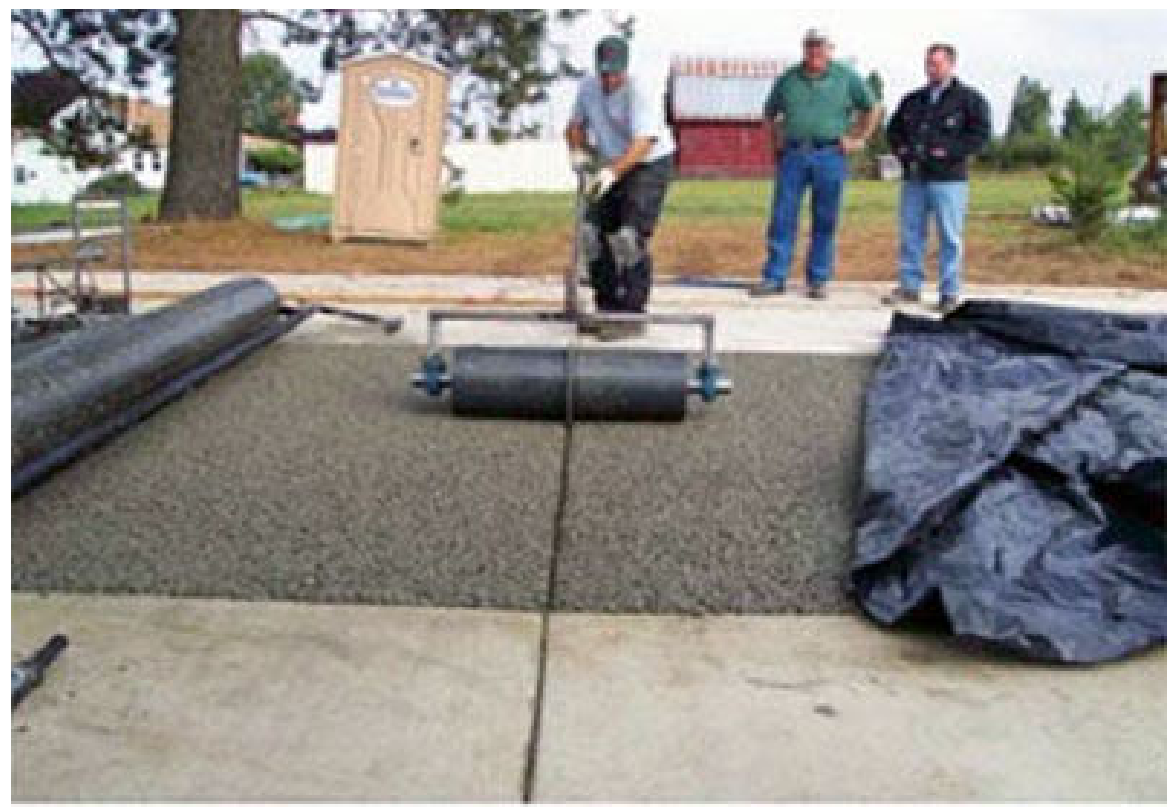

Figura 1.22: Rolo utilizado para fazer as juntas no concreto permeável (Fonte: www.perviouspavement.org)

Com relação à cura, o concreto permeável deve ser tratado com composto para cura (criador de película superficial antievaporação) e em seguida coberto com uma lona plástica, como apresentado na Figura 1.23. Este procedimento tem por finalidade prevenir a secagem muito rápida do material.

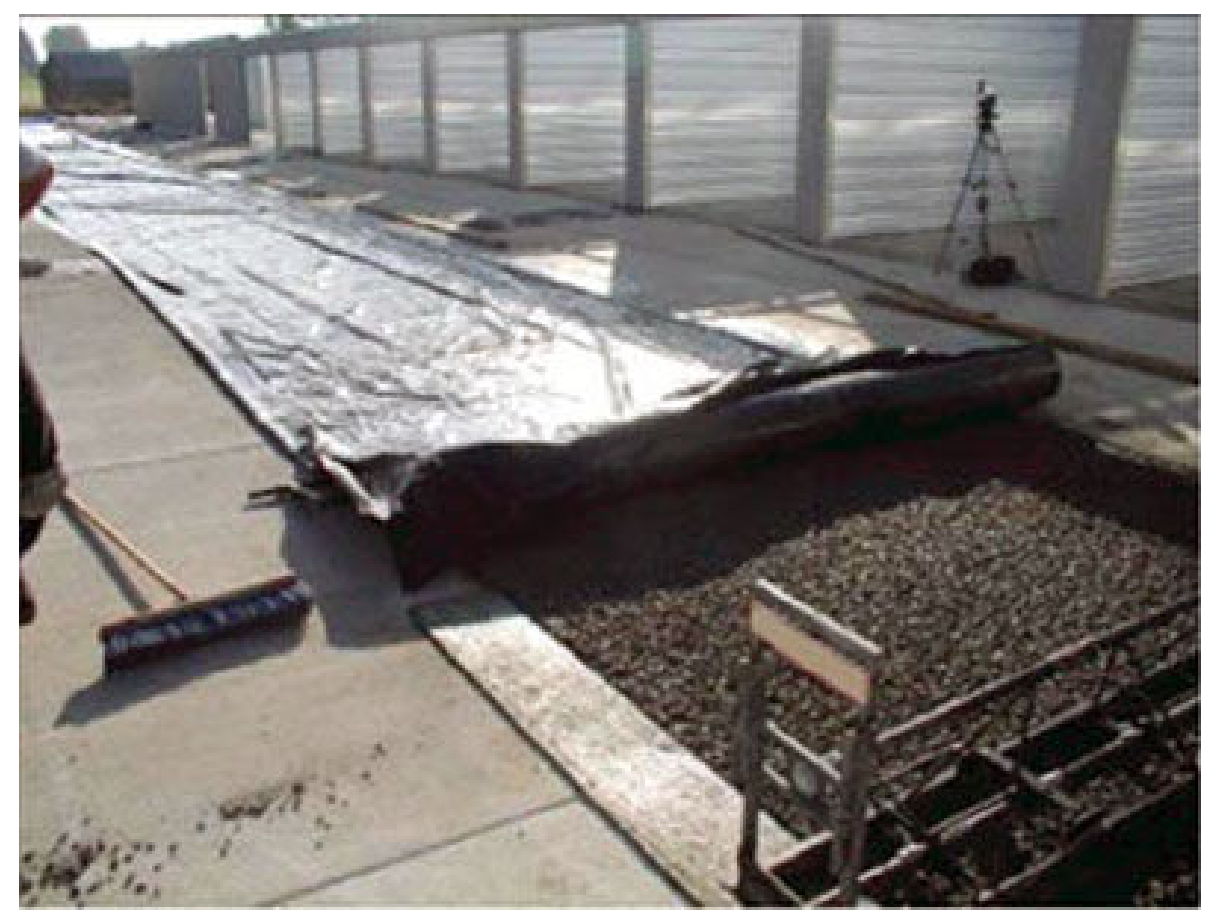

Figura 1.23: Lona plástica utilizada para proteção do concreto permeável contra a perda precoce de água

(Fonte: www.perviouspavement.org, 2011.) 
A lona plástica de cobertura do pavimento deve ser mantida em uso até que o pavimento seja aberto para operação, o que possivelmente poderá ocorrer sete dias após a sua execução (TENNIS et al., 2004).

\subsubsection{Dimensionamento e Projeto Estrutural}

São dois os fatores determinantes para projetar a espessura de pavimentos permeáveis: as propriedades hidráulicas, tais como permeabilidade e volume de vazios; e as propriedades mecânicas, como resistência e módulo de elasticidade. Quando utilizados como revestimento de sistemas de pavimentos, devem ser projetados para suportar os carregamentos do tráfego e contribuir positivamente como estratégia de controle de escoamento superficial proveniente de intempéries.

$\mathrm{Na}$ fase de projeto devem ser selecionados os materiais adequados e as espessuras apropriadas do pavimento, atendendo simultaneamente aos requisitos hidrológicos e de resistência mecânica. Análises em separado são necessárias considerando tanto o âmbito hidráulico quanto o de resistência, sendo que a maior espessura determinada entre estas duas situações será a escolhida como espessura final de projeto.

Com relação ao solo do subleito, algumas precauções devem ser tomadas na ocorrência de solos argilosos e expansivos. Assim, algumas disposições especiais são consideradas no projeto de pavimentos permeáveis quando contemplam-se subleitos com quantidades significativas de solos expansíveis ou compressíveis.

A base utilizada sob o revestimento permeável deve ser granular com diâmetro máximo de agregado na ordem de $25 \mathrm{~mm}$ ou subsolo natural quando há predominância de solos arenosos.

O tráfego atuante no pavimento pode ser caracterizado por um eixo padrão de rodas duplas e pela média diária do tráfego. Uma vez que as cargas dos caminhões são mais significativas que as cargas dos automóveis utilitários, a estimativa de caminhões no pavimento permeável é crítica para se obter um pavimento durável. Para o caso onde o pavimento for instalado em local de tráfego de veículos leves 
(estacionamento de Shopping Centers, por exemplo), podem-se tomar as cargas críticas a serem consideradas àquelas de automóveis e utilitários. 


\section{METODOLOGIA DA PESQUISA EM LABORATÓRIO}

Para os estudos de caracterização mecânica e hidráulica de concretos permeáveis foram preparadas amostras prismáticas e cilíndricas. As moldagens foram realizadas no laboratório da empresa Holcim Brasil S.A., em São Paulo, que disponibilizou suas instalações, materiais e mão de obra auxiliar para a confecção dos corpos de prova utilizados nesta pesquisa.

As medidas sobre os corpos de prova curados bem como a determinação do índice de vazios e do módulo de elasticidade dinâmico (ultrassônico), foram realizadas no Laboratório de Materiais de Construção Civil do Departamento de Engenharia de Construção Civil (PCC) da Escola Politécnica da Universidade de São Paulo (EPUSP).

Os ensaios de resistência, módulo de elasticidade estático e permeabilidade foram realizados no Laboratório de Mecânica dos Pavimentos (LMP) do Departamento de Engenharia de Transportes (PTR) da EPUSP.

\subsection{CARACTERIZAÇÃO DOS MATERIAIS E DOSAGEM}

\subsubsection{Agregados Graúdos}

Foram estudadas três diferentes misturas com variação do diâmetro máximo dos agregados graúdos. Para tanto, foram utilizados agregados graníticos provenientes da Jazida Cantareira, com diâmetro variando de 4,8 mm a 12,5 mm.

Na Figura 2.1 é apresentada a distribuição granulométrica e na Tabela 2.1 são apresentadas as demais características principais da brita comercial empregada (brita 0). Este agregado foi inicialmente peneirado e separado em frações relativas ao seu diâmetro para posterior composição das misturas. 


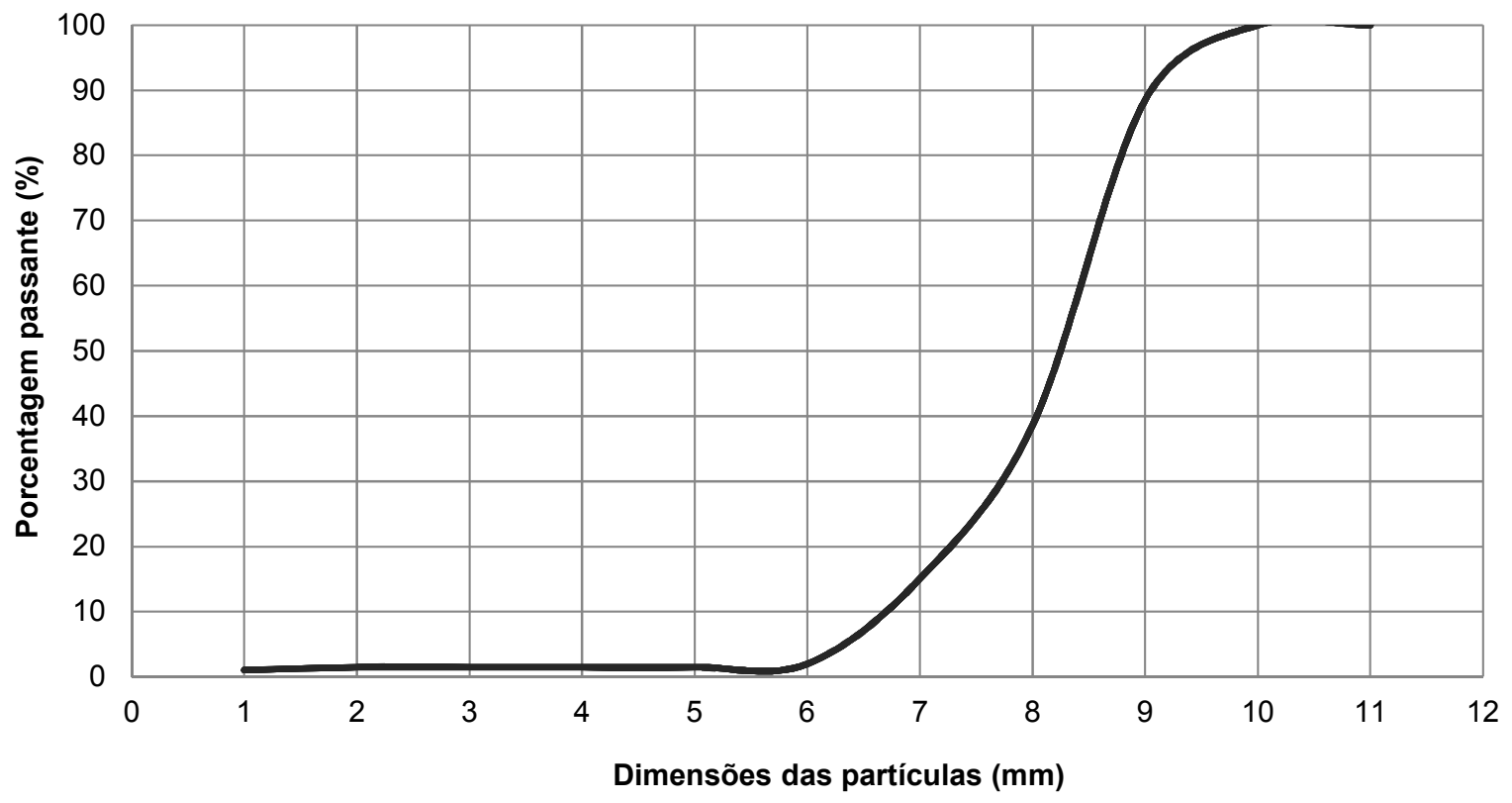

Figura 2.1: Curva granulométrica da brita 0

(Gentileza: Holcim Brasil)

Tabela 2.1: Características do agregado utilizado nas moldagens dos corpos de prova (Gentileza: Holcim Brasil S.A.)

\begin{tabular}{ccc}
\hline \hline Característica & Unid. & Valor \\
\hline \hline Módulo de finura & - & 5,88 \\
\hline Diâmetro máximo & $\mathrm{mm}$ & 12,5 \\
\hline Massa específica & $\mathrm{kg} / \mathrm{m}^{3}$ & 2.720 \\
\hline Massa Unitária Seca & $\mathrm{kg} / \mathrm{m}^{3}$ & 1.580 \\
\hline Material Pulverulento & $\%$ & 1,04 \\
\hline \hline
\end{tabular}

Em função da quantidade de material pulverulento ser muito reduzida, não foi realizada lavagem prévia dos agregados empregados nesta pesquisa.

\subsubsection{Cimento}

O cimento empregado foi O CP III 40 RS produzido pela Holcim Brasil S.A. e proveniente da fábrica de Barroso, Minas Gerais. É um ligante hidráulico produzido com moagem de clínquer Portland e adição de escória granulada de alto forno, atendendo às normas brasileiras NBR 5735 (ABNT, 1991) e NBR 5737 (ABNT, 1992). 
Este tipo de cimento é conveniente para a produção de concretos permeáveis, pois apresenta elevada resistência a sulfatos, característica importante para concretos com alto índice de vazios, a serem empregados em pavimentação a céu aberto de grandes superfícies. Na Tabela 2.2 são apresentadas as principais características do cimento utilizado nesta pesquisa.

Tabela 2.2: Características do cimento utilizado nas moldagens dos corpos de prova

\begin{tabular}{ccc}
\hline \hline Característica & Unid. & Valor \\
\hline Percentual passante na \# 325 & $\%$ & 1,9 \\
\hline Percentual passante na \# 400 & $\%$ & 4,6 \\
\hline Superfície específica - Blaine (NM 76/98) & $\mathrm{cm}^{2} / \mathrm{g}$ & 4.141 \\
\hline Relação a/c - pasta de consistência normal (NM & - & 0,312 \\
43/03) & min & $195-257$ \\
\hline Tempo de pega (NBR NM 65/03) & 9,8 (1 dia) \\
\hline Resistência à compressão & MPa & 26,0 (3 dias) \\
\hline Resíduo insolúvel (NBR NM 15/04) & & 38,9 (7 dias) \\
\hline Perda ao fogo - 1.000C (NBR NM 18/04) & $\%$ & 2,4 (28 dias) \\
\hline \hline
\end{tabular}

(Ensaios Realizados pela Holcim Brasil SA)

\subsection{DESCRIÇÃO DOS CONCRETOS PERMEÁVEIS CONCRETOS PERMEÁVEIS ESTUDADOS}

A dosagem para cada uma das misturas foi predefinida a partir da revisão da literatura, de maneira empírica, uma vez que não existe procedimento específico documentado para dosagem de concreto permeável. Durante a revisão, foi observado que alguns autores utilizam em suas misturas diferentes curvas 
granulométricas de agregados graúdos, sendo que alguns utilizam curvas granulométricas uniformes, onde existe somente um único tamanho de agregado e outros utilizam curvas contínuas, com a mistura de dois ou três diâmetros de agregados. Dessa maneira, para avaliar qual seria a variação dos parâmetros de drenabilidade e resistência mecânica em função dos diferentes diâmetros de agregado graúdo utilizados, foram estudados três traços com variação do diâmetro máximo dos agregados. As proporções de cada fração empregadas estão apresentadas na Tabela 2.3 .

Tabela 2.3: Proporções de agregados utilizados nas moldagens

\begin{tabular}{cccc}
\hline \hline \multirow{2}{*}{ Misturas } & \multicolumn{3}{c}{ \% Material retido } \\
\cline { 2 - 4 } & $\mathbf{1 2 , 5}$ a 9,5 $\mathbf{~ m m}$ & $\mathbf{9 , 5}$ a 6,3 $\mathbf{~ m m}$ & $\mathbf{6 , 3}$ a 4,8 $\mathbf{~ m m}$ \\
\hline \hline M1 & 0 & 100 & 0 \\
\hline M2 & 0 & 50 & 50 \\
\hline M3 & 30 & 40 & 30 \\
\hline \hline
\end{tabular}

O consumo de cimento e agregado utilizados foram $374 \mathrm{~kg} / \mathrm{m}^{3}$ e $1.660 \mathrm{~kg} / \mathrm{m}^{3}$, respectivamente, representando uma proporção cimento/agregado de 1:4,44. A relação água foi mantida em 0,3 .

Estes valores foram empregados segundo o trabalho de McCain e Dewoolkar (2009), que obtiveram valores de resistência à compressão na ordem de 10 MPa e condutividade hidráulica de $0,5 \mathrm{~cm} / \mathrm{s}$ para as misturas sem adição de agregados miúdos, como é o caso do presente trabalho. Os consumos de materiais e a relação a/c foram mantidos constantes para as três misturas estudadas.

Na Tabela 2.4 é apresentado o resumo das composições empregadas. 
Tabela 2.4: Composições utilizadas

\begin{tabular}{ccc}
\hline \hline Materiais & Unidades & Valores \\
\hline Consumo de cimento & $\left(\mathrm{kg} / \mathrm{m}^{3}\right)$ & 374 \\
\hline Consumo de agregado & $\left(\mathrm{kg} / \mathrm{m}^{3}\right)$ & 1.660 \\
\hline Relação a/c em massa & & 0,3 \\
\hline Relação cimento/agregado em massa & & $1: 4,44$ \\
\hline
\end{tabular}

\subsection{MOLDAGENS DOS CORPOS DE PROVA}

Inicialmente foi realizado o peneiramento do agregado para separação de suas frações nas quantidades necessárias para as moldagens. O material utilizado foi a brita 0 comercial, para a qual, a partir do estudo de sua curva granulométrica, verificou-se a existência de grande porcentagem das frações necessárias para as moldagens. Para tanto, foi utilizado um peneirador elétrico contendo as peneiras correspondentes às seguintes aberturas: $12,5 \mathrm{~mm}, 9,5 \mathrm{~mm}, 6,3 \mathrm{~mm}$ e 4,8 mm. Após a separação dos materiais foi iniciado o procedimento de moldagem dos corpos de prova. Nas Figuras 2.2 e 2.3 são apresentadas a peneira utilizada e a diferenciação visual das dimensões dos materiais separados.

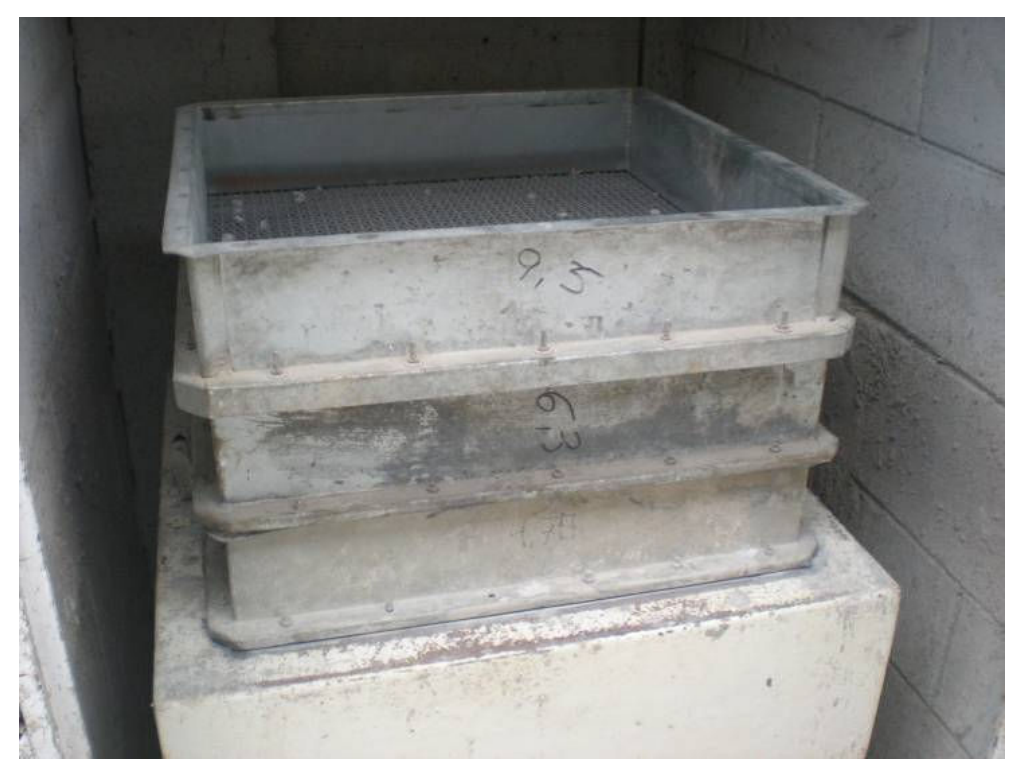

Figura 2.2: Peneiras utilizadas para separação das frações dos agregados 


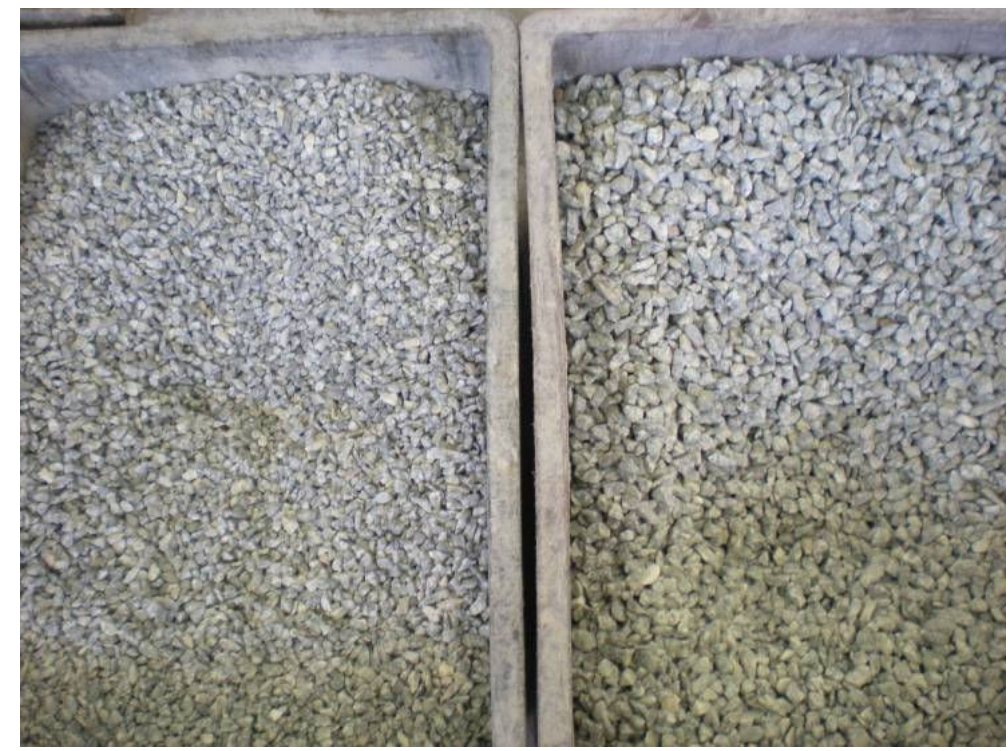

Figura 2.3: Diferenciação entre os diâmetros dos agregados (Esquerda - 4,75 mm; Direita $6,3 \mathrm{~mm})$

Schaefer et al. (2006) estudaram diferentes processos de mistura para confecção de corpos de prova de concreto permeável em laboratório. Os autores concluíram que a ordem de mistura dos componentes altera as características do produto final e estabeleceram então um procedimento pelo qual foi obtido um material com melhores propriedades mecânicas e hidráulicas. Este procedimento foi o mesmo utilizado na presente pesquisa e está apresentado a seguir:

a) Adicionar todo o agregado na betoneira com mais $5 \%$ do peso total do cimento;

b) Misturar por 1 minuto;

c) Adicionar o restante dos materiais;

d) Misturar por 3 minutos;

e) Deixar a mistura em repouso por 3 minutos;

f) Misturar por mais 2 minutos.

Na Figura 2.4 é apresentado o procedimento de mistura dos materiais. O controle das misturas de concreto foi realizado por meio da massa específica aparente no estado fresco e pela visualização do aspecto do material após término do tempo de mistura. Na Figura 2.5 é apresentado o procedimento para o controle da massa específica no estado fresco. 


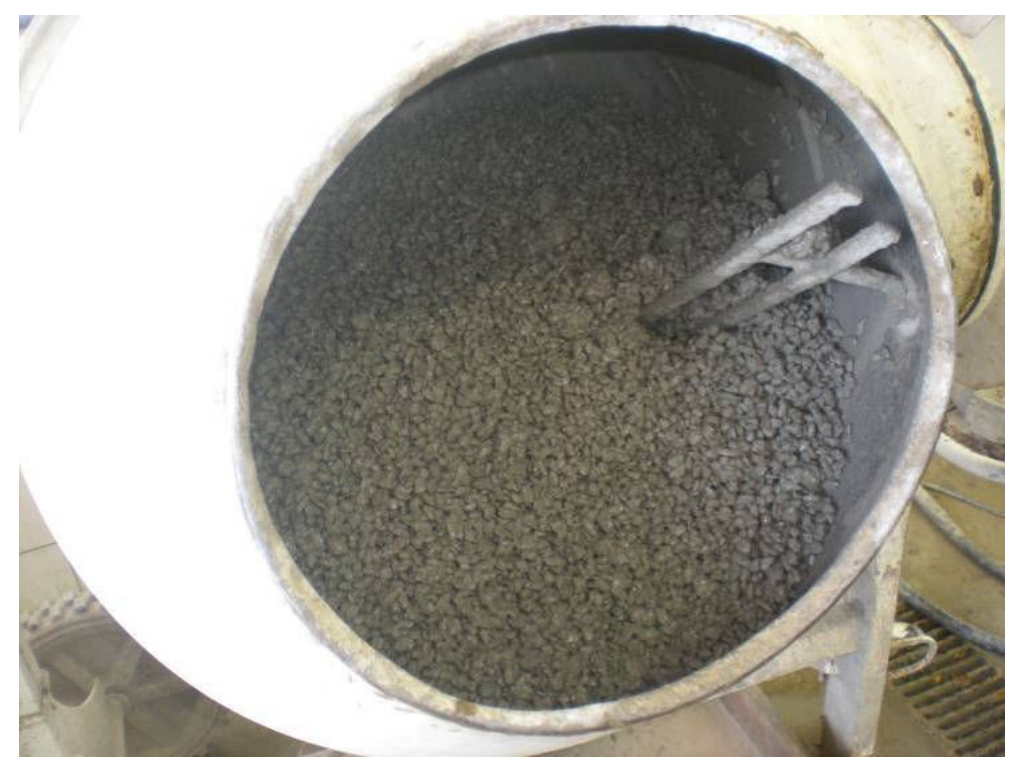

Figura 2.4: Mistura dos componentes do concreto permeável

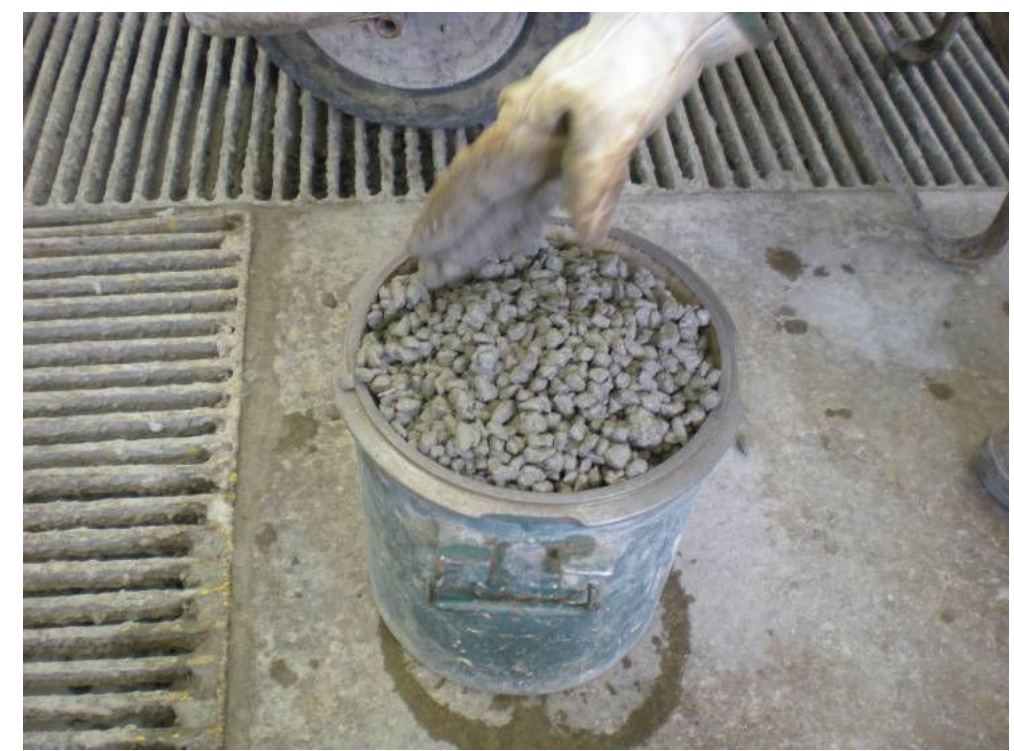

Figura 2.5: Determinação da massa específica aparente no estado fresco

$\mathrm{Na}$ literatura revisada, foi observado que a faixa de variação de massa específica aparente no estado fresco para os concretos já estudados é muito grande, sendo que os valores comumente variam de $1.300 \mathrm{~kg} / \mathrm{m}^{3}$, para misturas com maior índice de vazios, a $2.000 \mathrm{~kg} / \mathrm{m}^{3}$, para misturas com índice de vazios reduzido. 
$\mathrm{Na}$ Tabela 2.5 são apresentadas as massas específicas aparentes no estado fresco determinadas durante o processo de moldagem dos corpos de prova. Observa-se que os resultados se encontram dentro da faixa de valores anteriormente mencionada, se aproximando mais daqueles associados aos concretos permeáveis com elevado índice de vazios. Vale ressaltar que, devido à dificuldade de arrasamento do topo das amostras (devido ao tipo de concreto), podem ter ocorrido pequenas discrepâncias nos resultados.

Tabela 2.5: Massas específicas aparentes no estado fresco obtidas durante o procedimento de controle das misturas

\begin{tabular}{cc}
\hline \hline Mistura & $\begin{array}{c}\text { Massa Específica Aparente no } \\
\text { Estado Fresco }\left(\mathbf{k g} / \mathbf{m}^{3}\right)\end{array}$ \\
\hline M1 & 1.459 \\
\hline M2 & 1.421 \\
\hline M3 & 1.561 \\
\hline
\end{tabular}

Além da determinação da massa específica aparente, foi realizada uma análise visual da mistura pronta, que é um dos métodos utilizados na prática para controle da produção do concreto permeável, na qual se observa, após o término do tempo de mistura, se as partículas estão inteiramente cobertas de argamassa e se a mistura apresenta um aspecto brilhoso.

Além desta verificação, foi realizado um teste táctil visual, também indicado pela literatura, que consiste em apertar uma porção da mistura com a mão e verificar se há a formação de uma pequena aglomeração de partículas. Na Figura 2.6 é apresentada a realização do teste táctil visual. 


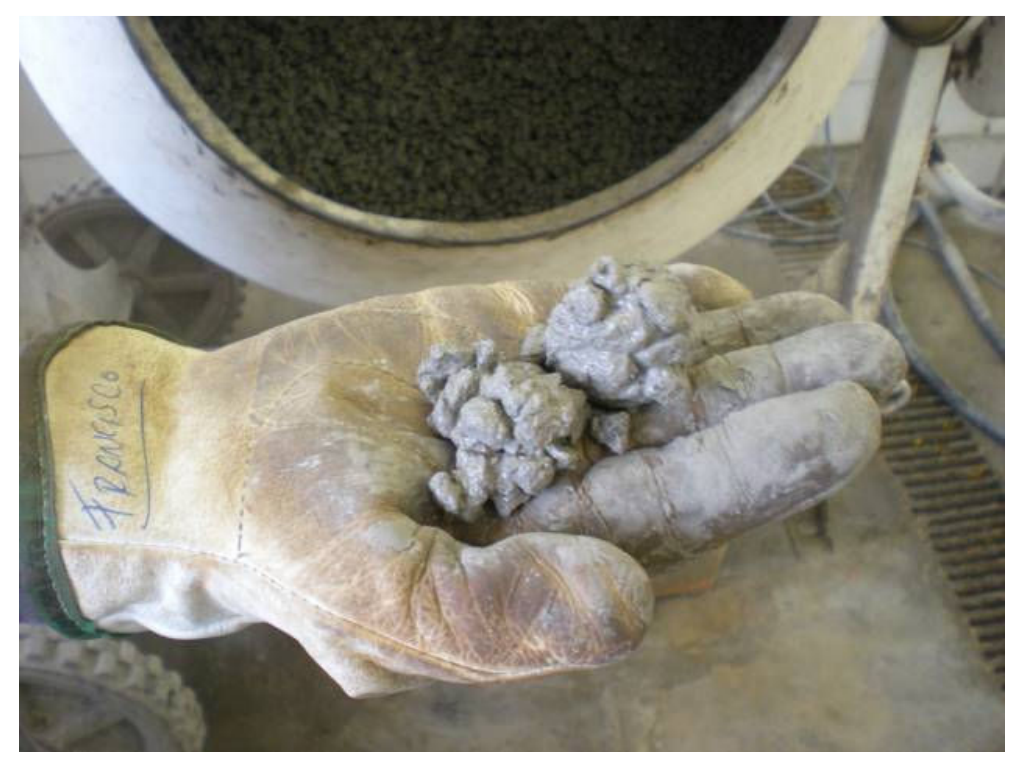

Figura 2.6: Teste visual para controle da mistura

Suleiman et. al. (2006) estudaram a influência da energia de compactação nas propriedades do concreto permeável e verificaram que moldagens utilizando 15 golpes de bastão metálico em cada uma das três camadas do corpo de prova cilíndrico, com posterior vibração, têm suas condições de resistência mecânica após a cura melhoradas, sem prejuízo à sua condutividade hidráulica.

Dessa maneira, o procedimento de compactação consistiu, para os corpos de prova cilíndricos, em 45 golpes por amostra, divididos em três camadas iguais, com posterior vibração do corpo de prova por 10 segundos em mesa vibratória. Já as amostras prismáticas foram compactadas em duas camadas iguais, com 25 golpes de bastão por camada, repetindo, em seguida, o mesmo tempo de vibração utilizado para os corpos de prova cilíndricos.

O tempo de vibração deve ser reduzido para evitar a segregação da pasta, fenômeno passível de ocorrência devido ao baixo teor de aglomerante característico desse tipo de mistura. $O$ excesso de vibração tende a fechar os vazios da porção superior dos corpos de prova, diminuindo a sua capacidade drenante. As Figuras 2.7 e 2.8 retratam o procedimento de compactação das amostras. 


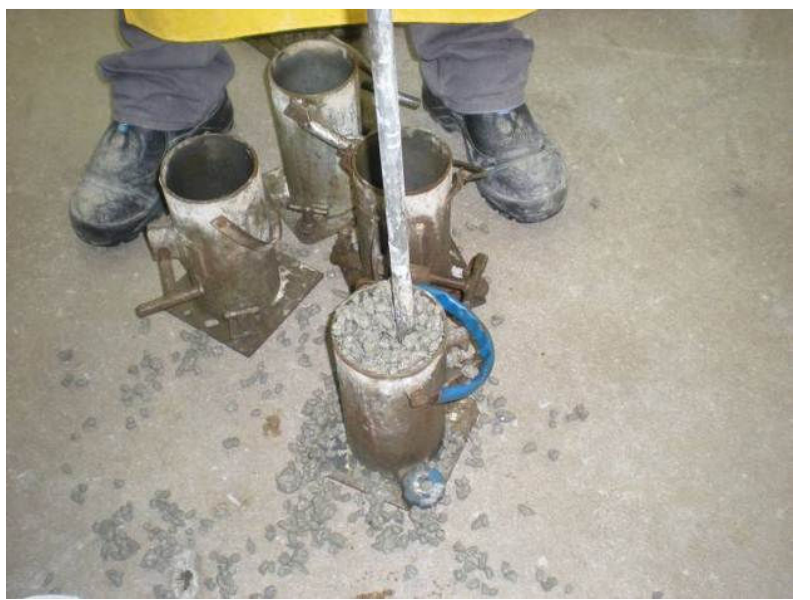

Figura 2.7: Procedimento de compactação de corpos de prova cilíndricos

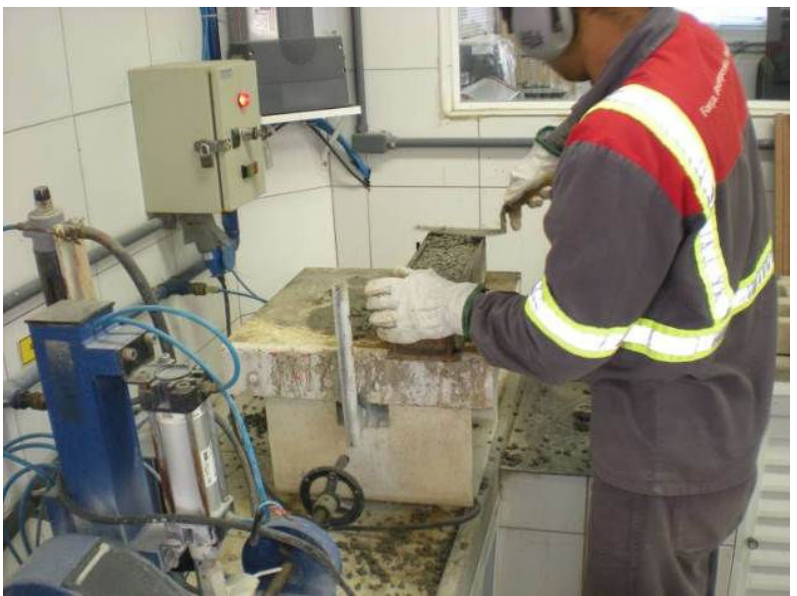

Figura 2.8: Procedimento de vibração dos corpos de prova prismáticos

Em seguida os corpos de prova foram numerados e colocados em câmera úmida com umidade constante de $98 \%$ seguindo as instruções para cura da NBR 5738 (ABNT, 1994). Nas Figuras 2.9 e 2.10 são apresentadas as amostras moldadas e posicionadas na câmara úmida. Na Figura 2.11 é apresentado um detalhe da estrutura aberta dos corpos de prova moldados na mistura M1.

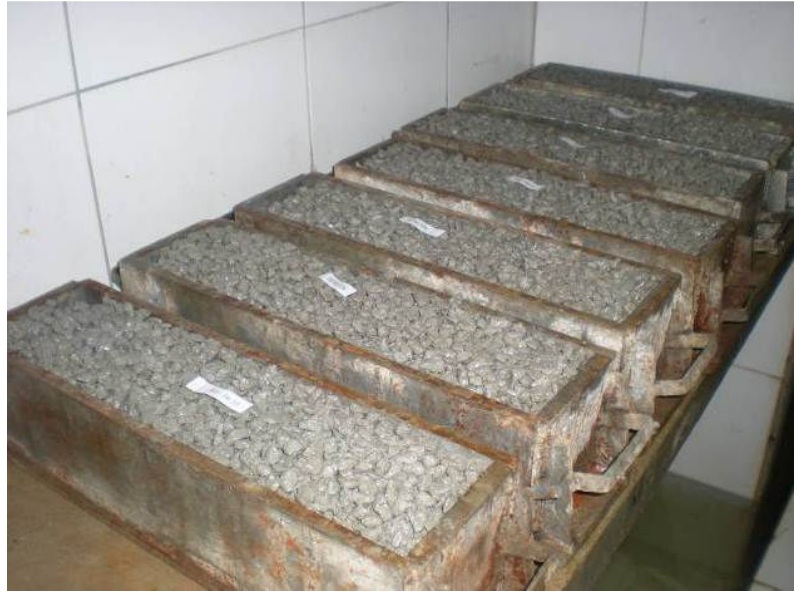

Figura 2.9: Corpos de prova prismáticos na câmara úmida

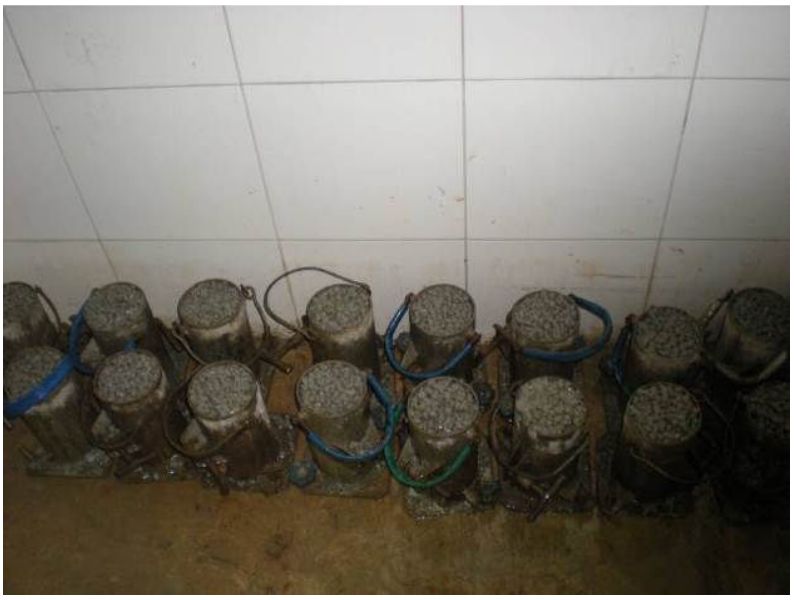

Figura 2.10: Corpos de prova cilíndricos na câmara úmida

Os corpos de prova foram mantidos nos moldes em câmara úmida pelo período de 7 dias uma vez que, diferentemente do concreto convencional, as amostras de concreto permeável não apresentaram estrutura suficientemente estável para serem desmoldadas após 24 horas, conforme preconiza a norma. Nas Figuras 2.12 e 2.13 pode ser observada a aparência peculiar dos corpos de prova de concreto permeável. 


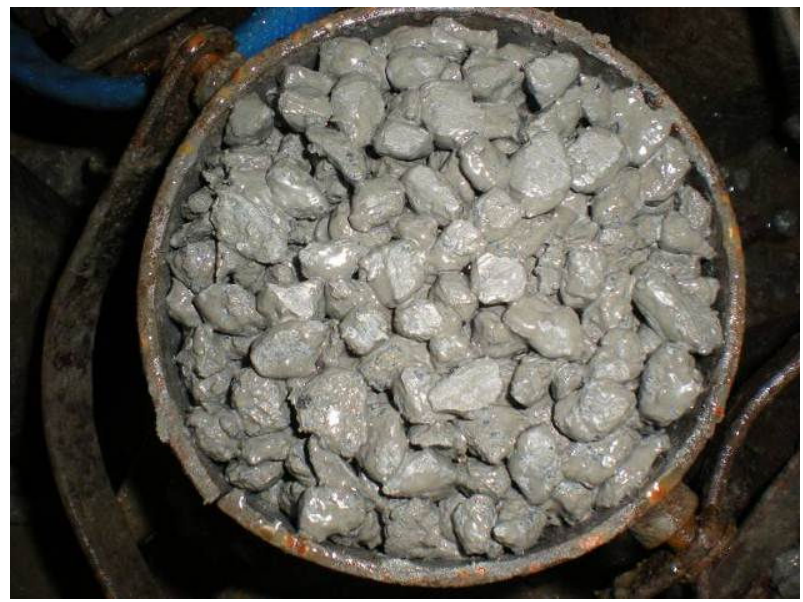

Figura 2.11: Detalhe da estrutura aberta do concreto permeável no estado fresco

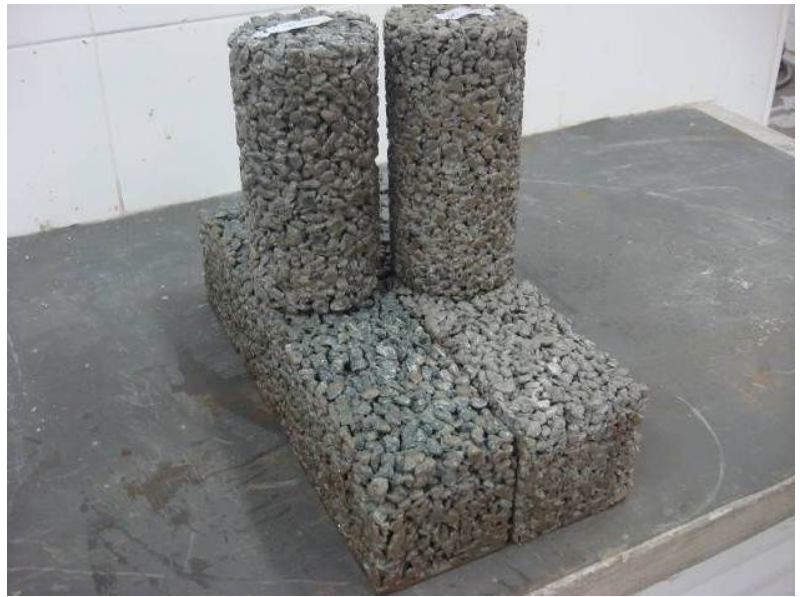

Figura 2.12: Corpos de prova desmoldados

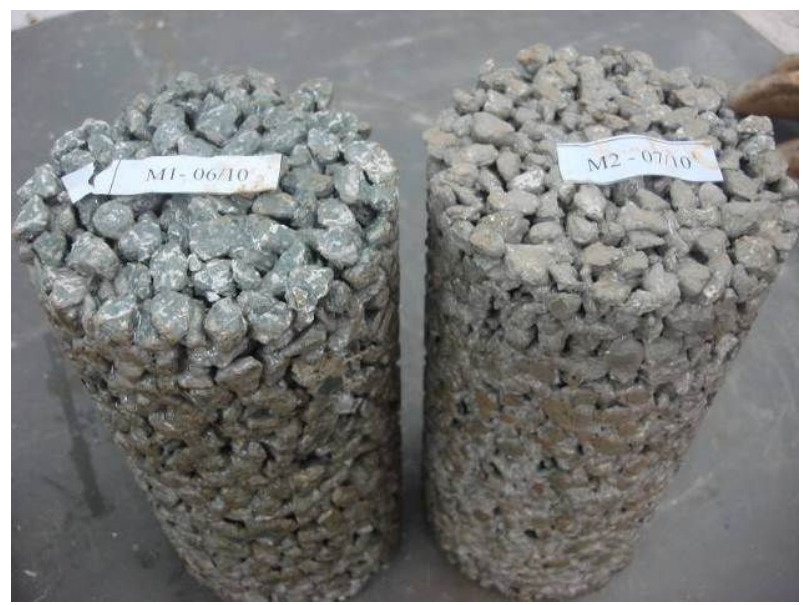

Figura 2.13: Diferença entre os corpos de prova cilíndricos moldados para a mistura M1 (esquerda) e M2 (direita) 


\subsection{DIMENSÕES E QUANTIDADE DOS CORPOS DE PROVA MOLDADOS}

A NBR 7583 (ABNT, 1986) determina que os corpos de prova prismáticos de concreto a serem utilizados no controle tecnológico para pavimentação através de ensaios de tração na flexão devem ter dimensões $150 \times 150 \times 500 \mathrm{~mm}$. Todavia, a adoção de amostras com estas dimensões implica no uso de elevadas quantidades de materiais, bem como na dificuldade de manuseio dos mesmos devido ao seu elevado peso (aproximadamente $27 \mathrm{~kg}$ após desmoldados) (CERVO, 2004).

Dessa maneira, foram utilizadas amostras com dimensões de $100 \times 100 \times 400 \mathrm{~mm}$, a partir da qual é gerada economia de cerca de $64 \%$ de materiais. $O$ valor da carga requerida para a ruptura do corpo de prova fica reduzido de 34 a $39 \%$ do valor da carga normalmente requerido para o corpo de prova convencional, considerando-se que as tensões de ruptura são estatisticamente equivalentes para os dois casos como demonstrou Cervo (2004). Para as amostras cilíndricas, foram utilizadas as dimensões padrão de 100 mm de diâmetro por 200 mm de altura.

Previamente à execução dos ensaios, foram realizadas três medições de diâmetro e altura, no caso dos corpos de prova cilíndricos, bem como de comprimento e de faces transversais no caso das amostras prismáticas, para determinação dos valores médios dessas dimensões (Figura 2.14). Vale a pena ressaltar que, em função das irregularidades existentes nos corpos de prova devido ao seu elevado índice de vazios, os resultados das medições podem ter sofrido alguma dispersão, ainda que pequena. 


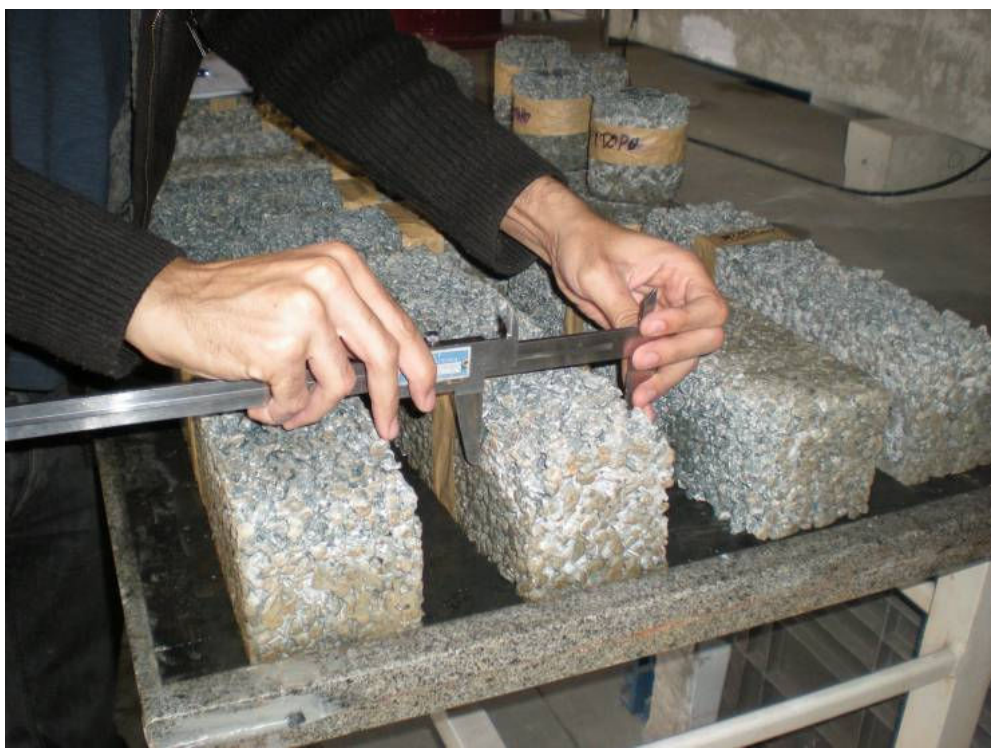

Figura 2.14: Procedimento de medição das amostras

Foi moldado um total de 45 corpos de prova cilíndricos, sendo 15 para cada mistura. No caso das amostras prismáticas foram moldados um total de 27, sendo 9 para cada mistura. Dos quinze corpos de prova cilíndricos três foram cortados ao meio para realização dos ensaios de permeabilidade e avaliar a variação da permeabilidade no topo e no fundo de cada amostra. Na Tabela 2.6 é apresentada a quantidade de corpos de prova que foram ensaiados na etapa laboratorial desta pesquisa.

Tabela 2.6: Quantidade de corpos de prova ensaiados

\begin{tabular}{lccc}
\hline \multirow{2}{*}{\multicolumn{1}{c}{ Ensaio }} & \multicolumn{3}{c}{ Misturas } \\
\cline { 2 - 4 } & M1 & M2 & M3 \\
\hline Tração na flexão & 9 & 9 & 9 \\
\hline Tração Indireta & 9 & 9 & 9 \\
\hline Compressão Uniaxial & 3 & 3 & 3 \\
\hline Módulo de Elasticidade Estático & $9^{*}$ & $9^{*}$ & $9^{*}$ \\
\hline Módulo de Elasticidade Dinâmico & $12^{*}$ & $12^{*}$ & $12^{*}$ \\
\hline Condutividade Hidráulica & $6^{* *}$ & $6^{* *}$ & $6^{* *}$ \\
\hline Índice de Vazios & $21^{*}$ & $21^{*}$ & $21^{*}$ \\
\hline Massa Específica Aparente Seca & $21^{*}$ & $21^{*}$ & $21^{*}$ \\
\hline \hline
\end{tabular}

$\left.{ }^{* *}\right)$ Três amostras cilíndricas que foram cortadas ao meio se tornando seis corpos de prova 


\subsection{ENSAIOS DE RESISTÊNCIA ESTÁTICA}

Foram realizados ensaios de resistência à tração na flexão, resistência à tração indireta por compressão diametral e resistência à compressão uniaxial. Todos os ensaios foram realizados seguindo-se as recomendações das normas brasileiras (NBR).

\subsubsection{Tração na Flexão}

O ensaio de resistência à tração na flexão pautou-se pela norma NBR 12142/MB 3483 (ABNT, 1991) que descreve o ensaio de dois cutelos em corpo de prova prismático. Tal ensaio se mostra de maior preferência quando comparado com o ensaio de 1 cutelo, em função de que neste último já existe uma predefinição da seção de ruptura do corpo de prova. Já no caso do ensaio de dois cutelos existe a possibilidade do corpo de prova romper em diferentes posições no espaço entre os cutelos, revelando assim a seção mais frágil do corpo de prova. Os ensaios foram realizados no Laboratório de Mecânica de Pavimentos (LMP) da EPUSP com uma prensa eletro-hidráulica com capacidade de 100 t e divisão do mostrador de 0,01 t. Para aumentar a precisão dos ensaios foi inserida uma célula de carga acoplada na rótula superior, ligada a um amplificador e condicionador de sinais que transmite os dados para um software especializado (AQDADOS). A resistência à tração na flexão foi então calculada pela equação (4) a seguir:

$$
f_{c t, f}=\frac{F_{u} \cdot l}{b \cdot d^{2}}
$$

onde:

$f_{c t, f}$ : resistência à tração na flexão (MPa);

$F_{u}:$ carga de ruptura $(\mathrm{N})$;

$l$ : distância entre os cutelos de suporte $(360 \mathrm{~mm})$;

$b$ : largura média do corpo de prova na seção de ruptura ( $\mathrm{mm})$;

$d$ : altura média do corpo de prova na seção de ruptura ( $\mathrm{mm})$. 
Nas Figuras 2.15 e 2.16 são apresentadas as disposições das amostras no equipamento para realização do ensaio de resistência à tração na flexão.

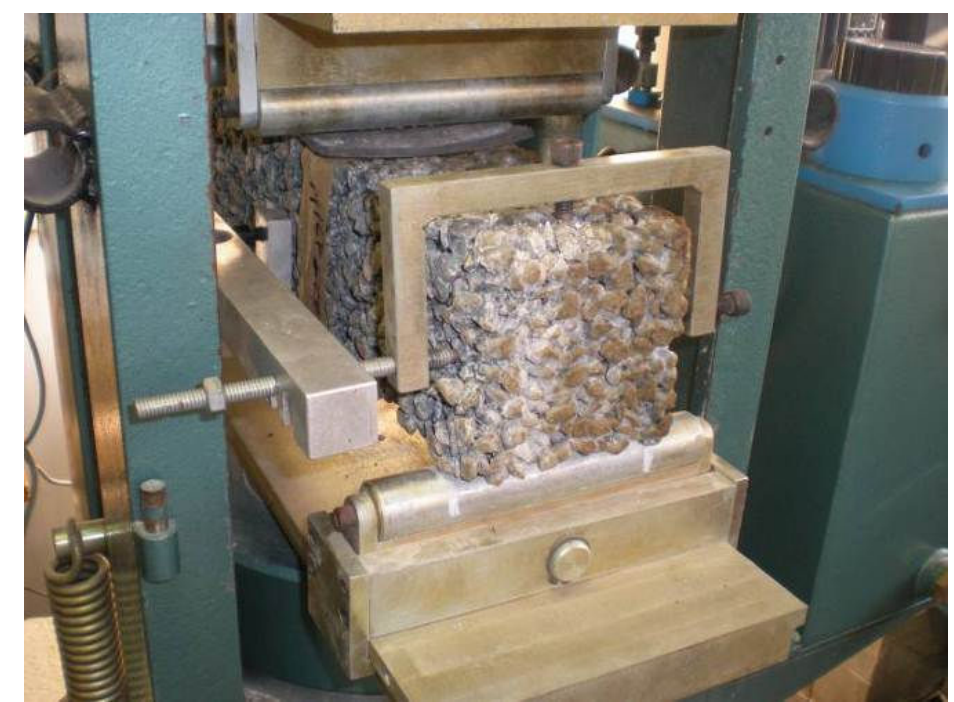

Figura 2.15: Ensaio de resistência à tração na flexão

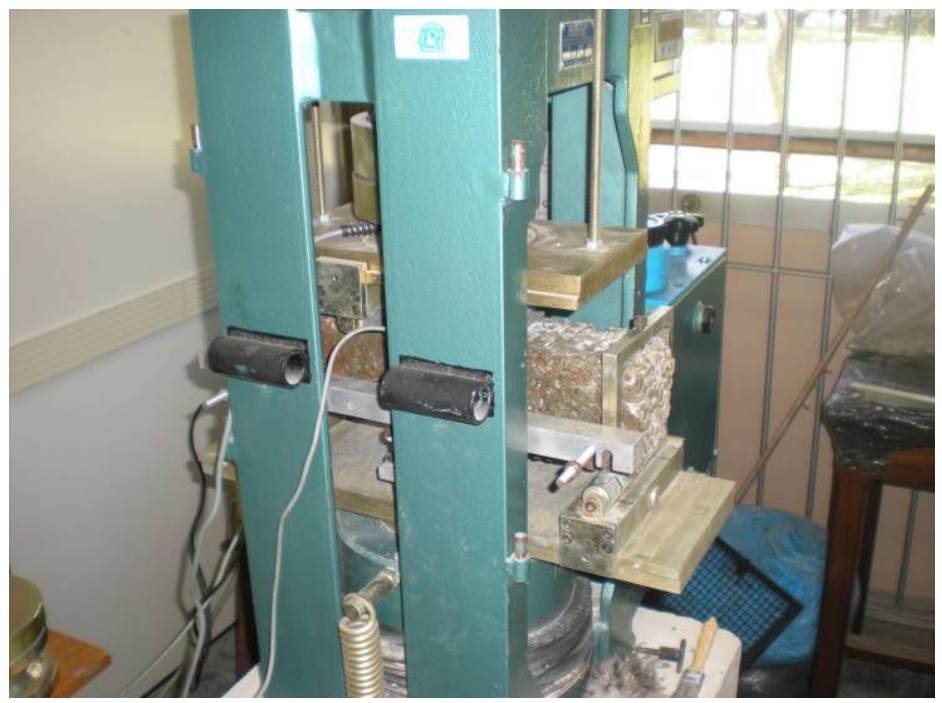

Figura 2.16: Ensaio de resistência à tração na flexão

\subsubsection{Tração Indireta por Compressão Diametral (Ensaio Brasileiro)}

O ensaio de tração indireta, ou ensaio de tração por compressão diametral, foi realizado conforme descrito na norma NBR 7222 (ABNT, 1994) no mesmo laboratório e com os mesmos equipamentos já descritos no ensaio anterior. A resistência à tração por compressão diametral foi calculada conforme equação (5) a seguir. 


$$
f_{c t, s p}=\frac{2 \cdot F_{u}}{\pi \cdot d \cdot L}
$$

onde:

$f_{c t, s p}$ : resistência à tração por compressão diametral (MPa);

$F_{u}:$ carga de ruptura $(\mathrm{N})$;

$d$ : diâmetro do corpo de prova $(\mathrm{mm})$;

$L$ : altura média do corpo de prova $(\mathrm{mm})$.

Nas Figuras 2.17 e 2.18 são apresentadas a montagem e execução do ensaio de tração por compressão diametral, bem como a linha de fissuração correspondente à ruptura do corpo de prova.

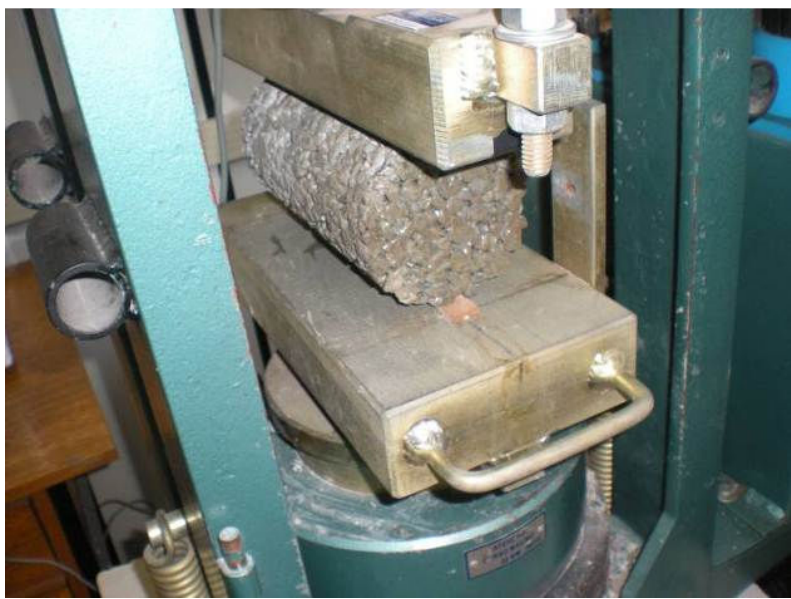

Figura 2.17: Montagem do ensaio de tração por compressão diametral

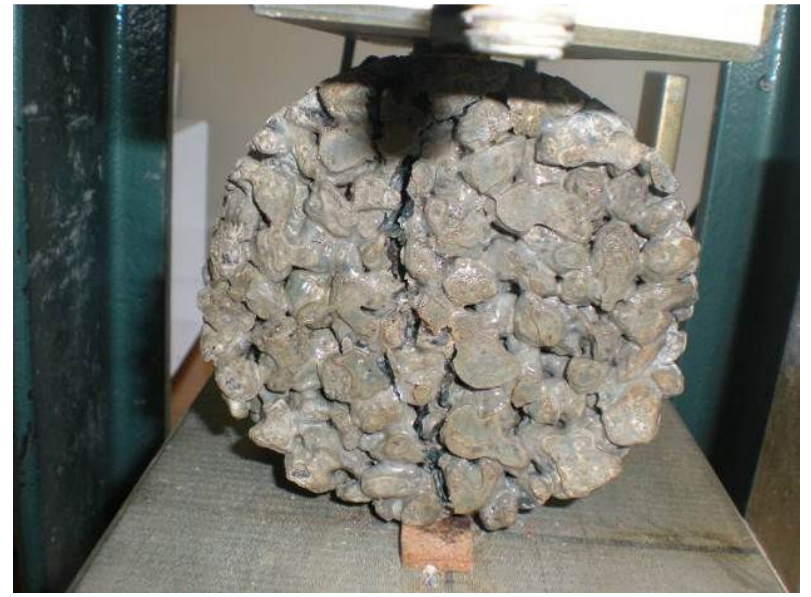

Figura 2.18: Amostra após ruptura

\subsubsection{Compressão Uniaxial}

Apesar da resistência à compressão do concreto não ser fator limitante para caracterização do material para fins de uso em pavimentação, ensaios de resistência à compressão foram realizados para se conhecer essa propriedade secundária.

Os ensaios de compressão simples foram executados conforme a norma NBR 5739 (ABNT, 1994). Os corpos de prova foram retificados no Laboratório de Materiais do PCC-EPUSP antes de serem ensaiados. A prensa utilizada foi a mesma descrita 
para os ensaios anteriores. A tensão de ruptura à compressão foi calculada pela equação (6) a seguir:

$$
f_{c}=\frac{F_{u}}{\left(\frac{\pi \cdot D^{2}}{4}\right)}
$$

onde:

$f_{c}$ : tensão de ruptura à compressão $(\mathrm{MPa})$;

$F_{u}$ : carga de ruptura $(\mathrm{N})$;

$D$ : diâmetro do corpo de prova $(\mathrm{mm})$.

Nas Figuras 2.19 e 2.20 são apresentadas a montagem da prensa para realização do ensaio de compressão uniaxial e as fissuras características observadas após a ruptura dos corpos de prova.

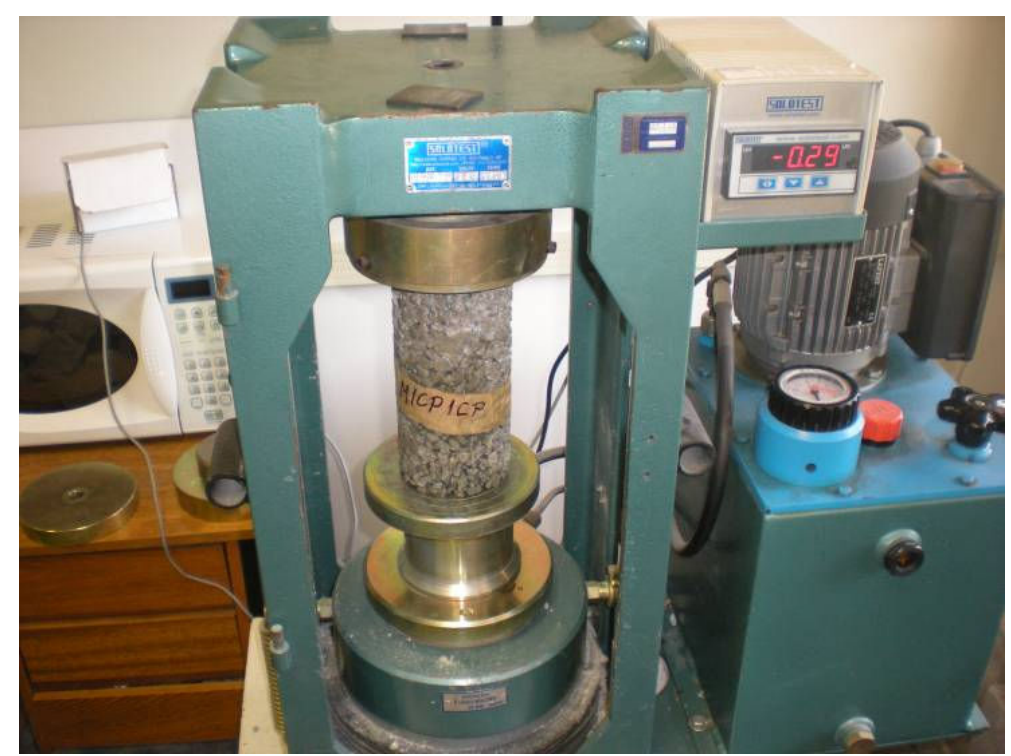

Figura 2.19: Ensaio de compressão uniaxial 


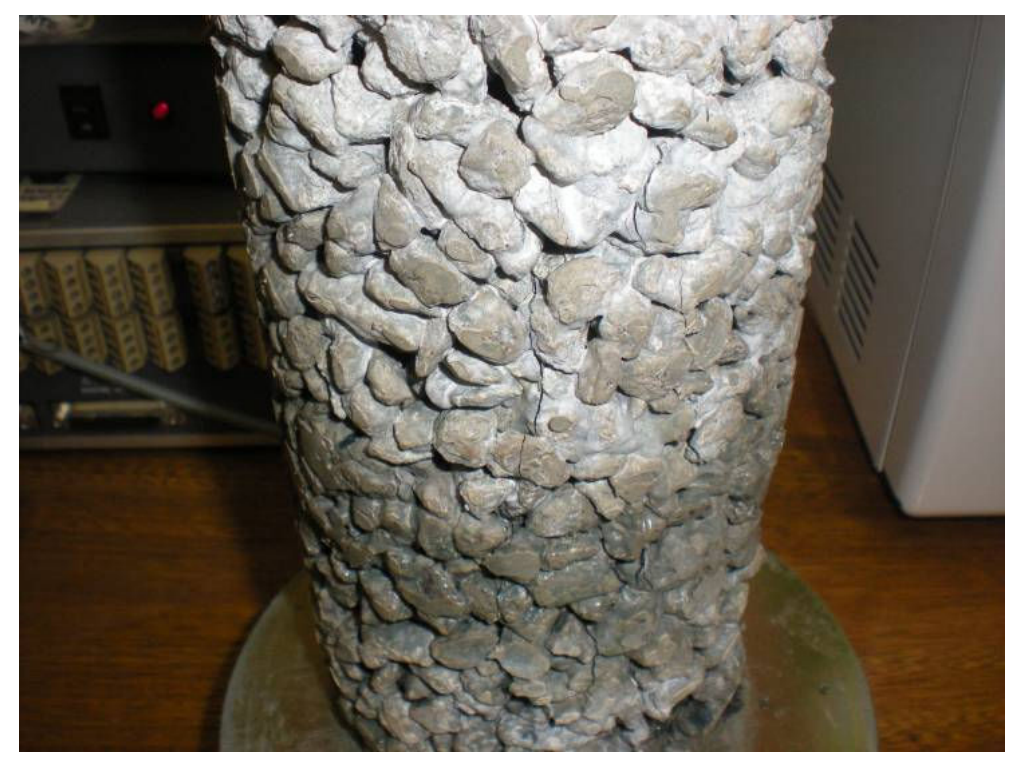

Figura 2.20: Fissuras observadas após ruptura da amostra em compressão

\subsection{MÓDULO DE ELASTICIDADE ESTÁTICO}

A determinação do módulo de elasticidade de misturas de concreto permeável ainda se encontra em fase de idealização, uma vez que a utilização de strain gages não se apresenta como uma boa solução, principalmente em função da textura peculiar do concreto permeável, que se mostra inadequada à colagem dos strain gages.

Empregou-se então, como solução para determinação do módulo de elasticidade, a medida de flecha no centro da vigota, com uso de LVDT (Linear Variable Differential Transformer). Tal técnica já foi utilizada em outros estudos, para diversos materiais, e quando comparada com as medidas obtidas por meio de strain gages mostraram resultados coerentes (TSENG, 2009).

Neste estudo foi determinado o módulo de elasticidade estático para cada mistura a partir do ensaio de tração na flexão por meio da analogia de Möhr, utilizando o valor da flecha medida por um LVDT posicionado no meio do vão. Foi adotado para o cálculo do módulo de elasticidade o valor da flecha medida no instante em que a carga aplicada corresponde a $70 \%$ da carga total de ruptura. O cálculo do módulo de 
elasticidade se deu pela analogia de Möhr que resulta na equação (7) para o caso de um corpo de prova prismático em ensaio de tração na flexão com dois cutelos:

$$
E=\frac{23 \cdot P \cdot l^{3}}{108 \cdot b \cdot h^{3} \cdot f}
$$

onde:

$E$ : módulo de elasticidade do concreto no ensaio de tração na flexão (MPa);

$P$ : carga a $70 \%$ da carga de ruptura $(\mathrm{N})$;

$l$ : dimensão do vão (mm);

$b$ : largura do corpo de prova $(\mathrm{mm})$;

$h$ : altura do corpo de prova $(\mathrm{mm})$;

$f$ : flecha no meio do vão (mm).

Na Figura 2.21 é apresentada a instrumentação do equipamento para obtenção da flecha nos corpos de prova para determinação do módulo de elasticidade estático.

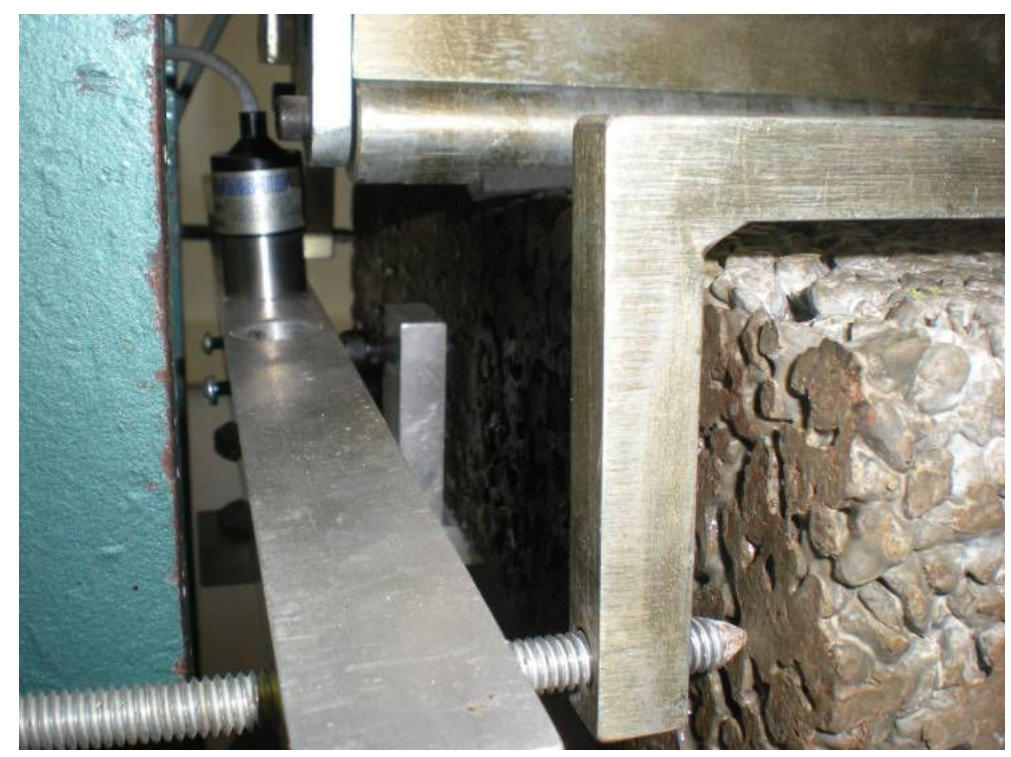

Figura 2.21: Posicionamento do LVDT para obtenção da flecha durante o ensaio de resistência a tração na flexão 


\subsection{MÓDULO DE ELASTICIDADE DINÂMICO}

O ensaio de propagação de onda ultrassônica pode ser considerado um dos ensaios não destrutivos mais úteis, obtendo certo destaque dentre os outros métodos para estimativa de vários parâmetros do concreto, tais como: módulo de elasticidade dinâmico, módulo de elasticidade estático, resistência à compressão e resistência à tração; sendo também útil na estimativa do grau de compactação de camadas e falhas nas peças de concreto.

A determinação do módulo de elasticidade ultrassônico baseia-se no conceito de que a velocidade de propagação de ondas longitudinais em um meio homogêneo e isotrópico depende das constantes elásticas do material, segundo a equação (8):

$$
V=\sqrt{\frac{E}{\gamma}}
$$

onde:

$V$ : velocidade de propagação de onda $(\mathrm{m} / \mathrm{s})$;

$E$ : módulo de elasticidade (MPa);

$\gamma:$ massa específica $\left(\mathrm{MN} / \mathrm{m}^{3}\right)$.

Para realização desta medida, foi utilizado um transdutor eletroacústico que possui um transmissor de ondas vibratórias que mede com exatidão o tempo de percurso do pulso pelo concreto. A velocidade de propagação de ondas foi então calculada segundo a equação (9) a seguir:

$$
V=\frac{L}{t}
$$

onde:

$V$ : velocidade de propagação de onda $(\mathrm{m} / \mathrm{s})$;

$L$ : distância entre os pontos de acoplamento dos centros das faces dos transdutores $(\mathrm{m})$; 
$t$ : tempo decorrido desde a emissão da onda até a sua recepção (s).

A partir da velocidade de propagação das ondas e considerando a dimensão da amostra, o cálculo do módulo de elasticidade dinâmico foi conduzido segundo a equação 10 (KOMLOS et al., 1996), a seguir:

$$
E_{d}=\gamma \cdot V^{2} \cdot \frac{(1+v) \cdot(1-2 v)}{(1-v)}
$$

onde:

$E_{d}$ : módulo de elasticidade dinâmico (MPa);

$V:$ velocidade longitudinal de propagação de onda $(\mathrm{km} / \mathrm{s})$;

$\gamma$ : massa especifica do material $\left(\mathrm{kg} / \mathrm{m}^{3}\right)$;

$v$ : coeficiente de Poisson $\rightarrow$ considerado igual a 0,22, conforme Goede (2009).

Sendo este um método não destrutivo e relativamente simples de se aplicar, todas as amostras cilíndricas passaram pela determinação do módulo de elasticidade por pulso de onda ultrassônica. As medições foram realizadas posicionando os transdutores nas faces paralelas mais distantes dos corpos de prova, respeitando as instruções da NBR 8802 (ABNT, 1994) (Figura 2.22).

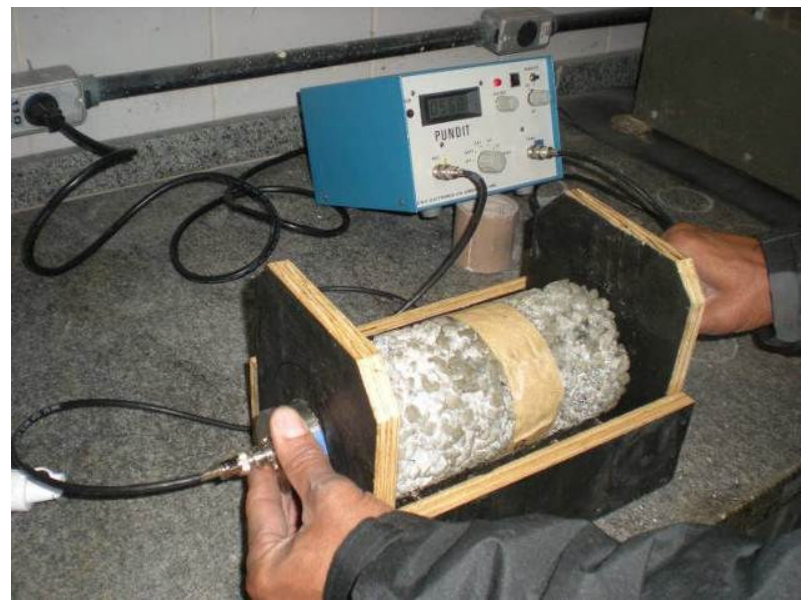

Figura 2.22: Equipamento para medida, por pulso de onda, do módulo de elasticidade dinâmico 


\subsection{ENSAIOS DE PERMEABILIDADE}

Para realização dos ensaios de permeabilidade foi empregado um permeâmetro com carga constante disponível no Laboratório de Tecnologia de Pavimentação (LTP) da EPUSP. O equipamento é munido em sua parte inferior por um anel plástico onde o corpo de prova é posicionado. Com a finalidade de evitar perda de água pelas laterais das amostras, foi utilizada uma membrana flexível posicionada internamente ao anel plástico. Uma vez que o corpo de prova era posicionado no interior do anel, aplicava-se uma pressão na membrana flexível deixando a amostra totalmente envolta pela membrana. O recipiente utilizado para produzir a pressão de água sobre o corpo de prova era munido de uma entrada e uma saída d'água, bem como por um ladrão para evitar transbordamento da água. Na Figura 2.23 é apresentado o permeâmetro utilizado.

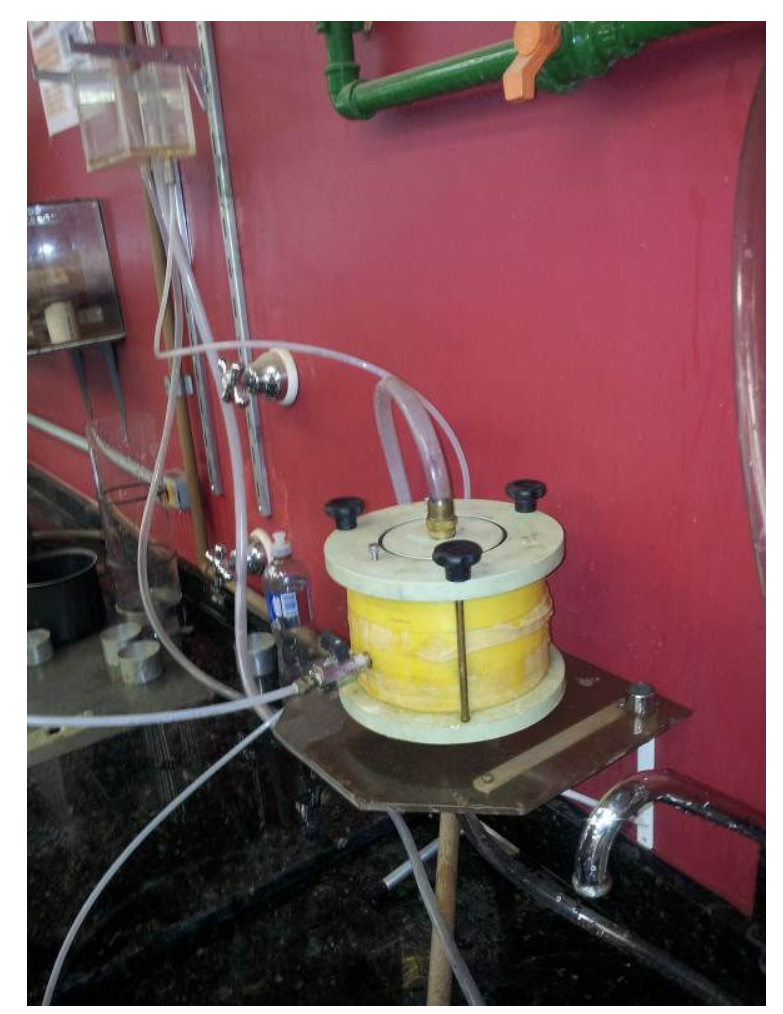

Figura 2.23: Permeâmetro de carga constante

Para realização do ensaio os corpos de prova cilíndricos de $20 \mathrm{~cm}$ moldados foram cortados em quatro partes, uma vez que a limitação de altura da amostra a ser ensaiada é de $5,5 \mathrm{~cm}$. As partes da superfície e do fundo das amostras foram 
descartadas e o ensaio foi realizado somente nas suas duas porções centrais (topo e fundo).

Os corpos de prova utilizados nos ensaios de condutividade hidráulica foram cortados com uso de uma serra diamantada, a fim de determinar se havia variação da permeabilidade nas porções superior e inferior de cada corpo de prova. Este procedimento foi realizado para avaliar a influência do processo de vibração utilizado na moldagem. Na Figura 2.24 é apresentado o procedimento de corte das amostras.

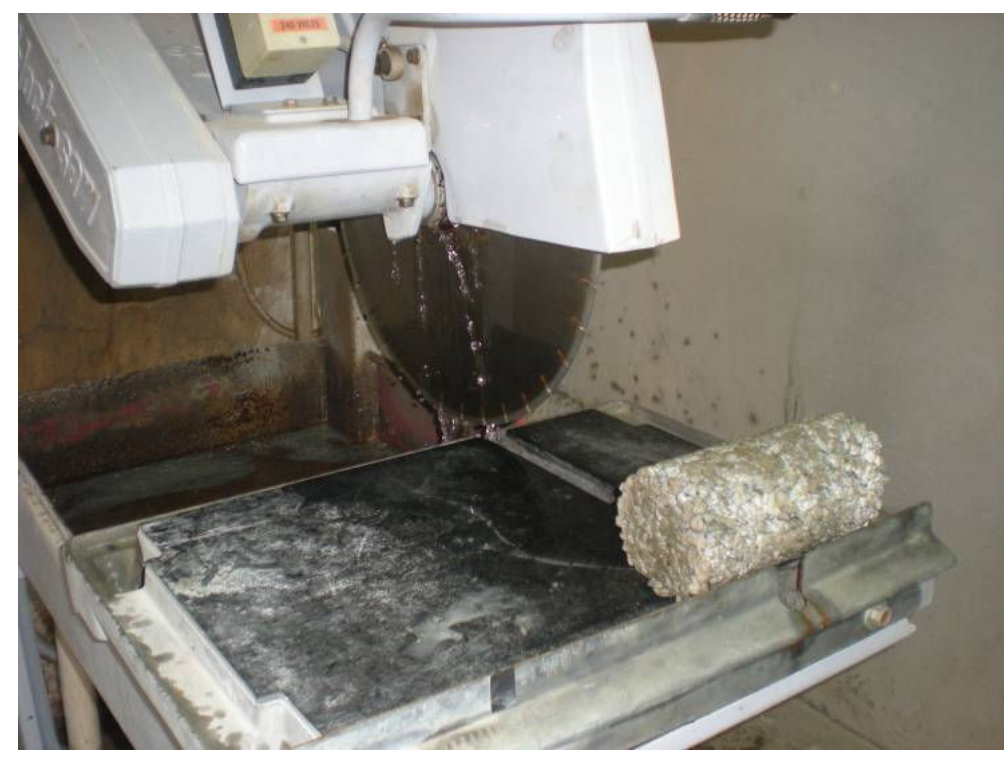

Figura 2.24: Procedimento de corte dos corpos de prova

O controle da coluna d'água era realizado pelo nivelamento de água no recipiente, que por sua vez era calibrado pela vazão da água de entrada. Com a finalidade de manter um fluxo laminar da água, que varia em função da velocidade do líquido, foram realizadas inúmeras tentativas para encontrar a altura de coluna d'água ideal para o material estudado.

O ensaio consistiu em posicionar a amostra na parte inferior do permeâmetro aplicando pressão à membrana flexível para vedação completa das laterais do corpo de prova (Figura 2.25). Em seguida liberou-se o fluxo para que todo o sistema ficasse preenchido com água. Com a finalidade de manter a altura de coluna d'água constante, a vazão foi aumentada até que o nível da água se apresentasse constante. Em seguida, coletou-se a água de saída em um recipiente 
cronometrando-se o tempo de coleta. Por fim o recipiente foi pesado para determinar o volume de água coletado. De posse do volume e o tempo decorrido na coleta, foi possível determinar a condutividade hidráulica da amostra a partir da equação (11) a seguir. Foram realizadas um total de quatro ensaios para cada corpo de prova, sendo que a condutividade hidráulica foi calculada pela média dos valores obtidos nos quatro ensaios.

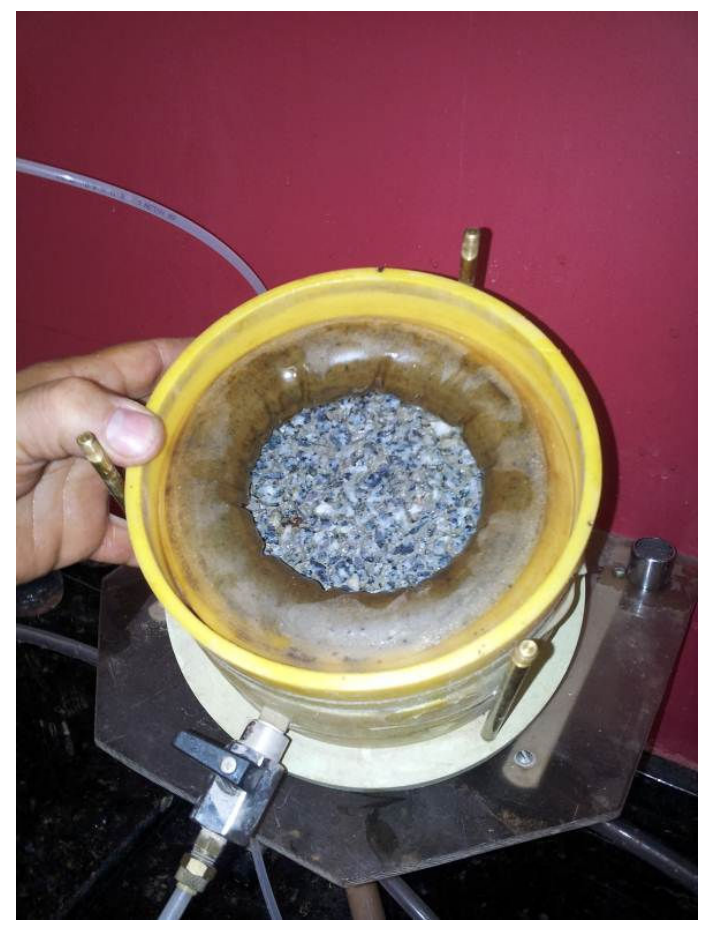

Figura 2.25: Corpo de prova envolto pela membrana flexível

$$
k=\frac{V \cdot L}{h \cdot A \cdot t}
$$

Onde:

$k$ : condutividade hidráulica $(\mathrm{cm} / \mathrm{s})$;

$V$ : volume de água coletado $\left(\mathrm{cm}^{3}\right)$;

$L$ : comprimento do corpo de prova (cm);

$h$ : carga hidráulica $(\mathrm{cm})$;

$A$ : área da seção transversal da amostra $\left(\mathrm{cm}^{2}\right)$;

$t$ : tempo decorrido para a coleta da água (s). 


\subsection{DETERMINAÇÃO DO ÍNDICE DE VAZIOS}

O índice de vazios de cada corpo de prova foi determinado em laboratório a partir da obtenção do peso seco e peso submerso das amostras, utilizando-se para o cálculo a equação (12) a seguir:

$$
V_{r}=\left(1-\frac{W_{2}-W_{1}}{\rho_{w} V o l}\right)
$$

onde:

$V_{r}$ Índice de vazios;

$W_{1}$ : Peso submerso $(\mathrm{kg})$;

$W_{2}$ : Peso seco $(\mathrm{kg})$;

$\mathrm{Vol}$ : Volume da amostra $\left(\mathrm{m}^{3}\right)$;

$\rho_{w}$ : Massa específica da água $\left(\mathrm{kg} / \mathrm{m}^{3}\right)$.

Nas Figuras 2.26 e 2.27 são apresentados os procedimentos de obtenção dos pesos seco e submerso de cada amostra.

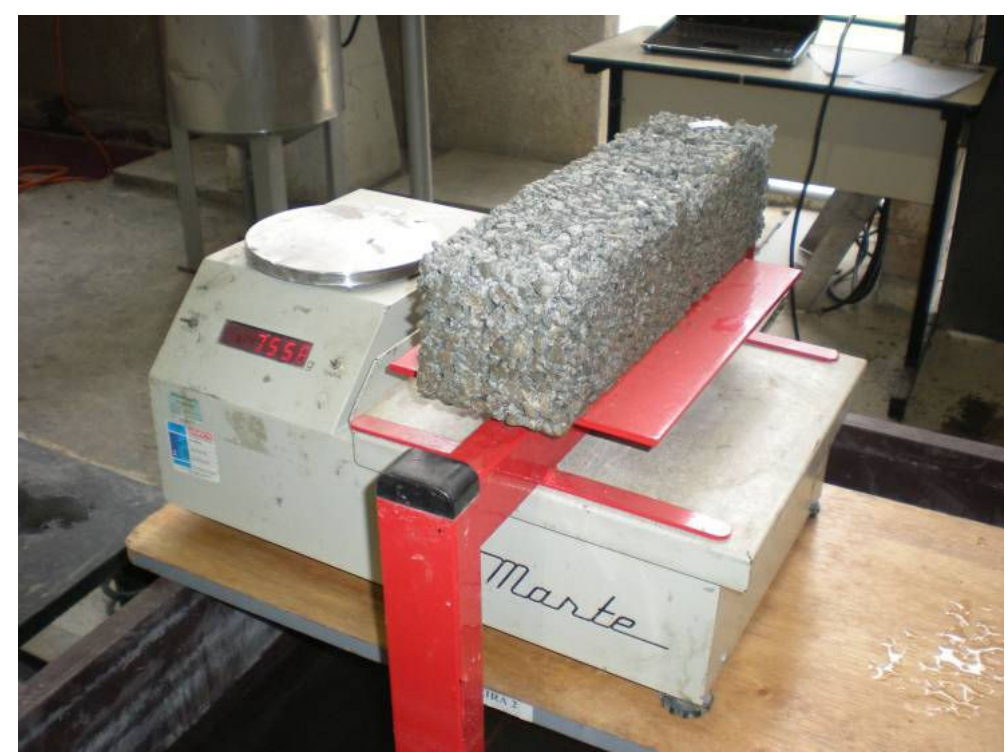

Figura 2.26: Procedimento de obtenção do peso seco 


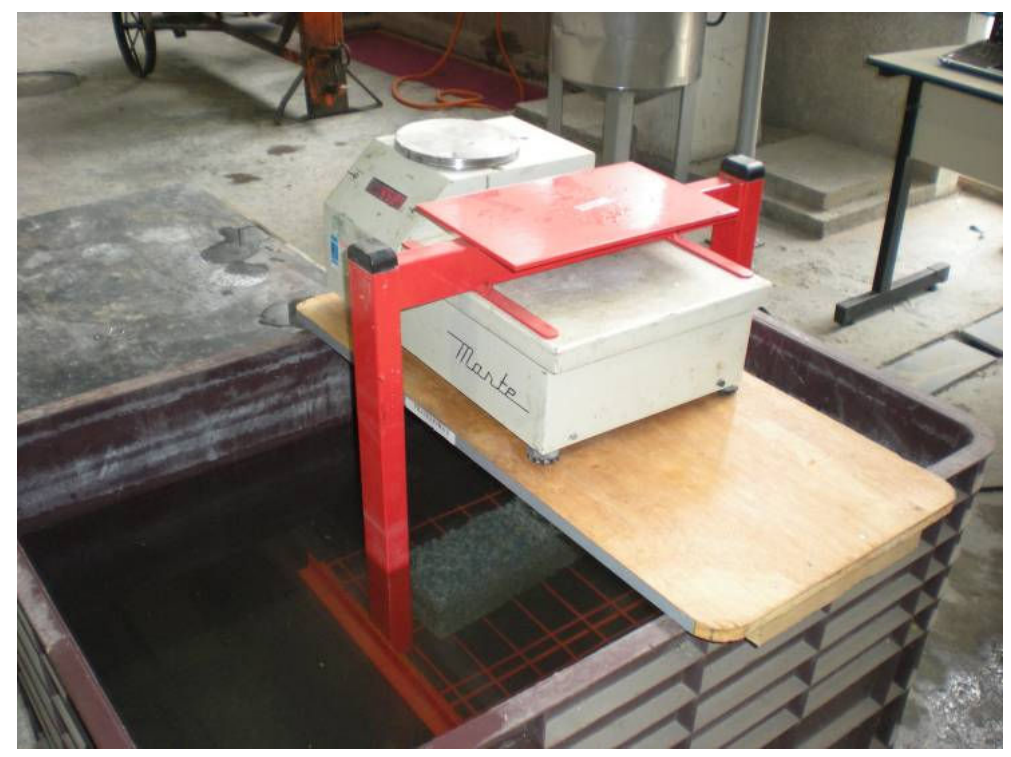

Figura 2.27: Procedimento de obtenção do peso submerso

Ressalta-se que corpos de prova de concreto permeável tendem a perder agregados facilmente de sua superfície, principalmente nas suas bordas, motivo pelo qual se deve considerar a possibilidade de dispersão dos resultados de índice de vazios e da massa específica aparente seca, uma vez que estes parâmetros dependem tanto do volume quanto do peso de cada amostra. 


\section{APRESENTAÇÃO E DISCUSSÃO DOS RESULTADOS}

\subsection{MASSA ESPECÍFICA APARENTE SECA E ÍNDICE DE VAZIOS}

Os resultados obtidos para massa específica aparente seca e índice de vazios tanto dos corpos de prova cilíndricos quanto prismáticos estão apresentados na Tabela 3.1. Na Tabela 3.2 são apresentadas a média $(\mu)$, o desvio padrão $(\sigma)$ e o coeficiente de variação (cv) dos resultados obtidos para as vinte e uma amostras de cada mistura.

Tabela 3.1: Massa específica e índice de vazios

\begin{tabular}{cccccc}
\hline & Índice de Vazios & & \multicolumn{3}{l}{ Massa Específica Aparente Seca $\left(\mathbf{k g} / \mathbf{m}^{3}\right)$} \\
\hline \hline M1 & M2 & M3 & M1 & M2 & M3 \\
\hline \hline 0,27 & 0,24 & 0,27 & 1.830 & 1.888 & 1.821 \\
\hline 0,20 & 0,25 & 0,25 & 1.955 & 1.862 & 1.852 \\
\hline 0,22 & 0,24 & 0,27 & 1.923 & 1.866 & 1.815 \\
\hline 0,24 & 0,23 & 0,26 & 1.841 & 1.910 & 1.815 \\
\hline 0,23 & 0,24 & 0,26 & 1.866 & 1.874 & 1.824 \\
\hline 0,29 & 0,26 & 0,23 & 1.741 & 1.853 & 1.890 \\
\hline 0,27 & 0,21 & 0,25 & 1.781 & 1.935 & 1.848 \\
\hline 0,24 & 0,27 & 0,24 & 1.879 & 1.819 & 1.860 \\
\hline 0,23 & 0,25 & 0,29 & 1.881 & 1.865 & 1.763 \\
\hline 0,25 & 0,23 & 0,26 & 1.854 & 1.888 & 1.821 \\
\hline 0,27 & 0,28 & 0,26 & 1.818 & 1.777 & 1.822 \\
\hline 0,22 & 0,25 & 0,28 & 1.895 & 1.856 & 1.780 \\
\hline 0,27 & 0,25 & 0,24 & 1.818 & 1.830 & 1.856 \\
\hline 0,23 & 0,27 & 0,24 & 1.860 & 1.803 & 1.844 \\
\hline 0,23 & 0,25 & 0,23 & 1.877 & 1.828 & 1.875 \\
\hline 0,23 & 0,26 & 0,22 & 1.857 & 1.821 & 1.879 \\
\hline 0,25 & 0,24 & 0,23 & 1.843 & 1.834 & 1.861 \\
\hline 0,25 & 0,25 & 0,24 & 1.843 & 1.836 & 1.842 \\
\hline 0,27 & 0,25 & 0,23 & 1.797 & 1.817 & 1.854 \\
\hline 0,23 & 0,24 & 0,22 & 1.858 & 1.853 & 1.879 \\
\hline 0,24 & 0,24 & 0,24 & 1.866 & 1.855 & 1.857 \\
\hline \hline & & & & & \\
\hline \hline
\end{tabular}


Tabela 3.2: Análise estatística dos resultados de massa específica e índice de vazios

\begin{tabular}{|c|c|c|c|c|c|c|}
\hline \multirow{2}{*}{ Dados } & \multicolumn{3}{|c|}{ Índice de Vazios } & \multicolumn{3}{|c|}{$\begin{array}{c}\text { Massa Específica Aparente } \\
\text { Seca }\left(\mathrm{kg} / \mathrm{m}^{3}\right)\end{array}$} \\
\hline & M1 & M2 & M3 & M1 & M2 & M3 \\
\hline$\mu$ & 0,24 & 0,25 & 0,25 & 1.851 & 1.851 & 1841 \\
\hline$\sigma$ & 0,022 & 0,015 & 0,019 & 47 & 37 & 32 \\
\hline $\mathrm{cv}(\%)$ & 9,11 & 6,24 & 7,82 & 2,53 & 1,97 & 1,74 \\
\hline
\end{tabular}

Observa-se que os resultados de índice de vazios e massa específica aparente seca se encontram dentro da faixa de valores anteriormente citada na revisão bibliográfica (Tabela 1.5 - Página 45). No caso do índice de vazios, que normalmente varia entre 0,15 e 0,3 , os valores estão mais próximos no limite superior da faixa, assemelhando-se aos concretos permeáveis com quantidade nula de agregado miúdo em sua mistura, o que implica em um valor muito elevado de índice de vazios. Nota-se também que as três misturas apresentaram valores médios desses parâmetros muito semelhantes, sugerindo que a variação dos agregados utilizados não provocou maiores alterações nestes parâmetros.

Os coeficientes de variação determinados são baixos, em especial com relação aos resultados de massa específica aparente seca, o que mostra boa confiabilidade na qualidade da produção dos corpos de prova. Além disso, a coerência entre os resultados obtidos na presente pesquisa frente àqueles apresentados na revisão da literatura faz com que haja boa coerência dos valores obtidos, mesmo diante das dificuldades encontradas durante as moldagens das amostras.

Com relação aos resultados de massa específica aparente seca, observa-se que foram na ordem de $25 \%$ inferiores a valores característicos de concretos convencionais, que geralmente possuem massa específica aparente seca variando de 2.400 a $2.500 \mathrm{~kg} / \mathrm{m}^{3}$.

Vale lembrar que tanto o índice de vazios quanto a massa específica aparente seca do concreto permeável dependem dos tipos de materiais utilizados na mistura e do 
procedimento empregado para compactação e adensamento do concreto. Além disso, estes são parâmetros essenciais no estudo desse tipo de material, uma vez que os parâmetros de maior importância para projeto, como resistência mecânica e condutividade hidráulica, estão intimamente ligados ao índice de vazios do concreto permeável.

\subsection{CONDUTIVIDADE HIDRÁULICA}

Os resultados de condutividade hidráulica estão apresentados na Tabela 3.3. Na Tabela 3.4 são apresentados a média, o desvio padrão e o coeficiente de variação dos resultados obtidos para os doze corpos de prova de cada mistura.

Tabela 3.3: Condutividade Hidráulica

\begin{tabular}{cccc}
\hline \hline \multicolumn{4}{c}{ Condutividade Hidráulica (cm/s) } \\
\hline \multirow{2}{*}{ Posição } & M1 & M2 & M3 \\
\hline \multirow{2}{*}{ TOPO } & 0,13 & 0,13 & 0,14 \\
\cline { 2 - 4 } & 0,14 & 0,13 & 0,14 \\
\hline \multirow{2}{*}{ FUNDO } & 0,13 & 0,13 & 0,14 \\
\hline & 0,14 & 0,11 & 0,14 \\
\hline & 0,14 & 0,13 & 0,14 \\
\hline
\end{tabular}

Tabela 3.4: Análise estatística dos resultados de condutividade hidráulica

\begin{tabular}{cccc}
\hline \hline \multirow{2}{*}{ Dados } & \multicolumn{3}{c}{ Condutividade Hidráulica (cm/s) } \\
\cline { 2 - 4 } & M1 & M2 & M3 \\
\hline \hline$\mu$ & 0,14 & 0,13 & 0,14 \\
\hline$\sigma$ & 0,008 & 0,009 & 0,002 \\
\hline $\mathrm{cv}(\%)$ & 5,66 & 6,80 & 1,50 \\
\hline \hline
\end{tabular}

Observa-se que os valores médios de permeabilidade obtidos neste estudo variam de 0,13 a $0,14 \mathrm{~cm} / \mathrm{s}$, aproximadamente. Estes valores se apresentam dentro da faixa de valores obtidos pela grande maioria dos autores que testaram esse parâmetro em 
concretos permeáveis. Schaefer et al. (2006) apresentaram resultados variando entre $0,01 \mathrm{~cm} / \mathrm{s}$ e $1,5 \mathrm{~cm} / \mathrm{s}$. Montes e Haselbach (2006) obtiveram resultados variando entre 0,014 e $1,19 \mathrm{~cm} / \mathrm{s}$.

Vale lembrar que a condutividade hidráulica de concretos permeáveis está intimamente ligada ao índice de vazios característico do material, uma vez que quanto maior a porosidade maior será a sua condutividade hidráulica. Ainda neste contexto, o procedimento de compactação deve ser selecionado e aplicado com cuidado, uma vez que, mesmo o material possuindo elevado índice de vazios, a utilização de um procedimento inadequado de compactação pode causar a redução da interconectividade entre os poros, prejudicando a capacidade permeável do material.

Na comparação da variação da condutividade hidráulica entre as misturas, observase que não houve diferença considerável nos resultados. Além disso, observa-se que não houve diferença considerável entre os resultados de condutividade hidráulica obtidos no topo e no fundo das amostras.

\subsection{MÓDULO DE ELASTICIDADE DINÂMICO}

Os resultados de módulo de elasticidade dinâmico obtidos por equipamento ultrassônico são provenientes somente dos corpos de prova cilíndricos e estão apresentados na Tabela 3.5 .

Na Tabela 3.6 são apresentados a média, o desvio padrão e o coeficiente de variação dos resultados obtidos para os doze corpos de prova de cada mistura. 
Tabela 3.5: Módulo de elasticidade dinâmico

\begin{tabular}{ccc}
\hline \hline \multicolumn{3}{c}{ Módulo de Elasticidade Dinâmico (GPa) } \\
\hline M1 & M2 & M3 \\
\hline 22,57 & 26,88 & 27,57 \\
\hline 27,74 & 23,66 & 26,74 \\
\hline 26,74 & 22,03 & 24,78 \\
\hline 20,18 & 24,83 & 22,35 \\
\hline 24,98 & 23,58 & 20,66 \\
\hline 15,84 & 22,66 & 22,88 \\
\hline 22,55 & 24,12 & 22,45 \\
\hline 21,65 & 19,73 & 24,78 \\
\hline 22,55 & 21,23 & 22,40 \\
\hline 22,58 & 24,72 & 25,56 \\
\hline 19,83 & 19,99 & 23,40 \\
\hline 25,23 & 22,18 & 24,02 \\
\hline \hline
\end{tabular}

Tabela 3.6: Análise estatística do resultados do módulo de elasticidade dinâmico

\begin{tabular}{cccc}
\hline \multirow{2}{*}{ Dados } & \multicolumn{3}{c}{ Módulo de Elasticidade Dinâmico (GPa) } \\
\cline { 2 - 4 } & M1 & M2 & M3 \\
\hline \hline$\mu$ & 22,70 & 22,97 & 23,97 \\
\hline$\sigma$ & 3,25 & 2,09 & 2,01 \\
\hline cV $(\%)$ & 14,32 & 9,10 & 8,38 \\
\hline$\mu=$ média; $\sigma=$ desvio padrão; cv = coeficiente de variação
\end{tabular}

Observa-se que os valores de módulo de elasticidade dinâmico variam de 22,7 a $24 \mathrm{GPa}$, aproximadamente. Estes resultados se encontram próximos aos valores de módulo de elasticidade estático de concretos convencionais, que normalmente são da ordem de $28 \mathrm{GPa}$.

Tseng (2009) determinou o módulo de elasticidade dinâmico de um concreto compactado a rolo (CCR) com incorporação de agregados reciclados de pavimentos antigos de concreto, empregando o mesmo equipamento ultrassônico utilizado na presente pesquisa. Obteve resultados variando entre $34,1 \mathrm{GPa}$ e 36,1 GPa, com coeficiente de variação máximo de $4,3 \%$.

Nota-se que ocorreu uma redução de coeficiente de variação na ordem de $70 \%$ quando comparado ao máximo valor observado na presente pesquisa. Esta 
ocorrência pode estar relacionada à grande diferença nos tipos de materiais estudados, uma vez que o concreto permeável apresenta uma estrutura muito porosa, diferentemente do CCR, que possui uma estrutura fechada e mais homogênea. Esta consideração pode ser também estendida na comparação dos parâmetros de resistência mecânica entre os dois materiais.

\subsection{RESISTÊNCIA À COMPRESSÃO}

Os resultados de resistência à compressão estão apresentados na Tabela 3.7. Eles encontram-se muito próximos ao limite inferior da faixa de valores verificada na revisão bibliográfica, em que a resistência à compressão de concretos permeáveis varia entre 4,1 MPa e 55,8 MPa. Este valor reduzido de resistência está atribuído ao elevado índice de vazios característico das misturas em estudo, o que caracteriza o material como de baixa resistência.

Tabela 3.7: Resistência à compressão

\begin{tabular}{ccccc}
\hline \hline \multicolumn{5}{c}{ Resistência à Compressão (MPa) } \\
\hline Misturas & \multicolumn{5}{c}{ Resultados } & Média \\
\hline M1 & 6,02 & 9,17 & 10,17 & 8,45 \\
\hline M2 & 9,09 & 8,93 & 8,01 & 8,68 \\
\hline M3 & 7,10 & 9,06 & 6,36 & 7,51 \\
\hline \hline
\end{tabular}

Goede (2009) realizou estudos de resistência à compressão de amostras cilíndricas de concreto permeável com índices de vazios variando entre 0,26 e 0,28. Determinou que a resistência à compressão variou entre 9,2 MPa e 11,5 MPa, com coeficiente de variação de $8,3 \%$. Observa-se que, considerando um valor médio de índice de vazios muito semelhante ao da presente pesquisa, o autor obteve resistências à compressão em média $17 \%$ mais elevadas. 


\subsection{RESISTÊNCIA À TRAÇÃO NA FLEXÃO E MÓDULO DE ELASTICIDADE ESTÁTICO}

Os resultados dos ensaios de resistência à tração na flexão e de módulo de elasticidade estático aos 28 dias estão apresentados na Tabela 3.8. Na Tabela 3.9 são apresentados a média, o desvio padrão e o coeficiente de variação dos resultados obtidos para os nove corpos de prova de cada mistura.

Tabela 3.8: Resistência à tração na flexão e módulo de elasticidade estático

\begin{tabular}{cccccc}
\hline \hline \multicolumn{2}{c}{ Resistência à Tração na Flexão (MPa) } & \multicolumn{3}{c}{ Módulo de Elasticidade Estático (GPa) } \\
\hline M1 & M2 & M3 & M1 & M2 & M3 \\
\hline 2,43 & 2,05 & 2,39 & 5,18 & 15,10 & 17,35 \\
\hline 2,51 & 2,01 & 2,52 & 18,17 & 13,40 & 19,62 \\
\hline 1,92 & 2,07 & 2,46 & 8,19 & 14,96 & 16,14 \\
\hline 2,08 & 2,20 & 1,84 & 20,41 & 87,77 & 11,11 \\
\hline 2,51 & 2,26 & 2,38 & - & 23,74 & 18,12 \\
\hline 2,19 & 2,11 & 1,77 & - & 27,52 & 17,72 \\
\hline 1,78 & 2,14 & 2,11 & 10,73 & 2,29 & 16,76 \\
\hline 2,04 & 1,87 & 2,29 & 13,01 & 16,25 & 32,63 \\
\hline 1,97 & 1,60 & 2,21 & 17,59 & 17,88 & 15,14 \\
\hline \hline
\end{tabular}

Tabela 3.9: Análise estatística dos resultados de resistência à tração na flexão e módulo de elasticidade dinâmico

\begin{tabular}{ccccccc}
\hline \hline \multirow{2}{*}{ Dados } & \multicolumn{3}{c}{$\begin{array}{c}\text { Resistência à Tração na Flexão } \\
\text { (MPa) }\end{array}$} & \multicolumn{3}{c}{ Módulo de Elasticidade Estático (GPa) } \\
\cline { 2 - 7 } & $\mathbf{M 1}$ & $\mathbf{M 2}$ & $\mathbf{M 3}$ & $\mathbf{M 1}$ & $\mathbf{M 2}$ & M3 \\
\hline $\mathrm{n}$ & 9 & 9 & 9 & 5 & 5 & 8 \\
\hline$\mu$ & 2,16 & 2,03 & 2,22 & 15,98 & 15,52 & 16,49 \\
\hline$\sigma$ & 0,27 & 0,20 & 0,27 & 3,98 & 1,66 & 2,55 \\
\hline $\mathrm{cv}(\%)$ & 12,44 & 9,71 & 12,03 & 24,91 & 10,73 & 15,48 \\
\hline $\mathrm{n}=$ número de amostras consideradas; $\mu$ & $=$ média; $\sigma=$ desvio padrão; cv = coeficiente de variação
\end{tabular}

Os dois resultados de módulo de elasticidade estático que estão faltando na mistura M1 não foram obtidos devido à ocorrência de problemas de execução do ensaio. Os resultados dos módulos de elasticidade apresentados em vermelho na Tabela 3.8 não foram considerados no cálculo das médias apresentadas. Tal consideração se deve à elevada dispersão destes resultados quando comparados aos demais, o que assume-se como provável erro na execução do teste. 
Para o caso da mistura M2, verifica-se que os quatro módulos de elasticidade desconsiderados para o cálculo da média estão posicionados em sequência. Como esta última foi a mesma empregada para a ruptura dos corpos de prova, considerase que provavelmente a dispersão dos resultados se deve à ocorrência de algum desajuste durante a instalação do LVDT.

Os valores de módulo de elasticidade de 23,74, 27,52 e 32,63 GPa, apesar de se encontrarem relativamente próximos dos demais valores, foram desconsiderados em função de que estão próximos aos valores típicos de módulos de elasticidade admitidos para concretos convencionais, que apresentam porosidade muito reduzida quando comparada com a do concreto permeável (em média 15 vezes inferior). Uma vez que com o aumento da porosidade os valores de módulo de elasticidade diminuem, entende-se que estes valores sejam inválidos. Os valores 5,18 MPa e 8,19 MPa da mistura M1 também foram desconsiderados por se distanciarem muito da maioria dos valores encontrados.

Observa-se que os resultados de resistência à tração na flexão obtidos variam de 1,60 a 2,52 Mpa. Apesar da mistura M3 ter apresentado valor médio de resistência mais elevado, os valores para as três misturas são semelhantes.

Em projetos rodoviários no Brasil, é comum a utilização de resistências à tração na flexão das placas de concreto variando entre 4,5 MPa e 5,0 MPa (para aeroportos, normalmente se utilizam resistências variando de 4,0 a 5,0 MPa). Dessa maneira, as baixas resistências dos concretos permeáveis aqui estudados quando comparadas às resistências de concretos convencionais (aproximadamente 50\% inferiores), possivelmente promoverão a necessidade de implantação de revestimentos com espessuras impraticáveis, o que torna difícil a sua utilização para níveis de tráfego mais elevados.

Albuquerque et. al. (2011) estudaram a resistência à tração na flexão de um CCR confeccionado com adição de areia industrial e escória de alto forno utilizando a mesma prensa e equipamentos utilizados na presente pesquisa. Os autores determinaram que a resistência à tração na flexão aos 35 dias varia entre 2,29 MPa, 
para o CCR com incorporação de escória de alto forno e 4,25 MPa para o CCR contendo areia artificial. Apesar disso, recorda-se que tais valores foram determinados a partir de ensaios de um cutelo apenas, o que resulta em maiores valores de resistência.

Com relação aos coeficientes de variação, nota-se que os valores foram elevados, em especial no caso do módulo de elasticidade estático da mistura M1, que possui coeficiente de variação de $42 \%$. Como já comentado, o material estudado possui elevada porosidade, o que pode provocar elevada dispersão dos resultados em ensaios de resistência mecânica. Além disso, a elevada dispersão pode estar associada a desajustes do LVDT durante a execução dos ensaios; deslocamentos mesmo de muito pequena ordem nesse aparelho, na superfície irregular do concreto permeável, poderia em tese alterar sensivelmente o resultado. Julga-se portanto que caso empregados dois LVDTs grande parte desses problemas poderiam ser sanados.

A equação (3) apresentada na revisão bibliográfica e reproduzida a seguir foi obtida por Goede (2009) e, segundo o autor, pode ser utilizada para estimar o módulo de elasticidade estático do concreto permeável, em função da sua massa unitária e resistência à compressão simples.

$$
E=39,1 \cdot W_{c}^{1,5} \cdot\left(f_{c}\right)^{\frac{1}{2}}
$$

Na Tabela 3.10 são apresentados os valores de módulo de elasticidade estático obtidos a partir da equação proposta por Goede (2009) utilizando-se os dados de resistência à compressão e de massa específica aparente seca obtidos na presente pesquisa. 
Tabela 3.10: Módulo de elasticidade estático segundo a equação de Goede (2009)

\begin{tabular}{cccc} 
Mistura & $\begin{array}{c}\text { Resistência à } \\
\text { compressão (MPa) }\end{array}$ & $\begin{array}{c}\text { Massa Específica } \\
\text { Aparente Seca } \\
\left(\mathbf{k g} / \mathbf{m}^{3}\right)\end{array}$ & $\mathbf{E}(\mathbf{G P a})$ \\
\hline \multirow{3}{*}{ M1 } & 6,02 & 1.830 & 7,51 \\
\cline { 2 - 4 } & 9,17 & 1.955 & 10,23 \\
\cline { 2 - 4 } & 10,17 & 1.923 & 10,51 \\
\hline \multirow{3}{*}{ M2 } & 9,09 & 1.888 & 9,66 \\
\cline { 2 - 4 } & 8,93 & 1.861 & 9,38 \\
\hline \multirow{3}{*}{ M3 } & 8,01 & 1.866 & 8,92 \\
\cline { 2 - 4 } & 7,10 & 1.820 & 8,09 \\
\hline \hline
\end{tabular}

Observa-se que os valores calculados a partir da equação de Goede (2009) se apresentam em média aproximadamente $40 \%$ inferiores àqueles obtidos no presente estudo. Tal ocorrência pode estar atribuída ao fato de que o autor alcançou seus resultados de módulo de elasticidade estático para formulação do modelo por meio de ensaios de compressão simples, diferentemente do método utilizado na presente pesquisa, na qual os módulos foram obtidos nos ensaios de resistência à tração na flexão.

\subsection{RESISTÊNCIA À TRAÇÃO INDIRETA POR COMPRESSÃO DIAMETRAL}

Os resultados de resistência à tração indireta por compressão diametral estão apresentados na Tabela 3.11. Na Tabela 3.12 são apresentados a média, o desvio padrão e o coeficiente de variação dos resultados obtidos para os nove corpos de prova de cada mistura.

Observa-se que o máximo valor médio de resistência à tração por compressão diametral encontrado foi de 1,45 MPa para a mistura M2. Esse resultado é reduzido quando comparado às resistências de concretos convencionais, normalmente utilizados em pavimentação. 
Tabela 3.11: Resistência à tração indireta por compressão diametral

\begin{tabular}{ccc}
\hline \hline \multicolumn{3}{c}{ Resistência à Tração Indireta (MPa) } \\
\hline $\mathbf{M 1}$ & $\mathbf{M} 2$ & $\mathbf{M 3}$ \\
\hline 1,30 & 1,77 & 1,42 \\
\hline 1,46 & 1,46 & 1,58 \\
\hline 0,94 & 1,43 & 1,55 \\
\hline 1,19 & 1,23 & 1,49 \\
\hline 1,19 & 1,37 & 1,29 \\
\hline 1,25 & 1,32 & 1,34 \\
\hline 1,27 & 1,27 & 1,33 \\
\hline 1,24 & 1,39 & 0,81 \\
\hline 1,35 & 1,76 & 1,66 \\
\hline \hline
\end{tabular}

Tabela 3.12: Análise estatística do resultados da resistência à tração indireta

\begin{tabular}{cccc}
\hline \hline \multirow{2}{*}{ Dados } & \multicolumn{3}{c}{ Resistência à Tração Indireta (MPa) } \\
\cline { 2 - 4 } & $\mathbf{M 1}$ & $\mathbf{M 2}$ & $\mathbf{M} 3$ \\
\hline \hline$\mu$ & 1,24 & 1,45 & 1,39 \\
\hline$\sigma$ & 0,14 & 0,19 & 0,25 \\
\hline $\mathrm{cv}(\%)$ & 11,34 & 13,47 & 18,10 \\
\hline \hline$\mu$ = média; $\sigma=$ desvio padrão; $\mathrm{cv}=$ coeficiente de variação
\end{tabular}

Wang e Wang (2011) estudaram um asfalto poroso com incorporação de resíduo de telhas compostas por asfalto e fibras de vidro, material de utilização comum em coberturas nos EUA. Os autores obtiveram valores de resistência à tração por compressão diametral variando de 0,21 a 0,52 $\mathrm{MPa}$, sugerindo relativa diferença entre revestimentos em concreto permeável e misturas asfálticas porosas estudadas.

\subsection{RELAÇÕES ENTRE OS PARÂMETROS}

\subsection{1 Índice de Vazios X Massa Específica Aparente Seca}

Na Figura 3.1 é apresentada a variação do índice de vazios em função da massa específica aparente seca para todos os resultados obtidos na presenta pesquisa. Observa-se que o índice de vazios tende a diminuir com a elevação da massa específica aparente seca, sendo que o valor do coeficiente de correlação $\left(R^{2}\right)$ obtido é satisfatório. 
Esta relação se mostra importante para futuros estudos de dosagem específica de concretos permeáveis, uma vez que a massa específica aparente seca do material é um parâmetro fácil de ser obtido, tanto em laboratório como em campo, e, como mostra o gráfico acima, está intimamente ligada ao índice de vazios do material, que por sua vez influencia nas condições de resistência mecânica e de condutividade hidráulica do concreto permeável.

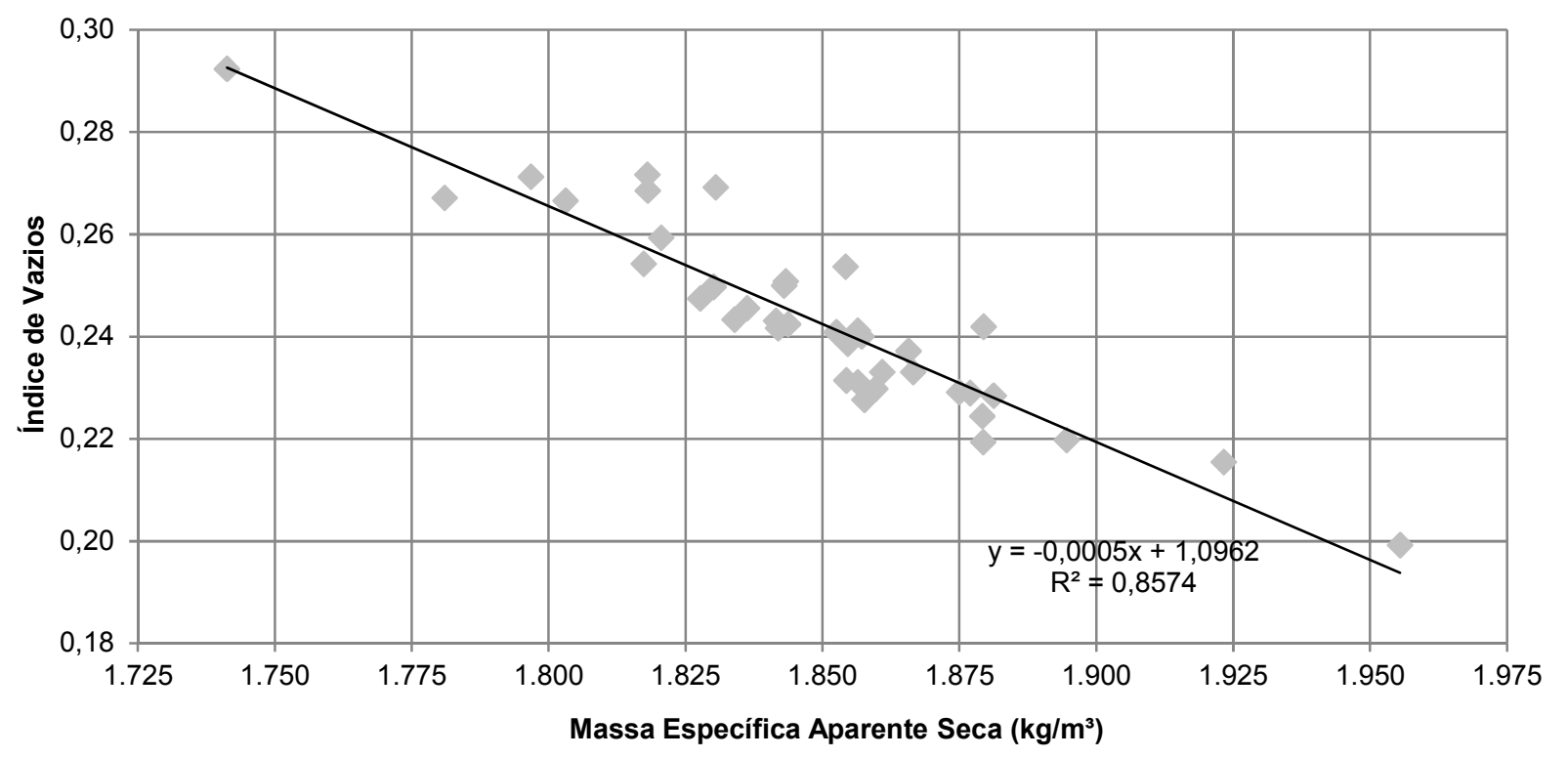

Figura 3.1: Índice de vazios em função da massa específica aparente seca

3.7.2 Resistência à Tração na Flexão X Módulo de Elasticidade Estático

$\mathrm{Na}$ Figura 3.2 são apresentados os resultados alcançados nos ensaios de resistência à tração na flexão aos 28 dias, em função do módulo de elasticidade estático obtido para as misturas ensaiadas. 


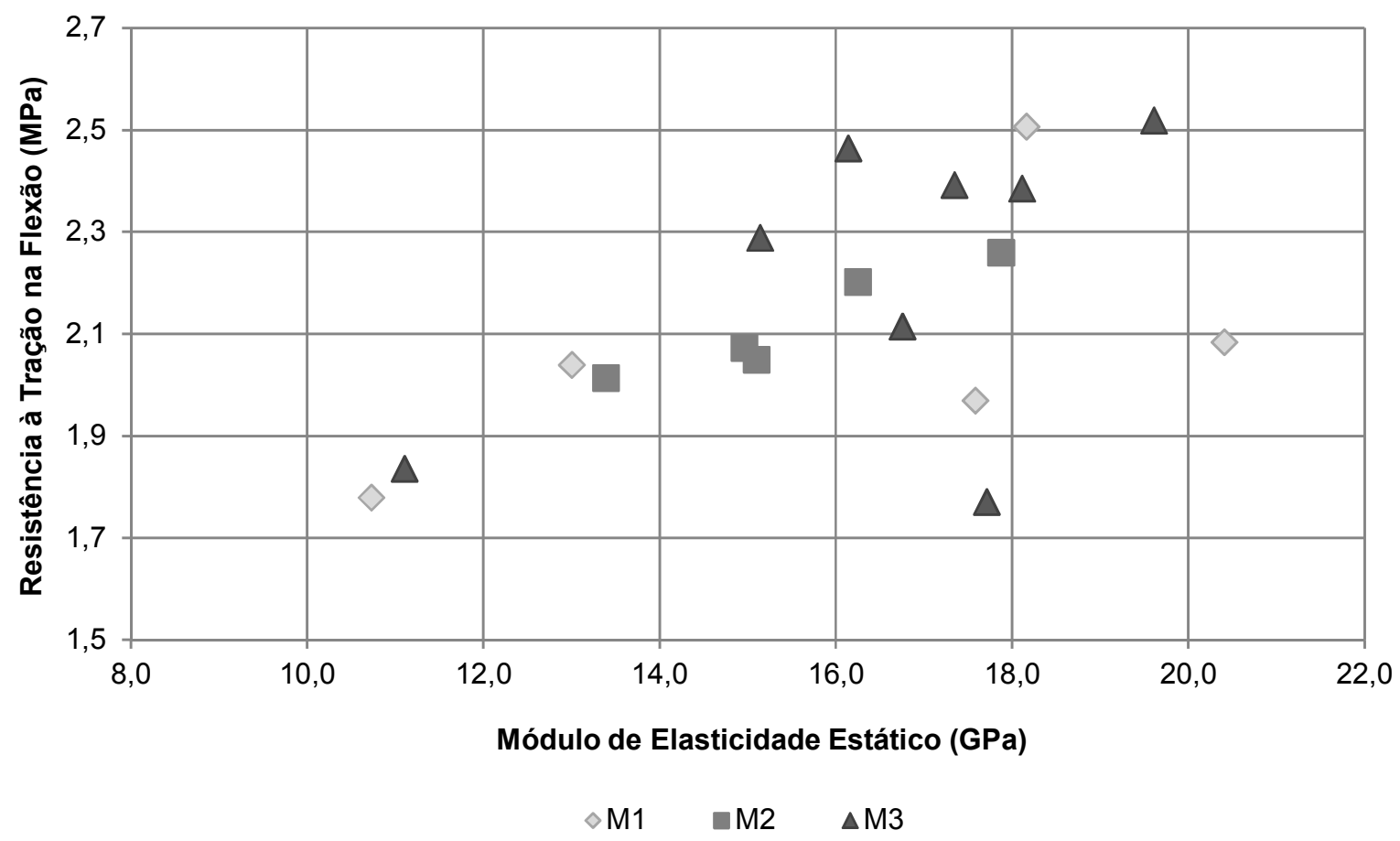

Figura 3.2: Resistência à tração na flexão em função do módulo de elasticidade estático

Observa-se que a resistência à tração na flexão se eleva com o acréscimo do módulo de elasticidade estático. Além disso, nota-se que não houve diferenciação bem definida entre os resultados para as três misturas.

\subsubsection{Módulo de Elasticidade Estático X Módulo de Elasticidade Dinâmico}

Na Figura 3.3 são apresentados os resultados médios obtidos nos ensaios de módulo de elasticidade estático em função do módulo de elasticidade dinâmico obtidos para cada mistura. 


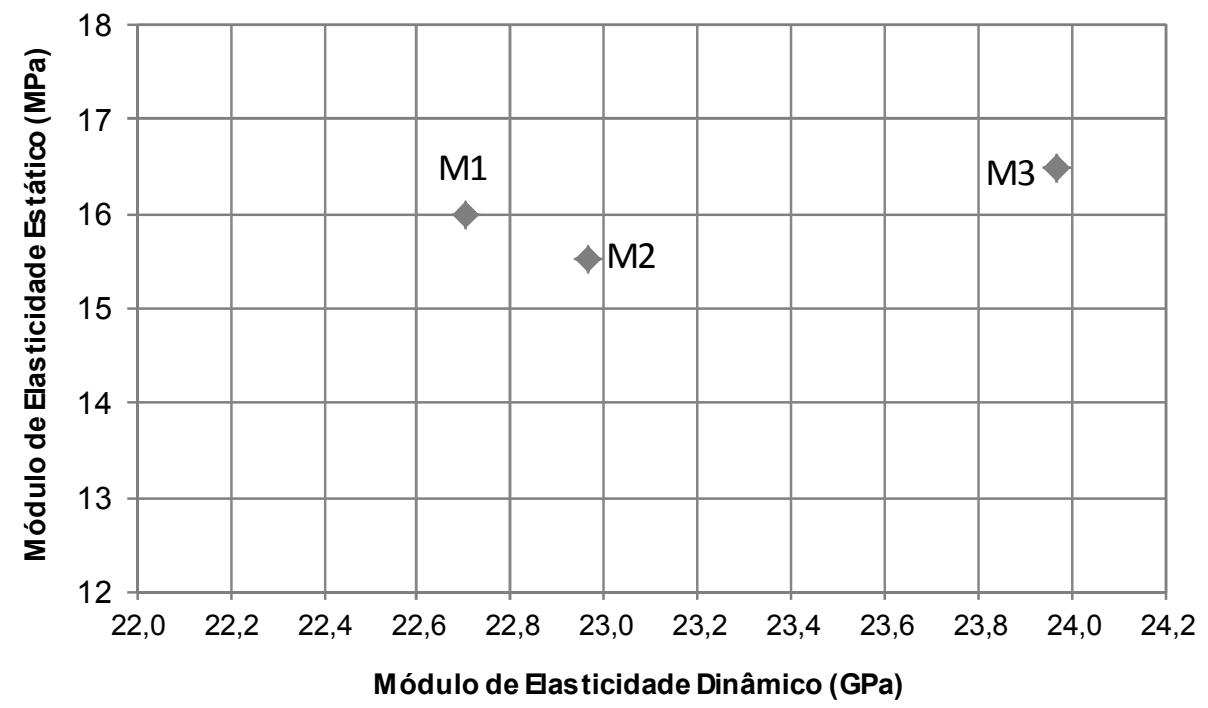

Figura 3.3: Módulo de elasticidade estático em função do módulo de elasticidade dinâmico

Observa-se que o módulo de elasticidade estático eleva-se em função da elevação do módulo de elasticidade dinâmico. Além disso, é possível notar que o módulo de elasticidade estático se apresenta substancialmente inferior ao módulo de elasticidade dinâmico. Segundo Neville (1982), o módulo dinâmico é aproximadamente igual ao módulo tangente inicial, portanto, maior que o módulo secante determinado no ensaio estático. Isso ocorre em função da heterogeneidade do concreto, que influencia os módulos estático e dinâmico de maneiras diferentes (TSENG, 2009).

\subsubsection{Módulo de Elasticidade Estático X Índice de Vazios}

Na Figura 3.4 são apresentados os resultados do módulo de elasticidade estático médio em função do índice de vazios obtidos no presente estudo, comparados aos resultados encontrados por Goede (2009), que estudou um material com índice de vazios semelhante ao material analisado nesta pesquisa. 


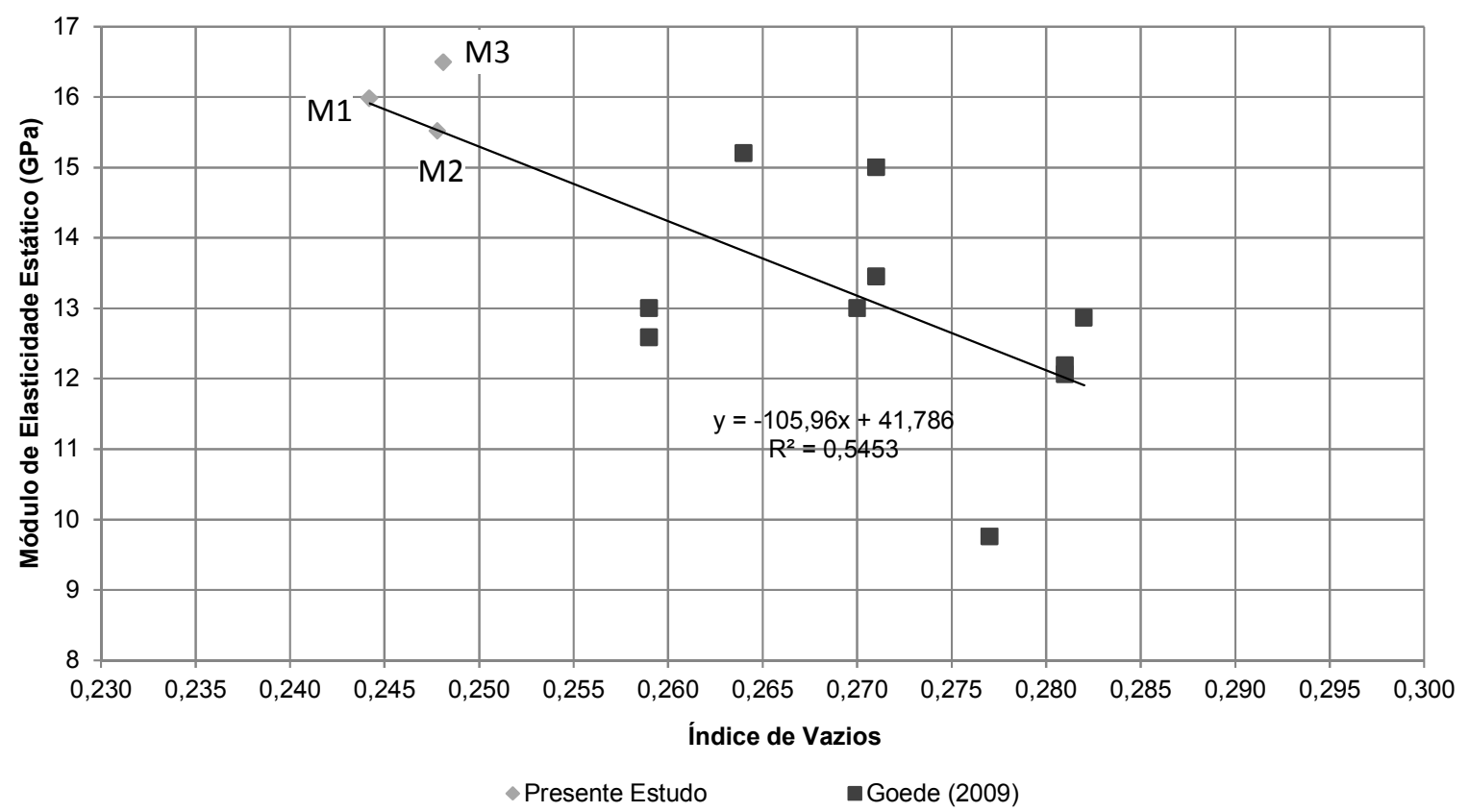

Figura 3.4: Comparação entre o módulo de elasticidade estático em função do índice de vazios

Observa-se que os resultados apresentados na presente pesquisa complementam os resultados demonstrados por Goede (2009), sendo possível traçar uma linha de tendência utilizando os grupos de resultados de cada pesquisa. Apesar do valor de $\mathrm{R}^{2}$ ser baixo, observa-se que o módulo de elasticidade tende a diminuir com a elevação do índice de vazios.

3.7.5 Módulo de Elasticidade Dinâmico X Massa Específica Aparente Seca e Índice de Vazios

Nas Figuras 3.5 e 3.6 são apresentados os resultados médios obtidos nos ensaios de módulo de elasticidade dinâmico em função da massa específica aparente seca e do índice de vazios verificados para cada mistura.

Observa-se que o módulo de elasticidade tende a se elevar com o aumento da massa específica aparente seca e diminuir com o aumento do índice de vazios para todas as misturas, sendo o coeficiente de correlação aceitável somente para as misturas M1 e M2. 


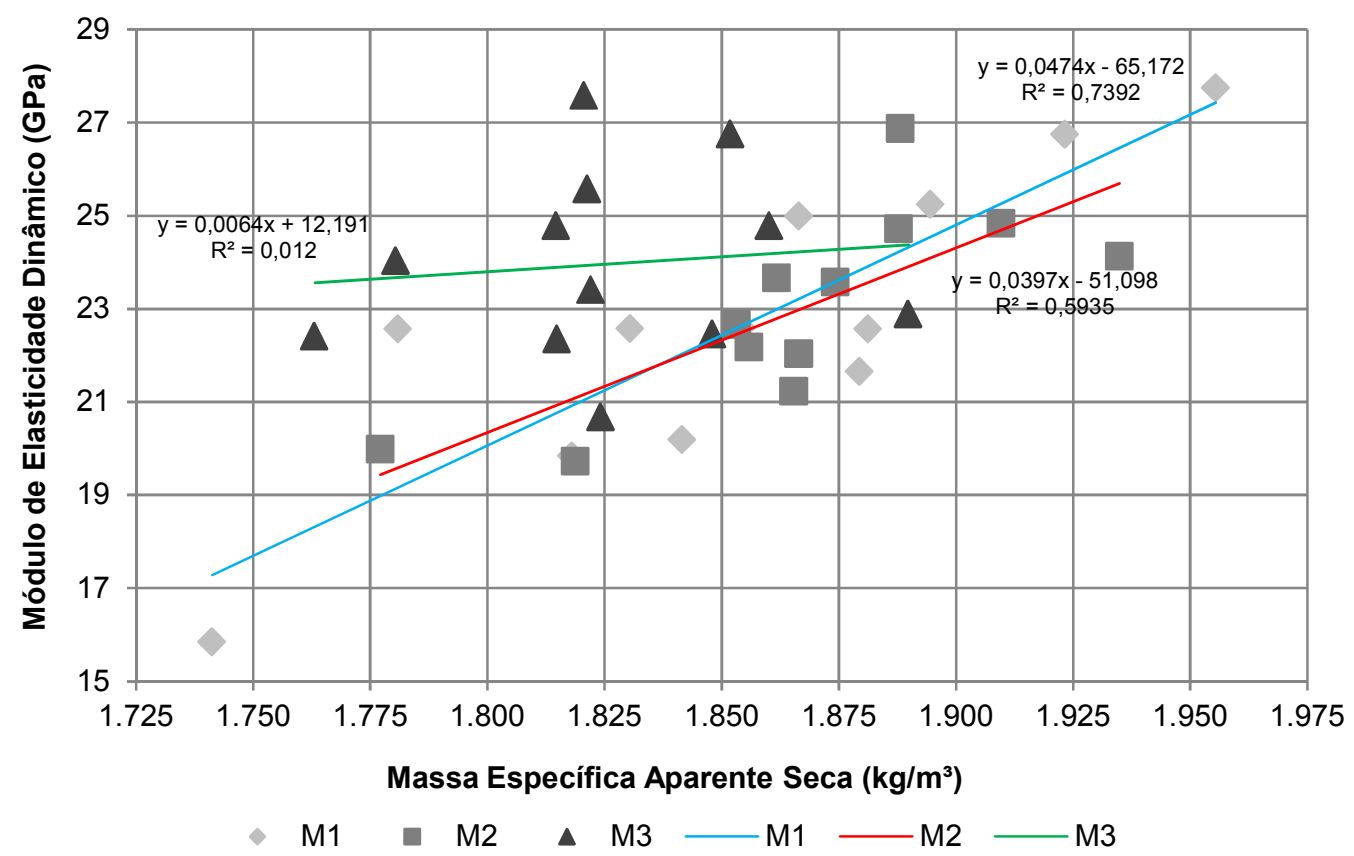

Figura 3.5: Módulo de elasticidade dinâmico em função da massa específica aparente seca

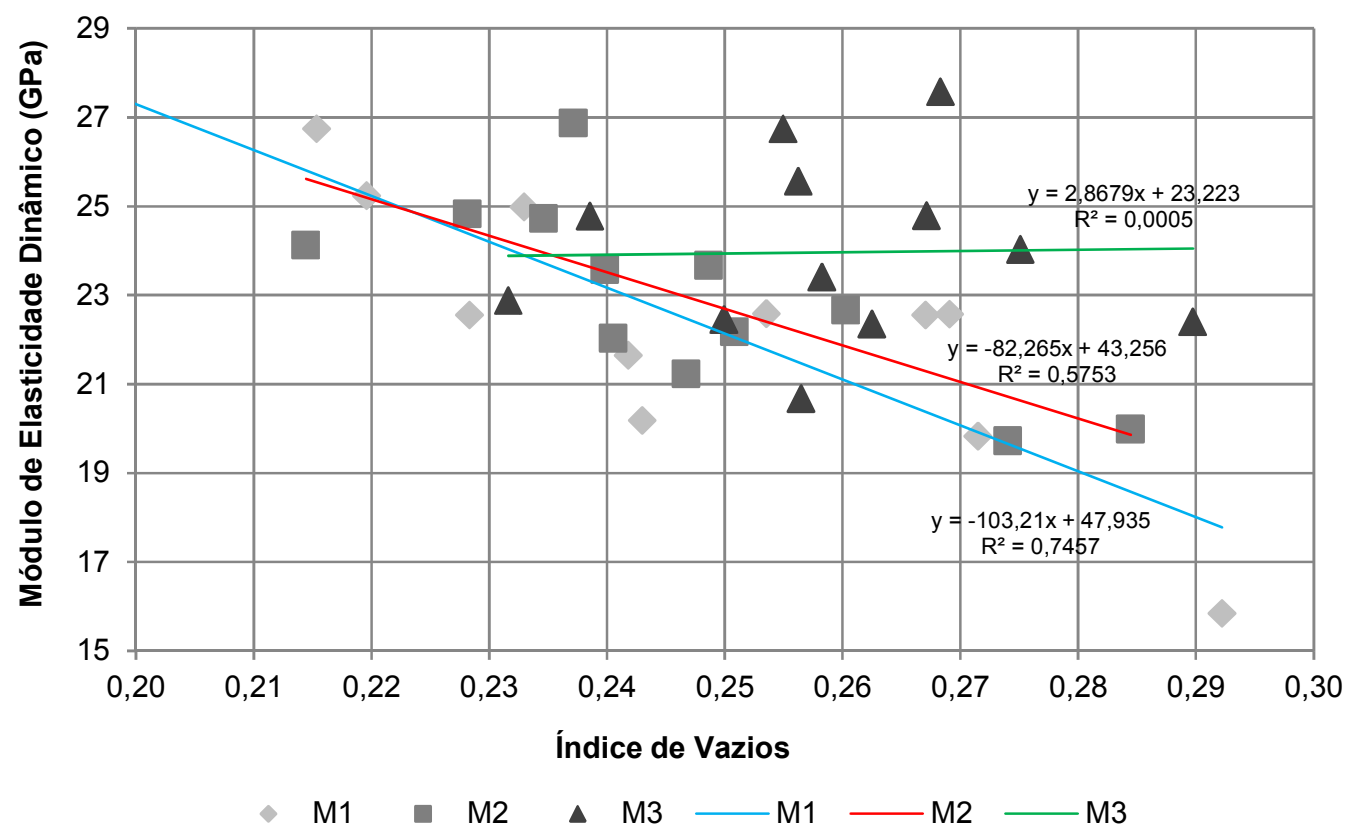

Figura 3.6: Módulo de elasticidade dinâmico em função do índice de vazios

\subsubsection{Resistência à Tração na Flexão X Índice de Vazios}

Na Figura 3.7 são apresentados os resultados obtidos nos testes de resistência à tração na flexão média aos 28 dias em função dos índices de vazios médios observados para as misturas ensaiadas em comparação com outros autores. 


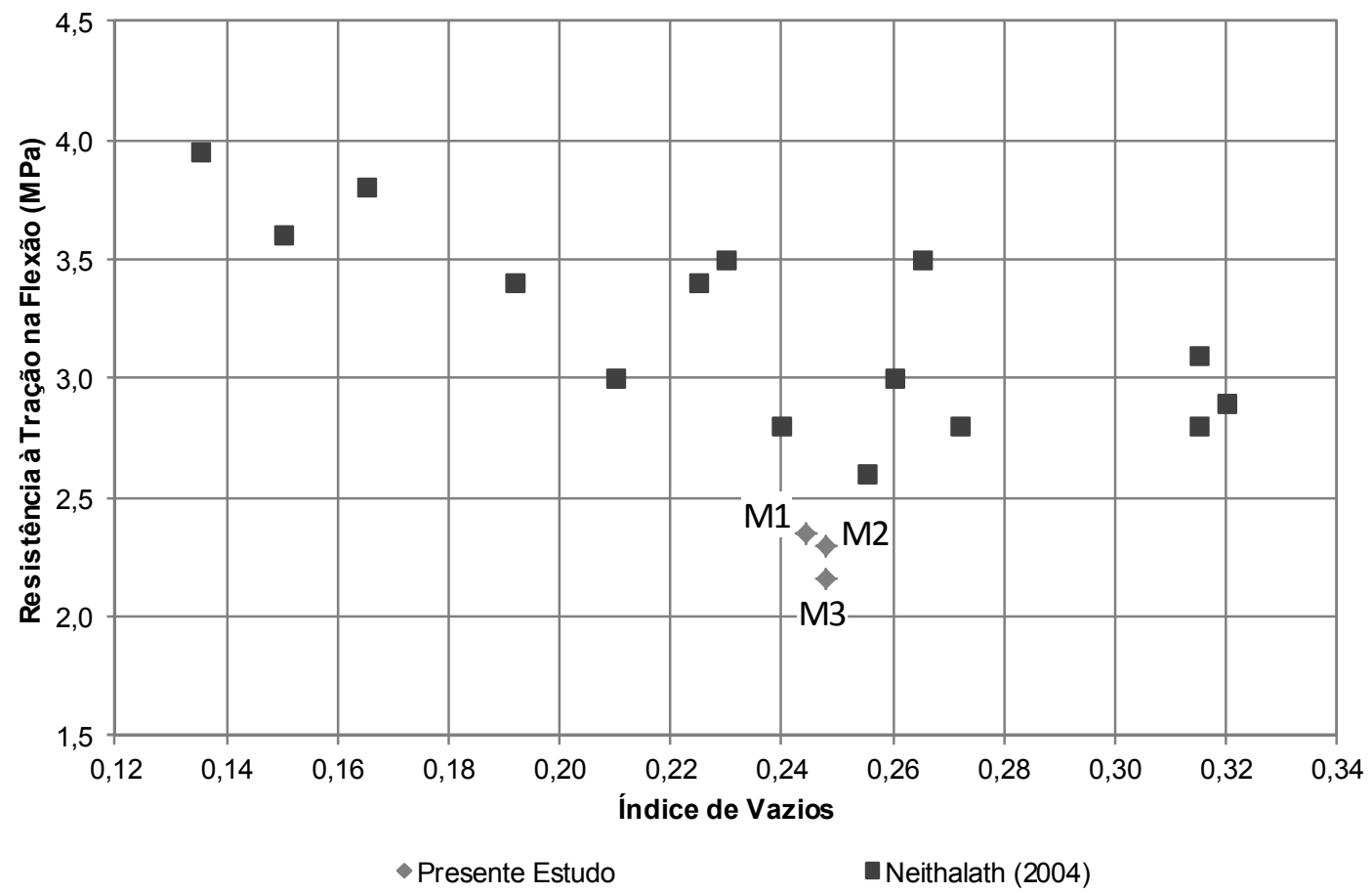

Figura 3.7: Comparação da variação da resistência à tração na flexão média em função do índice de vazios médio

Observa-se que os resultados obtidos de resistência à tração na flexão no presente estudo se encontram abaixo, porém próximos, aos valores encontrados por Neithalath (2004), o qual estudou misturas com granulometria contínua (diâmetro único - mesmo caso da mistura M2 do presente estudo) com agregados de 12,5 $\mathrm{mm}, 9,5 \mathrm{~mm}$ e $4,8 \mathrm{~mm}$ diâmetro.

A elevada faixa de variação do índice de vazios observada por este autor, considerando-se que a composição das misturas utilizadas é semelhante à composição empregada no presente estudo, deve-se ao procedimento de compactação aplicado, em que golpes de soquete Proctor foram usados na moldagem de algumas das misturas, aumentando-se assim a densidade do material com a consequentente redução do seu índice de vazios. 
3.7.7 Resistência à Tração Indireta por Compressão Diametral X Índice de Vazios

Na Figura 3.8 são apresentados os resultados obtidos nos ensaios de resistência à tração indireta em função dos índices de vazios, em comparação aos resultados de Delatte (2009).

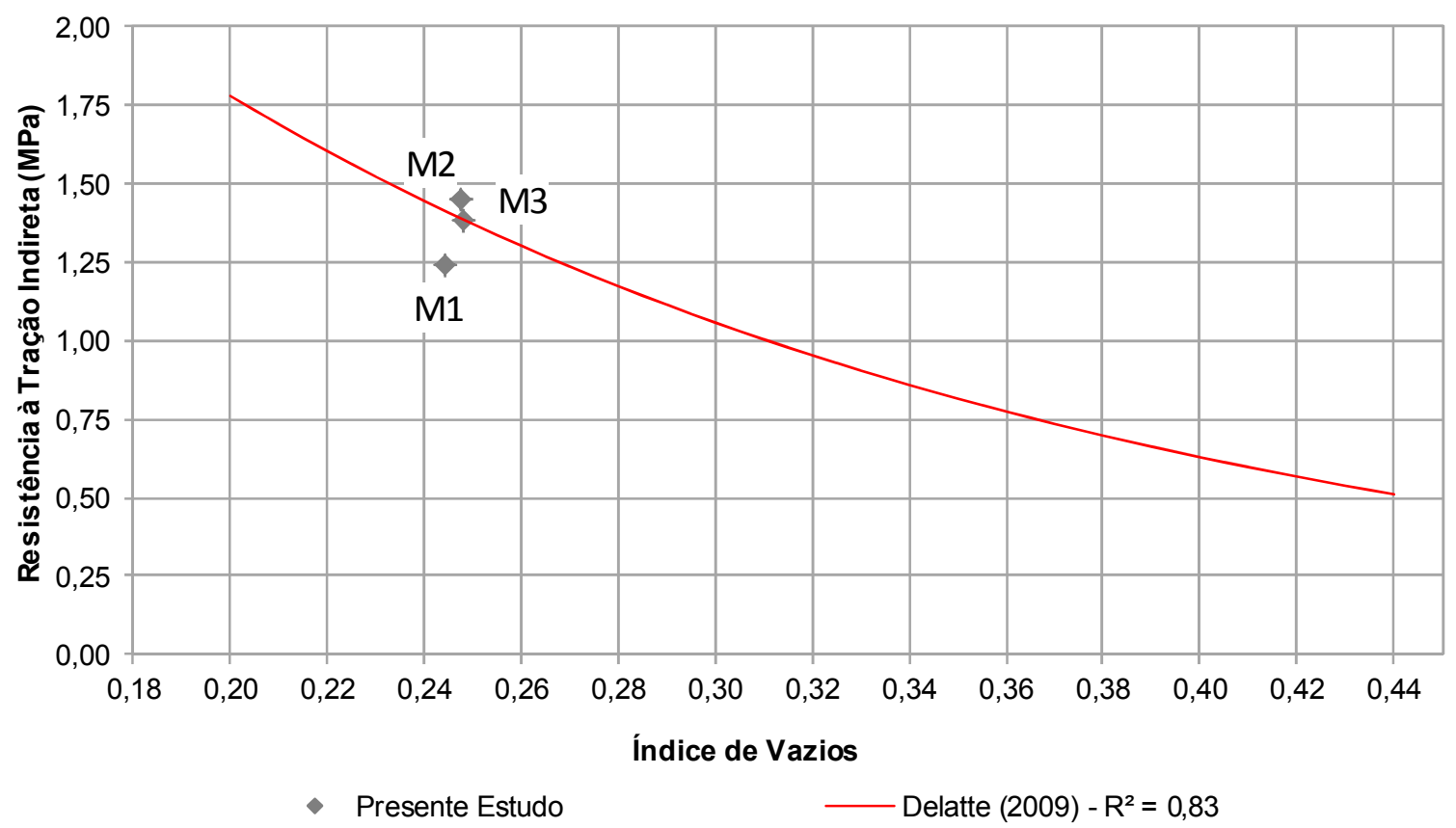

Figura 3.8: Comparação da variação da resistência à tração por compressão diametral média em função do índice de vazios médio

Delatte (2009) estudou uma grande faixa de índices de vazios e determinou a curva de tendência apresentada no gráfico com $R^{2}$ igual a 0,83 . Observa-se que para os valores de índices de vazios semelhantes, os resultados de resistência à tração indireta se apresentam muito próximos em ambas as pesquisas.

\subsubsection{Resistência à Compressão X Índice de Vazios}

Na Figura 3.9 são apresentados os resultados obtidos nos ensaios de resistência à compressão em função dos índices de vazios em comparação aos resultados de diversos autores. 


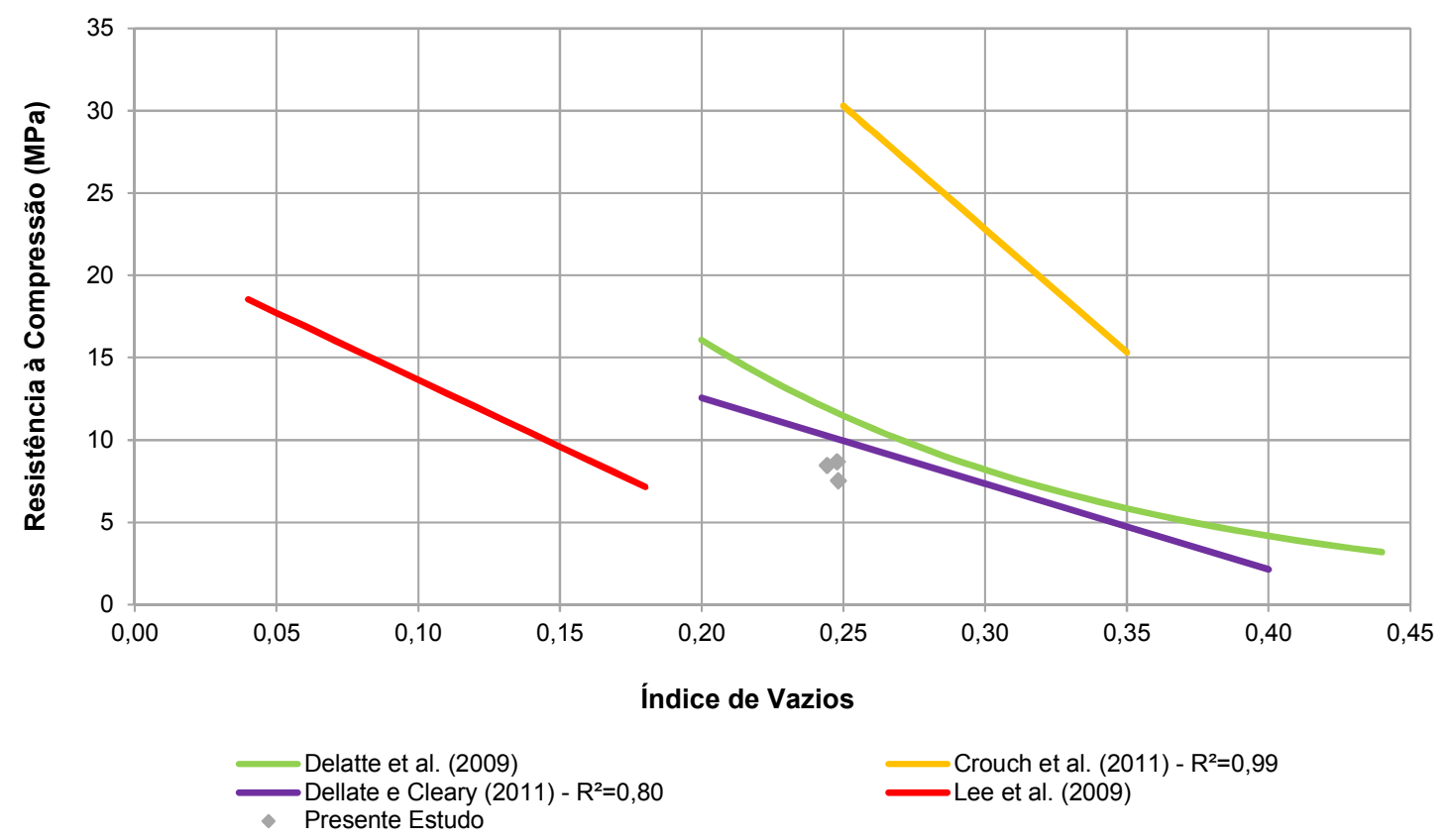

Figura 3.9: Comparação da variação da resistência à compressão média em função do índice de vazios médio

Observa-se que os resultados obtidos nas diferentes pesquisas apresentam grande variação. No caso do estudo realizado por Crouch et al. (2011), a resistência à compressão decresce linearmente com o aumento do índice de vazios. Já para Delatte et al. (2009) e Delatte e Cleary (2011), os valores de resistência à compressão tendem a decrescer exponencialmente com o aumento do índice de vazios.

Ao se comparar os valores de $\mathrm{R}^{2}$, observa-se que a tendência linear proposta por Crouch et al. (2011) apresenta uma menor variabilidade dos resultados obtidos quando comparado aos resultados dos demais autores, tornando esta hipótese estatisticamente mais confiável. Contudo, não foram encontradas publicações de outros autores apresentando valores de resistência a compressão tão elevados para uma faixa de índice de vazios também tão elevada como exposta no estudo de Crouch et al. (2011). 


\subsubsection{Condutividade Hidráulica X Índice de Vazios}

Na Figura 3.10 é apresentada a variação da condutividade hidráulica em função do índice de vazios da presente pesquisa em comparação aos resultados de outros autores, respectivamente.

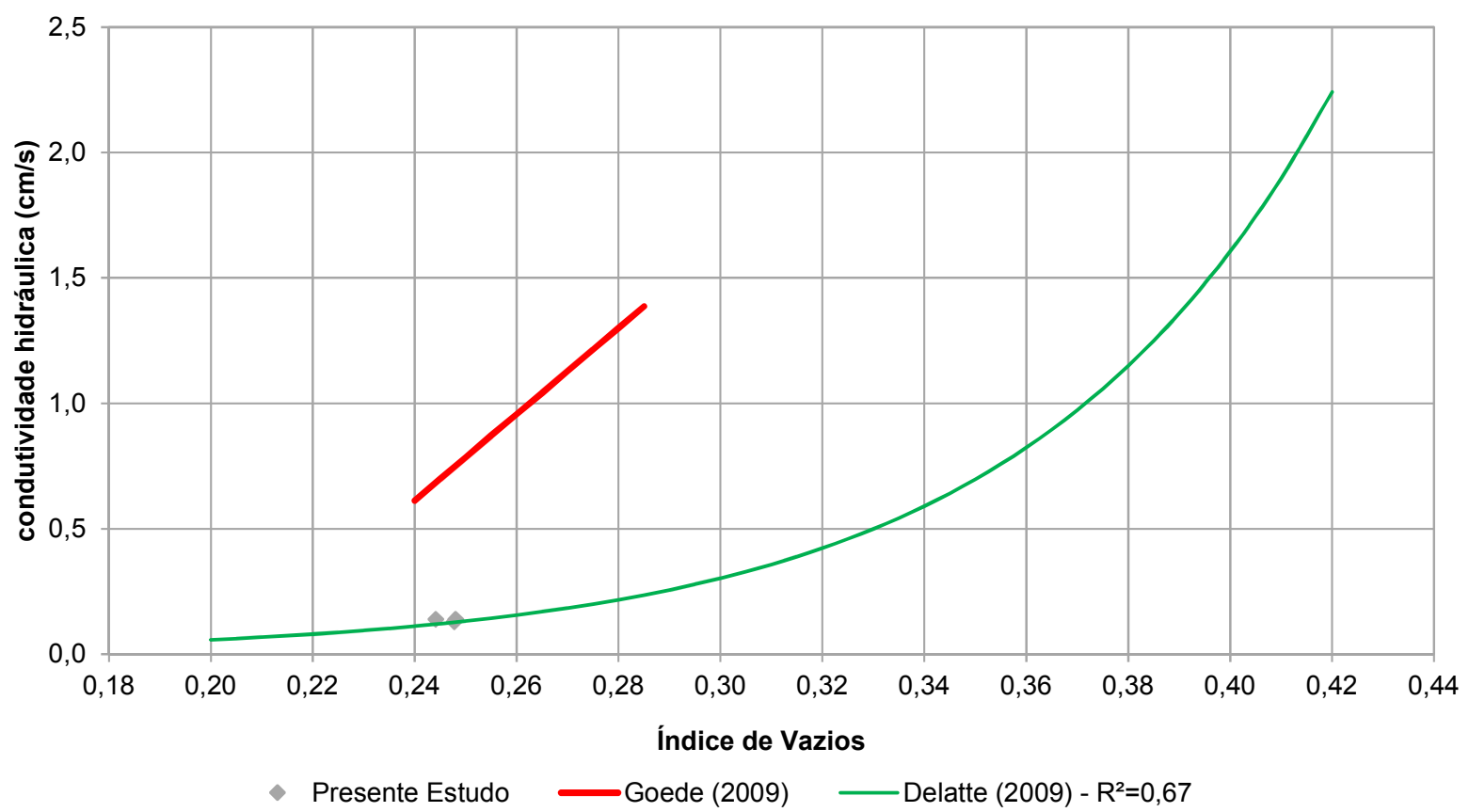

Figura 3.10: Comparação da variação da condutividade hidráulica em função do índice de vazios médio

Observa-se que os valores de condutividade hidráulica obtidos no presente estudo são muito semelhantes àqueles obtidos por Delatte (2009) para o índice de vazios de 0,25 , aproximadamente. Já Goede (2009) obteve valores de condutividade hidráulica aproximadamente 5 vezes maiores quando comparados aos resultados da presente pesquisa para índice de vazios igual a 0,25. 


\section{ANÁLISES MECANICISTAS}

A analogia considerada no âmbito de projetos para pavimentos de concreto relaciona a tensão atuante de tração na fibra inferior da placa de concreto devido aos efeitos do tráfego e do clima com a resistência à tração na flexão do material. Dessa maneira, o estudo laboratorial deve estar aliado a um estudo mecanicista, em que pode ser definida uma distribuição de tensões em placas de concreto sobre determinadas camadas de estruturas de pavimento, possibilitando-se dessa maneira determinar qual é a relação entre a tensão atuante e a tensão resistente do material.

Desse modo, para o adequado estudo e reflexão sobre a aplicabilidade de tais revestimentos com comportamento mais semelhante às estruturas de pavimentos rígidos, foram conduzidas análises mecanicistas por meio da estimativa das tensões de tração na flexão oriundas do carregamento de dois tipos de veículos que possam solicitar estas estruturas.

\subsection{METODOLOGIA}

Utilizou-se para a realização das análises mecanicistas o Método dos Elementos Finitos (MEF), que permite avaliar os efeitos de cargas de veículos em estruturas de pavimentos. O programa utilizado foi o EverFe versão 2.24. Esse programa foi desenvolvido pela Universidade de Maine - EUA, sem fins lucrativos, sendo um software livre (Davids et al., 2003).

O EverFE é um programa de análise 3D por elementos finitos utilizado para simulação de carregamentos e cálculo das tensões e deformações de sistemas de placas de concreto submetidos tanto ao carregamento por eixos de veículos quanto por variações climáticas.

$\mathrm{Na}$ etapa inicial das análises mecanicistas foi realizado um estudo de caso considerando a aplicação de uma carga do eixo padrão de $80 \mathrm{kN}$ sobre uma placa de concreto de $3,5 \times 5,0 \mathrm{~m}$, com bordas livres. Nas Figuras 4.1 e 4.2 estão 
apresentadas a tela inicial do software com as dimensões da placa empregada nas análises, bem como as dimensões do eixo simples de roda dupla de $80 \mathrm{kN}$ considerado.

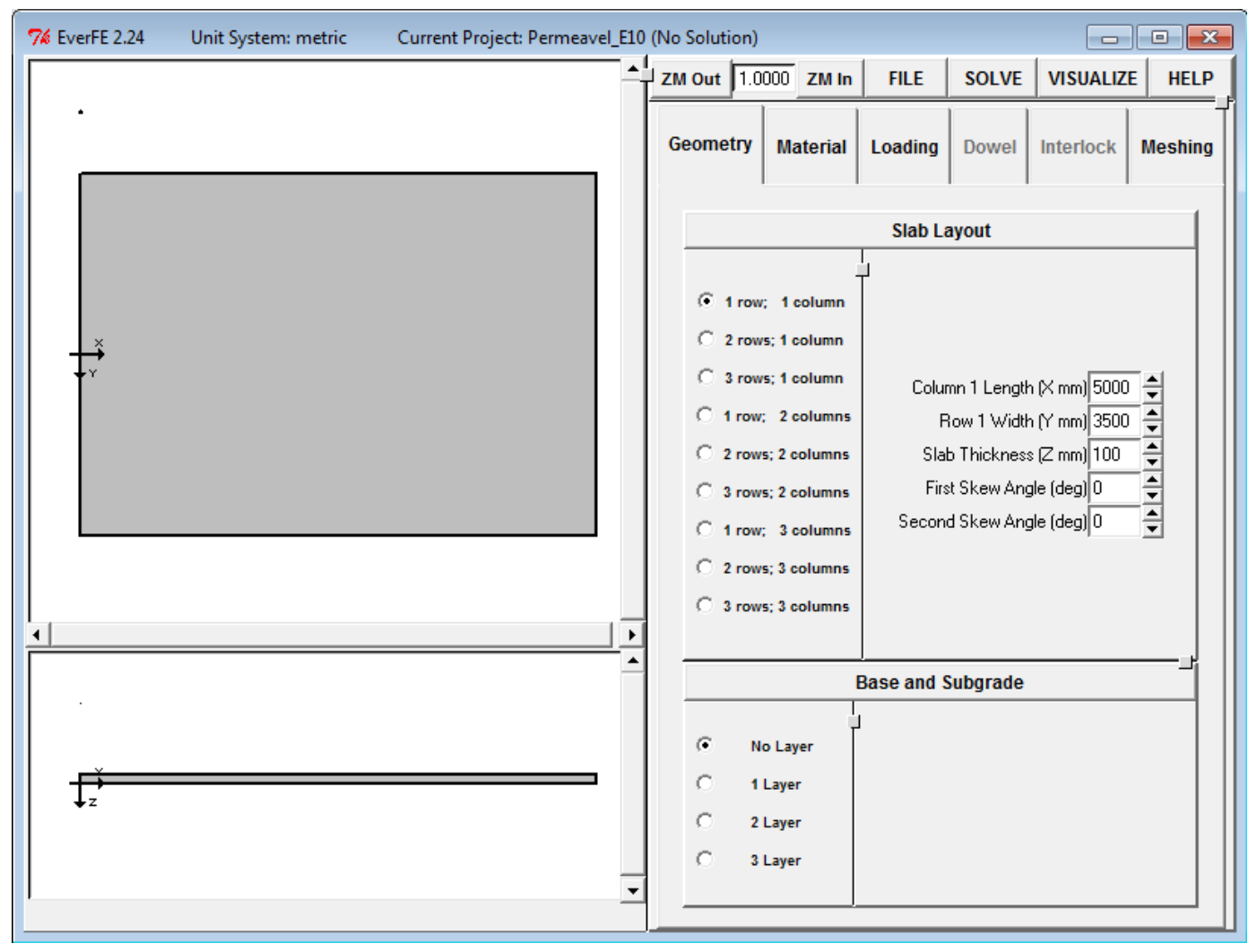

Figura 4.1: Tela inicial do programa com dados da placa estudada

Em um segundo momento, as simulações foram realizadas considerando um eixo de rodas simples com carga de $22 \mathrm{kN}$, o qual caracteriza um veículo utilitário comercial. Nessa etapa tomou-se por base que o pavimento permeável seria implantado em um estacionamento de Shopping Center, com restrição de acesso aos veículos pesados. Nas Figuras 4.3 e 4.4 são apresentados um esquema das dimensões do veículo e o posicionamento crítico do eixo sobre a placa, respectivamente. 


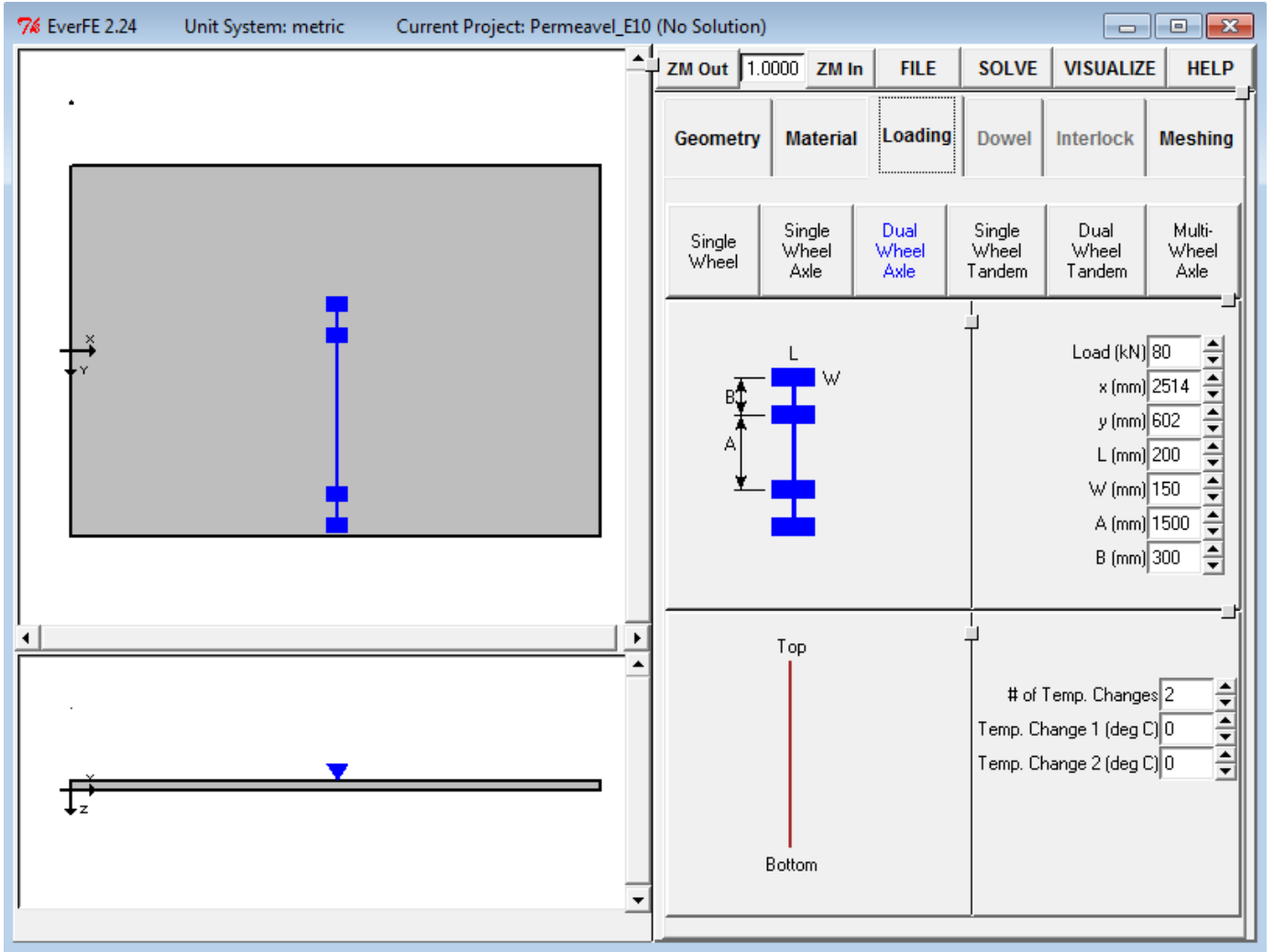

Figura 4.2: Eixo de $80 \mathrm{kN}$
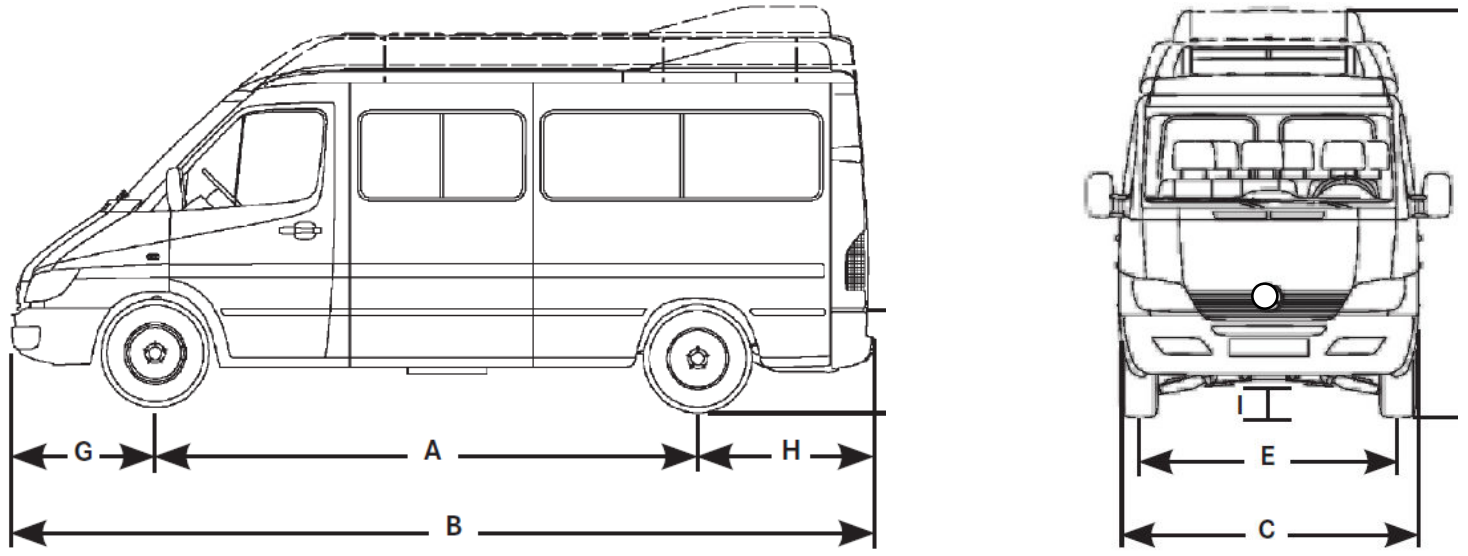

Figura 4.3: Esquema do veículo utilitário

Sendo:

$$
\begin{aligned}
& A=300 \mathrm{~cm} ; \\
& B=489 \mathrm{~cm} ; \\
& C=192,2 \mathrm{~cm} ; \\
& E=163,8 \mathrm{~cm} ; \\
& G=93,9 \mathrm{~cm} ; \\
& H=95 \mathrm{~cm} .
\end{aligned}
$$




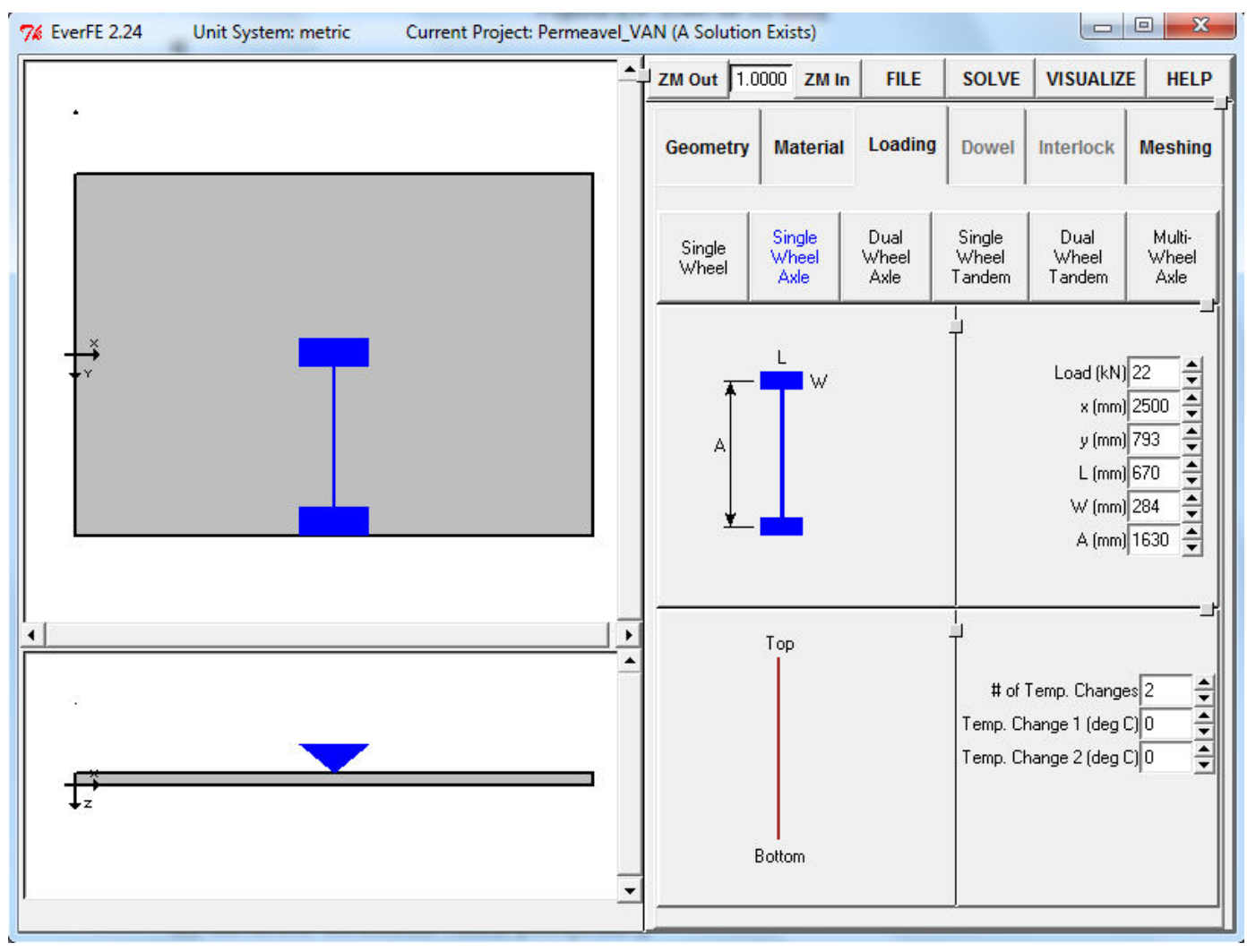

Figura 4.4: Eixo de 22 kN

Foram realizadas várias análises preliminares com a variação da posição do eixo sobre a placa com a finalidade de verificar qual a posição crítica do eixo em função das tensões geradas. A disposição apresentada nas Figuras 4.2 e 4.4 , na borda transversal da placa, foi a posição crítica adotada para as demais análises.

Não foram utilizadas camadas de base e sub-base durante as análises, sendo que estas foram substituídas por um módulo de reação do subleito (k). Antes do início efetivo das análises, foram realizados testes com vários valores de $k$ e determinouse que a sua variação influi muito pouco nas tensões determinadas. Consequentemente, foi fixado um valor de $\mathrm{k}$ de $0,05 \mathrm{MPa} / \mathrm{mm}$ para todas as análises, considerando um subleito de qualidade mediana.

Para o concreto permeável, os parâmetros considerados de módulo de elasticidade e de resistência à tração na flexão foram os resultados médios aproximados obtidos na etapa laboratorial do presente estudo. Já o coeficiente de Poisson foi empregado de acordo com o estudo realizado por Goede (2009), que determinou em laboratório 
o valor do coeficiente de Poisson de um concreto com características semelhantes ao concreto analisado na presente pesquisa.

Para fins de comparação, foi também simulado, utilizando as mesmas cargas e dimensões da placa e do eixo de $80 \mathrm{kN}$, um revestimento de concreto convencional, empregando-se os parâmetros médios de pavimentos rígidos comumente encontrados na literatura. A Tabela 4.1 apresenta os parâmetros elásticos e de resistência utilizados para cada material.

Tabela 4.1: Parâmetros de resistência utilizados nas análises mecanicistas

\begin{tabular}{lcc}
\hline \multicolumn{1}{c}{ Material } & $\begin{array}{c}\text { Concreto } \\
\text { Permeável }\end{array}$ & $\begin{array}{c}\text { Concreto } \\
\text { Convencional }\end{array}$ \\
\hline \hline Módulo de Elasticidade (MPa) & 15.000 & 28.000 \\
\hline Coeficiente de Poisson & 0,22 & 0,15 \\
\hline $\begin{array}{l}\text { Resistência à Tensão na Flexão } \\
(\mathrm{MPa})\end{array}$ & 2,13 & 4,50 \\
\hline \hline
\end{tabular}

Rodden e Smith (2011) expuseram um estudo de caso de dimensionamento estrutural e hidrológico de pavimentos de concreto permeável, utilizando uma resistência à tração na flexão de $2 \mathrm{MPa}$ e módulo de elasticidade de $13.500 \mathrm{Mpa}$ para a camada de revestimento, sendo estes valores de parâmetros sugeridos pela American Concrete Pavement Association (ACPA) em projetos de pavimentos com revestimento em concreto permeável. Observa-se grande semelhança entre os valores sugeridos pela ACPA e os valores obtidos na presente pesquisa.

Cabe ressaltar que para realização das análises mecanicistas foi utilizado o modelo elástico linear que considera o concreto permeável como um material homogêneo isotrópico. Porém, devido à elevada quantidade de poros característicos desse material, pode ser que esse modelo seja insuficiente para a obtenção das tensões reais a serem geradas nas placas devido ao carregamento dos veículos.

Previamente ao início das análises mecanicistas foi efetuado um estudo comparativo da malha de elementos finitos a ser utilizada. Pode-se perceber que quanto mais refinada era a malha, mais elevados eram os resultados das tensões nas placas. 
Porém, sabe-se que quanto maior o número de elementos, maior será o tempo de processamento para realização das análises. Portanto, foram realizadas análises com diferentes refinamentos de malha, sendo que a malha final foi escolhida quando os acréscimos de tensões verificados tornaram-se desconsideráveis. Na Figura 4.5 é apresentada a malha utilizada nas análises.

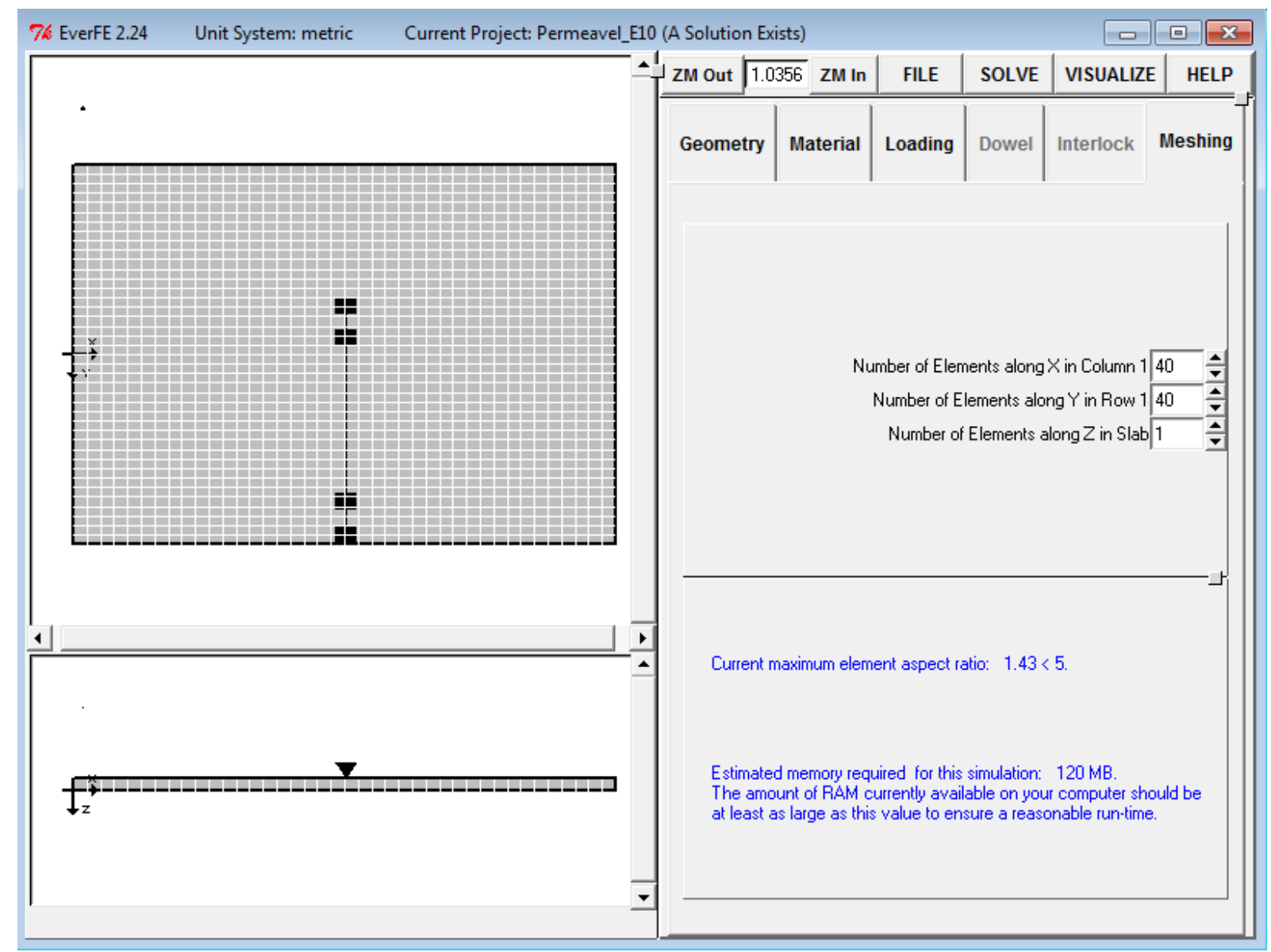

Figura 4.5: Malha de elementos finitos

\subsection{RESULTADOS}

Na Figura 4.6 são apresentados os resultados da variação da tensão máxima de tração em função da variação das espessuras da placa tanto para o concreto permeável quanto para o concreto convencional. 


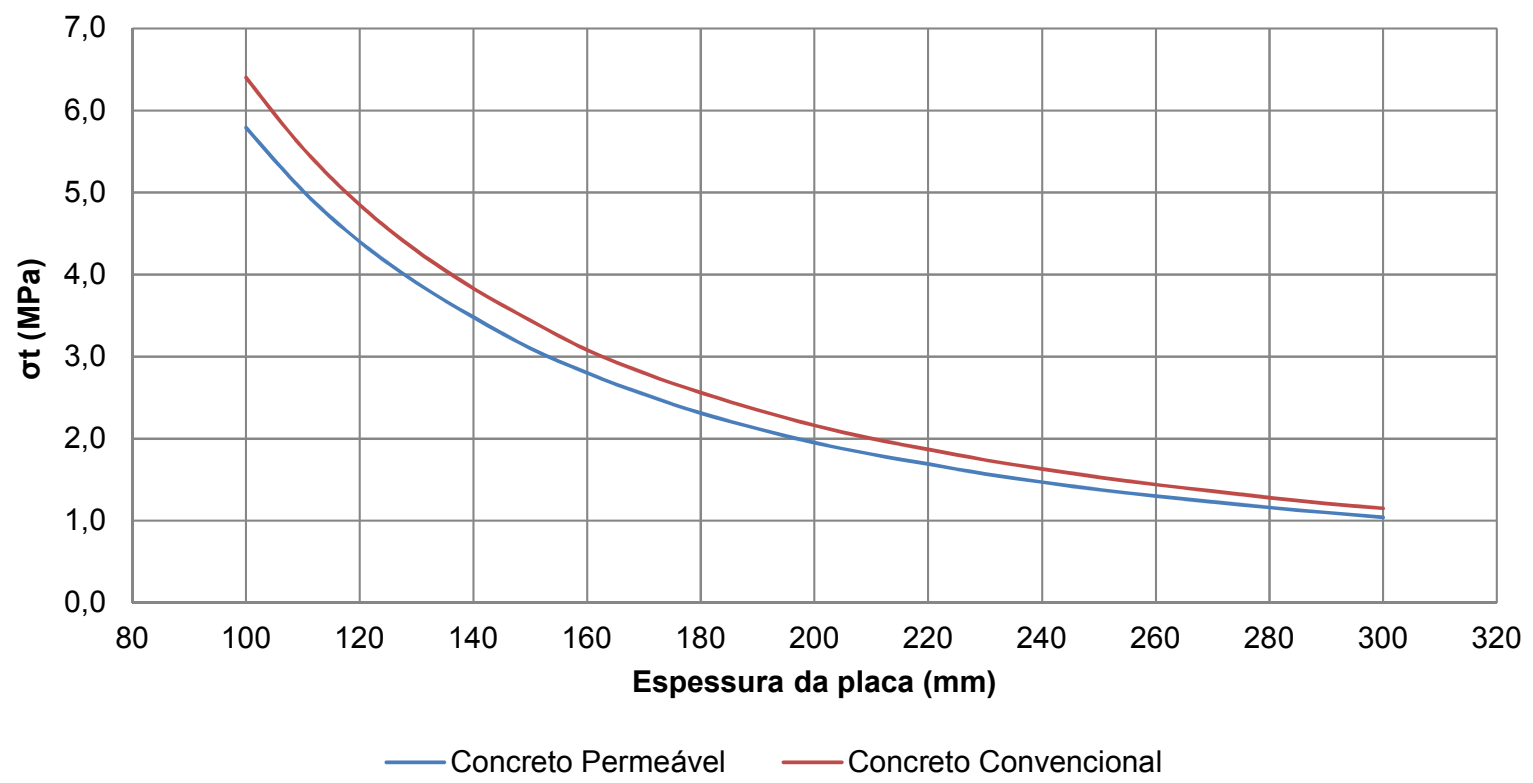

Figura 4.6: Tensões máximas de tração em função da variação das espessuras da placa

Observa-se que nas estruturas com revestimento em concreto convencional, as tensões de tração máximas atuantes ocasionadas pelo carregamento do eixo de 80 kN são mais elevadas, independentemente da espessura das placas. Isso ocorre em função do módulo de elasticidade do concreto convencional ser superior ao do concreto permeável, conferindo maior rigidez ao concreto convencional para mesmas espessuras, fazendo com que este absorva tensões mais elevadas.

Na Figura 4.7 é apresentada a variação da relação entre tensões de tração atuantes e tensões resistentes (RT) em função das espessuras da placa para o carregamento do eixo de $80 \mathrm{kN}$.

O modelo de fadiga da Portland Cement Association - PCA (1984) para pavimentos de concreto sugere que estruturas que apresentem RT inferiores a 0,45 não serão submetidas à perda de resistência por fadiga. No gráfico, a RT limitante de 0,45 é representada pela linha tracejada vermelha. 


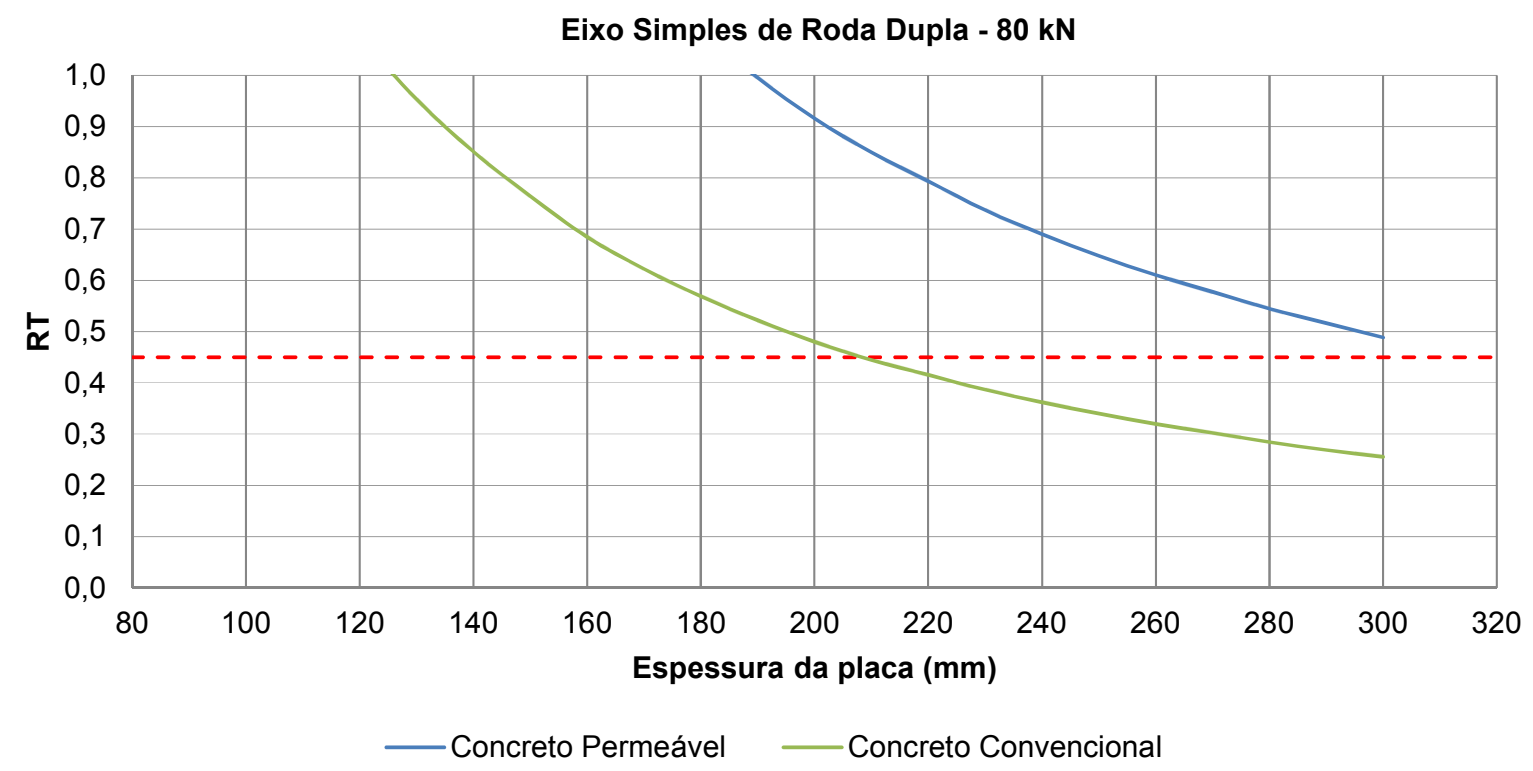

Figura 4.7: Variação da RT em função da espessura da placa

Observa-se que no caso do concreto convencional, para espessuras de placa superiores a $20 \mathrm{~cm}$, obtém-se valores de relações entre tensões inferiores a 0,45 para o eixo analisado. Já para a placa de concreto permeável, observa-se que mesmo para as maiores espessuras de placa (teoricamente aplicáveis na prática), a RT nunca é menor que 0,45. Tal ocorrência sugere que o concreto permeável estudado na presente pesquisa não demonstra resistência suficiente para ser utilizado como revestimento para áreas de tráfego com cargas elevadas.

Ressalta-se que esta relação entre tensões considerada no método da PCA (1984) é aplicável para concretos convencionais, que apresentam uma microestrutura muito diferente da de concretos permeáveis, que, em função de sua porosidade muito elevada, podem exibir uma condição totalmente diferente de evolução de dano causada por carregamentos cíclicos, sendo que este limite de RT pode variar muito de material para material. Nesse caso, o ideal seria realizar estudos aprofundados de tenacidade e resistência à fadiga do concreto permeável com a finalidade de melhor entender como a condição de fadiga tende a evoluir nesse material, sugerindo assim uma RT mais apropriada.

Por fim, observa-se também que, para espessuras de placa de concreto convencional e de concreto permeável inferiores a 13 e $19 \mathrm{~cm}$, respectivamente, 
ocorre a ruptura da placa com somente uma passagem do veículo de análise, uma vez que a tensão de tração na fibra inferior gerada na placa devido a aplicação da carga se iguala a tensão resistente do material, ou seja, a RT se iguala a 1.

Na Figura 4.8 está apresentada a variação da RT em função das espessuras das placas, considerando o eixo com carga de $22 \mathrm{kN}$, referente ao veículo utilitário considerado.

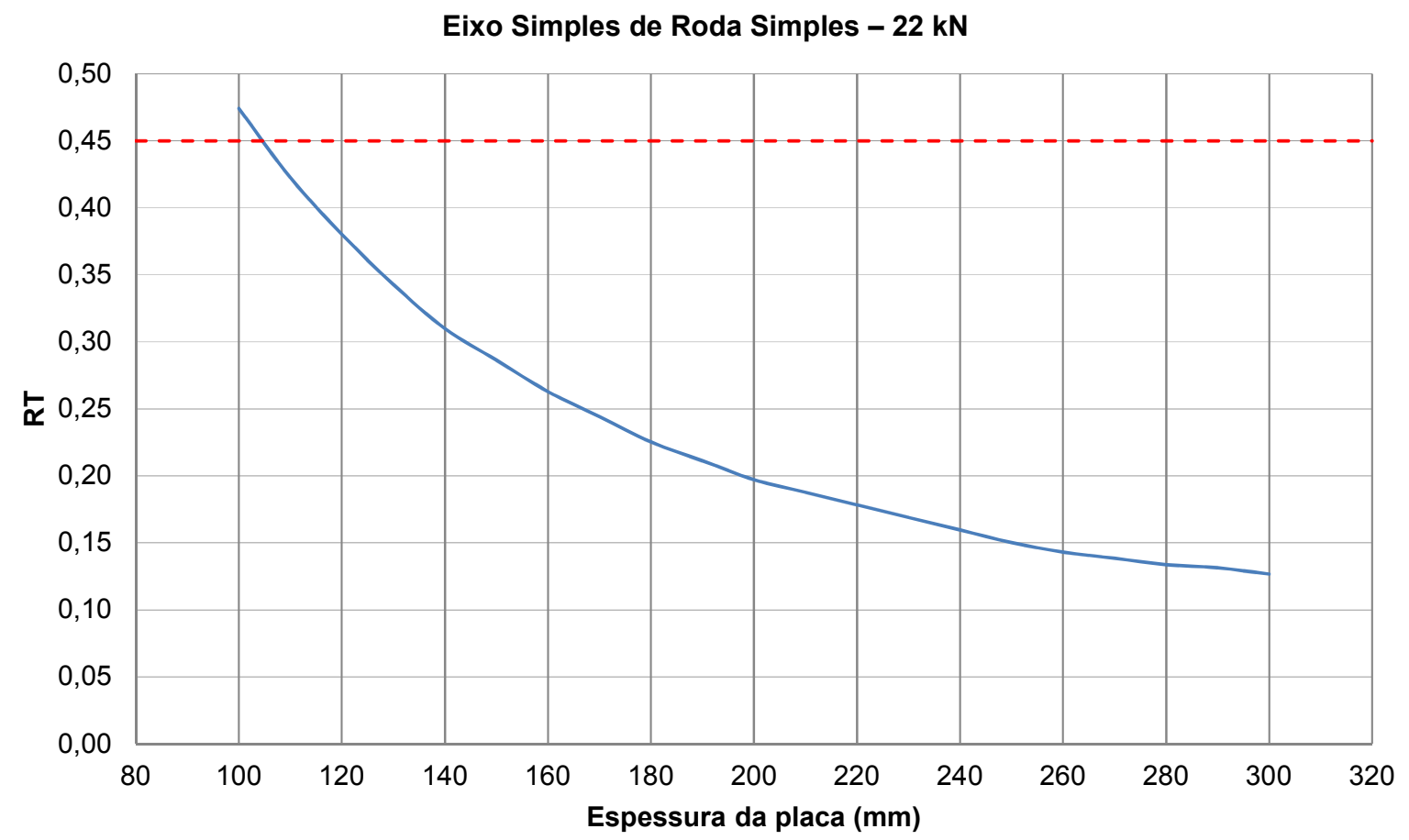

Figura 4.8: Variação da RT em função da espessura das placas de concreto permeável

Observa-se que para a carga considerada, os valores de RT resultaram inferiores a 0,45 para espessuras de placa acima de $110 \mathrm{~mm}$. Dessa maneira, considera-se que esse material pode ser empregado como revestimento de um pavimento no qual a carga máxima aplicada não ultrapasse aquela considerada nas análises realizadas. Cabe lembrar que tal situação é válida tomando por base que a limitação ou condição crítica para ruptura da estrutura seja a vida de fadiga, e que o modelo da PCA seja adequado a este material.

Segundo a U.S. Environmental Protection Agency (2012), as espessuras de revestimentos em concreto permeável variam normalmente entre 100 e $200 \mathrm{~mm}$, quando utilizados em áreas de veículos leves. Nesse sentido, em função da boa 
coerência nos resultados apresentados quando comparados às espessuras comumente utilizadas na prática, pode-se sugerir que a implantação de placas moldadas com o concreto em estudo com espessuras acima de $110 \mathrm{~mm}$ podem ser empregadas como revestimento de pavimentos permeáveis implantados em áreas de veículos leves. Cabe ressaltar que estas considerações são baseadas em avaliações estruturais, uma vez que, dependendo do dimensionamento hidráulico, mesmo que uma placa com espessura de $110 \mathrm{~mm}$ seja aceita com relação à sua resistência mecânica, poderá necessitar de espessuras maiores devido às características hidrológicas locais.

Nas Figuras 4.9 e 4.10 são apresentadas respectivamente a distribuição das tensões geradas no topo e no fundo de uma placa de concreto permeável com $110 \mathrm{~mm}$ de espessura quando solicitada pela carga do eixo simples de roda dupla de $80 \mathrm{kN}$.
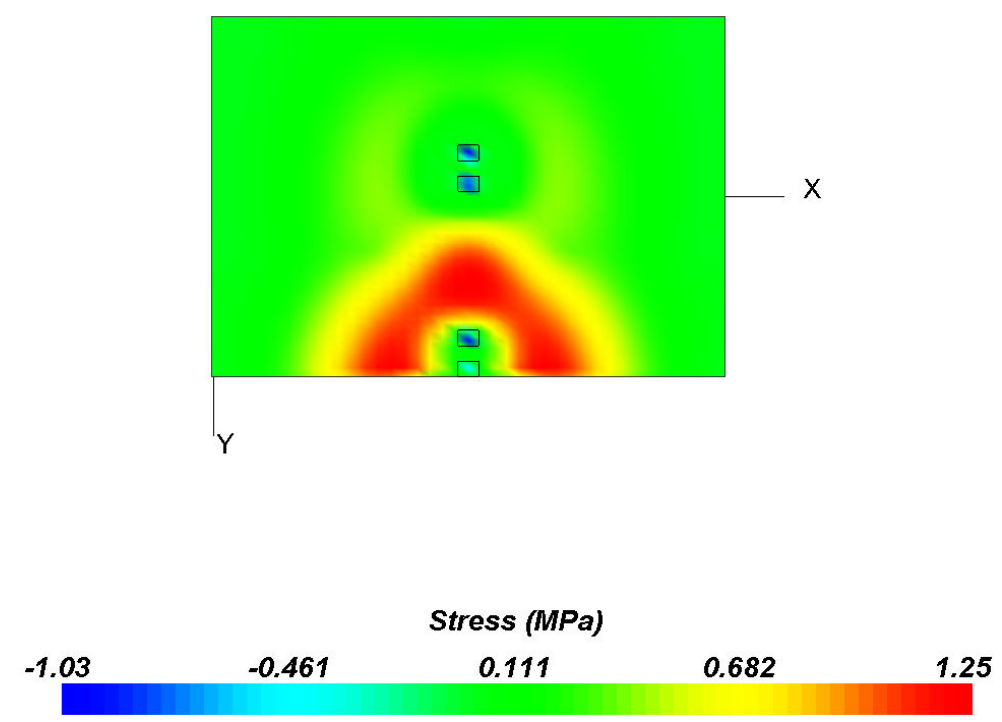

Figura 4.9: Distribuição das tensões no topo da placa em função da solicitação do eixo de 80 $\mathrm{kN}$ 


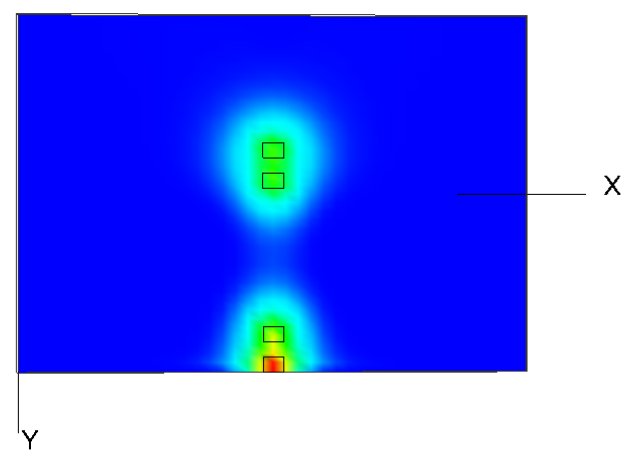

\begin{tabular}{ccccc}
\multicolumn{5}{c}{ Stress (MPa) } \\
-0.0133 & 1.25 & 2.50 & 3.76 & 5.02
\end{tabular}

Figura 4.10: Distribuição das tensões no fundo da placa em função da solicitação do eixo de $80 \mathrm{kN}$

Observa-se que a tensão máxima de tração gerada no fundo da placa foi de $5,02 \mathrm{MPa}$, ou seja, na ordem de quatro vezes mais elevadas do que a tensão máxima de tração gerada no topo da placa, que foi de 1,25 MPa.

Na Figura 4.11 são apresentadas as tensões obtidas no fundo de uma placa de $110 \mathrm{~mm}$ de espessura quando solicitada por um eixo simples de roda simples com carga de $22 \mathrm{kN}$.
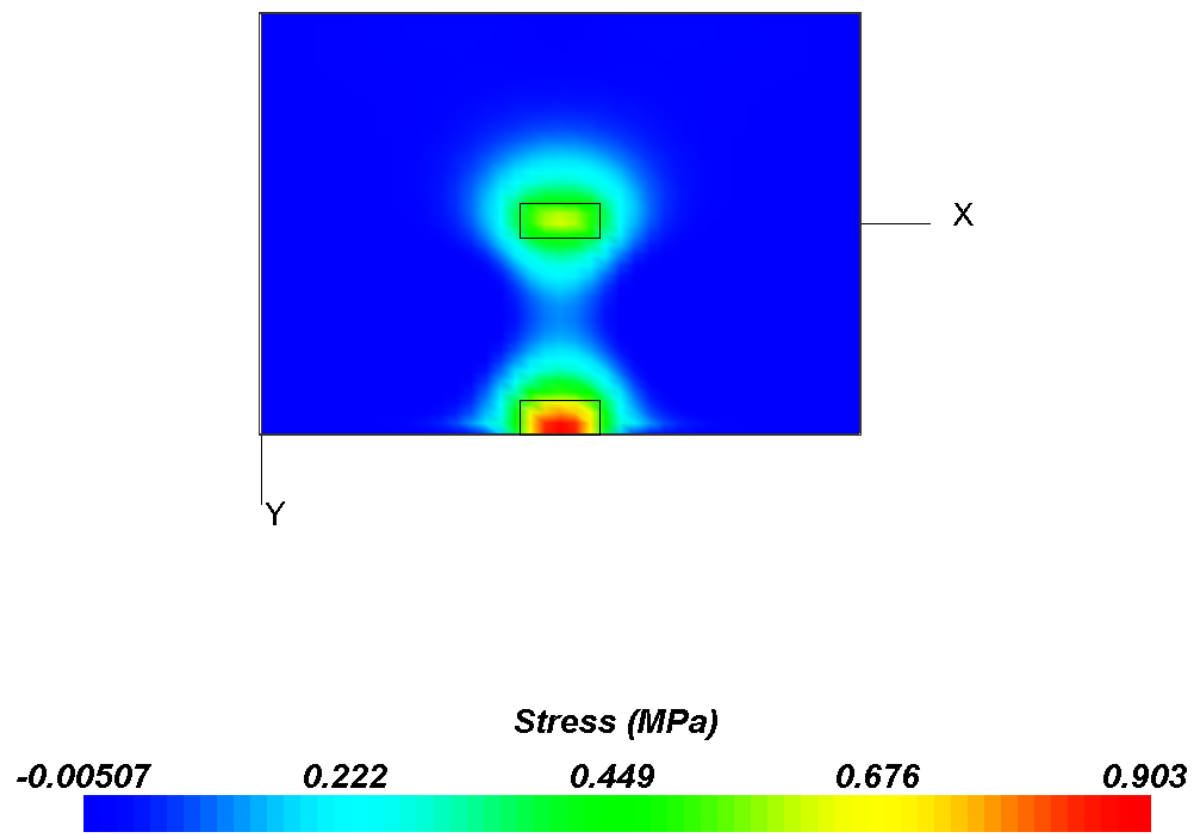

Figura 4.11: Distribuição das tensões no fundo da placa em função da solicitação do eixo de $22 \mathrm{kN}$ 
Observa-se que a tensão máxima gerada na placa submetida à solicitação do eixo com carga de $22 \mathrm{kN}$ é de 0,903 MPa, ou seja, aproximadamente cinco vezes menor quando comparado à tensão máxima na placa submetida ao carregamento do eixo com carga de $80 \mathrm{kN}$.

Nas Figuras 4.12 e 4.13 são apresentadas de maneira qualitativa as deformações ocorridas na placa com espessura de $110 \mathrm{~mm}$ em função da variação da carga aplicada pelos diferentes eixos empregados nas análises.

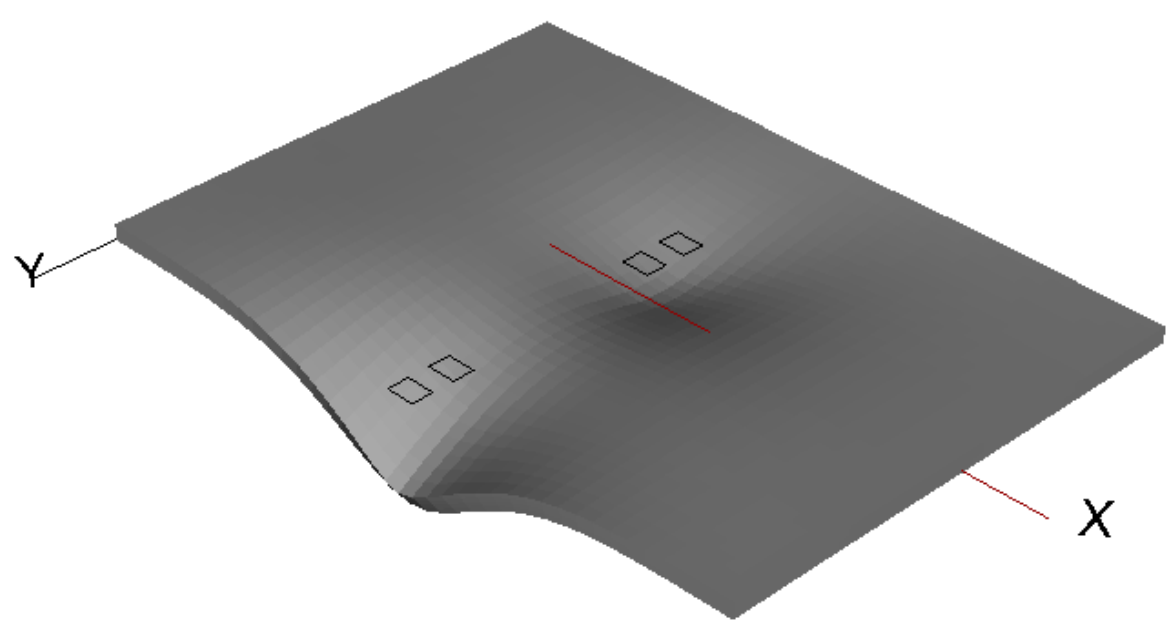

Figura 4.12: Deformação gerada em função da solicitação do eixo de 80 kN

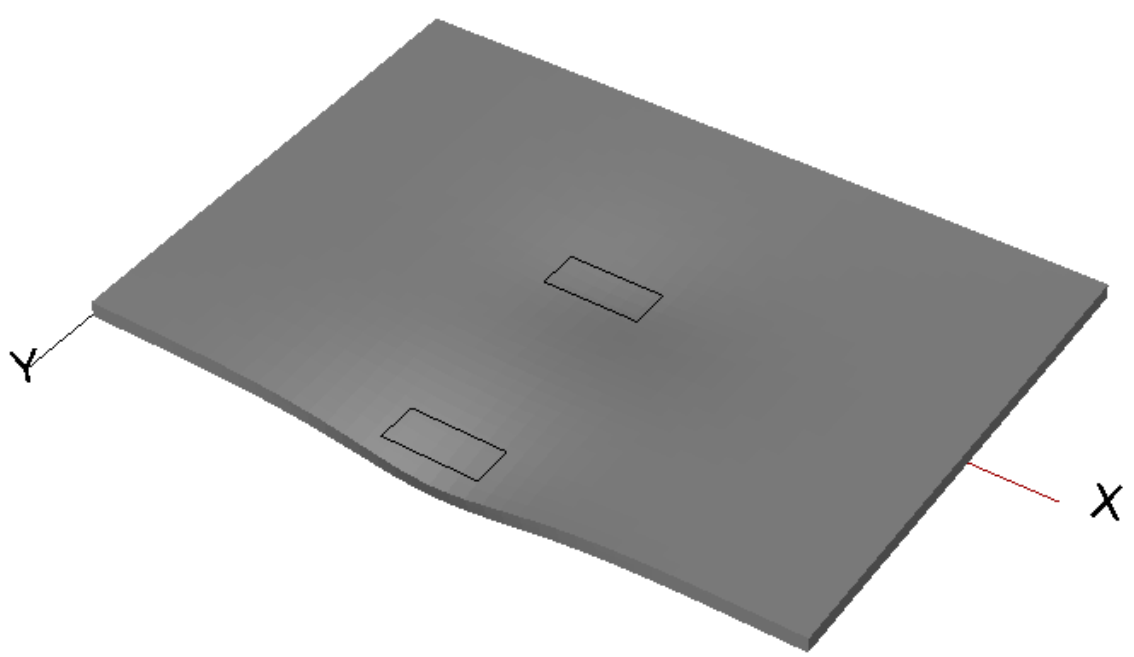

Figura 4.13: Deformação gerada em função da solicitação do eixo de 22 kN 
Verifica-se qualitativamente que as deformações ocorridas referentes às solicitações do eixo de $80 \mathrm{kN}$ são muito mais elevadas quando comparadas às deformações devidas às solicitações do outro eixo, considerando que a escala de deformação é a mesma para as duas figuras. Além disso, observa-se que a deformação na borda é ligeiramente maior do que a deformação ocorrida no centro da placa. 


\section{CONCLUSÕES E RECOMENDAÇÕES}

O trabalho de pesquisa realizado permitiu elaborar as seguintes conclusões principais:

- Os testes realizados mostraram que os resultados de ensaios destrutivos em corpos de prova de concreto permeável são tipicamente mais variáveis que os resultados de ensaios em misturas convencionais de concreto. Esta ocorrência se dá principalmente devido aos elevados índices de vazios característicos desse tipo de concreto, o que tende a aumentar a variabilidade dos resultados. No caso dos ensaios não destrutivos, notou-se menor variabilidade dos resultados;

- $\quad$ Pode-se notar que as três misturas não apresentaram variação considerável dos resultados para praticamente todos os parâmetros avaliados no presente estudo, ou seja, a faixa de variação do diâmetro máximo dos agregados utilizada não influenciou de maneira considerável nas características dos concretos permeáveis produzidos;

- $\quad$ Foi observado que as resistências à tração na flexão obtidas para estas misturas específicas estudadas se mostraram em média 50\% inferiores às resistências características de concretos convencionais para pavimentação. $O$ mesmo caso ocorreu para o módulo de elasticidade, que foi também reduzido para esta mesma taxa, aproximadamente;

- $\quad$ Observou-se que as misturas estudadas se mostraram como um bom material drenante, apresentando condutividades hidráulicas dentro da faixa de valores observadas na revisão da literatura. Nesse caso, nota-se a possibilidade de incluir nas misturas de concreto permeável certa quantidade de agregado miúdo bem como de adições, melhorando assim a sua resistência mecânica e mantendo a condutividade hidráulica compatível com aquelas utilizadas na prática; 
- No caso das análises mecanicistas observa-se que as placas de concreto permeável, em função de apresentarem um módulo de elasticidade reduzido, absorvem menores tensões quando comparadas às placas de concreto convencional para mesmas espessuras. Além disso, para carregamentos do eixo padrão de $80 \mathrm{kN}$ as placas de concreto permeável necessitam de espessuras impraticáveis para atender aos requisitos de vida de fadiga, tomando-se por base o conceito de relações entre tensões (RT) da PCA 0,45. Verificou-se também que para condições de carregamentos características de um estacionamento de shopping center, por exemplo, onde se considerou como carregamento crítico o eixo de um veículo utilitário de $22 \mathrm{kN}$, a limitação por fadiga deixa de ser o caso crítico, uma vez que as relações entre a tensão atuante e a tensão resistente são muito reduzidas, até mesmo para as menores espessuras de placas estudadas;

- Finalmente, comparando os resultados das análises mecanicistas realizadas com as espessuras comumente empregadas na prática, nota-se que espessuras de revestimentos maiores ou iguais a $110 \mathrm{~mm}$ (para as misturas utilizadas nesta pesquisa) podem ser utilizadas em pavimentos permeáveis implantados em áreas de tráfego de veículos leves, levando em consideração a sua resistência mecânica. Vale lembrar que essas considerações são válidas considerando que o concreto permeável estudado é um material homogêneo e isotrópico.

Em vista dos tangíveis benefícios econômicos e ambientais advindos do uso de estruturas de pavimento revestidos com concreto permeável, torna-se indispensável a continuidade de estudos que possam analisar com maior exatidão quais são os fatores que influenciam no comportamento deste material em pista. Nesse trabalho foram estudados somente aspectos de resistência mecânica e a condutividade hidráulica de amostras moldadas em laboratório. Sendo assim, seguem algumas sugestões para temas futuros para continuação deste projeto: 
- Produzir misturas com incorporação limitada de agregado miúdo, adições e aditivos;

- Análise microscópica que possibilite uma interpretação mais detalhada do comportamento microestrutural do concreto permeável;

- $\quad$ Comportamento do concreto permeável quanto à tenacidade e à fratura;

- Comportamento do concreto permeável quanto à fadiga;

- Comportamento de misturas de concreto permeável quanto ao desgaste e abrasão;

- Definição de um procedimento racional de dosagem de concretos permeáveis, tomando por base o índice de vazios;

- Implantação de pista experimental para estudo conjunto das propriedades mecânicas e hidráulicas do material quando submetido a carregamentos reais;

- Busca de critérios de projeto empírico mecanicistas para o dimensionamento dessas estruturas, considerando outros modelos constitutivos para análise mais realista do material. 


\section{REFERÊNCIAS BIBLIOGRÁFICAS}

ASSOCIAÇÃO BRASILEIRA DE NORMAS TÉCNICAS. NBR NM 15: Cimento Portland - determinação de resíduo insolúvel. Rio de Janeiro, 2004.

. NBR NM 18: Cimento Portland - determinação de perda ao fogo. Rio de Janeiro, 2004.

. NBR NM 43: Cimento Portland - determinação da pasta de consistência normal. Rio de Janeiro, 2003.

. NBR NM 65: Cimento Portland - determinação do tempo de pega. Rio de Janeiro, 2003.

. NBR NM 76: Cimento Portland - determinação da finura pelo método de permeabilidade do ar (Método de Blaine). Rio de Janeiro, 1998.

. NBR 12142/MB 3483: Concreto - Determinação da resistência à tração na flexão em corpos-de-prova prismáticos. Rio de Janeiro, 1991, 3p.

NBR 5735: Cimento Portland de alto-forno. Rio de Janeiro, 1991, 5p.

. NBR 5737: Cimentos Portland resistentes a sulfatos. Rio de Janeiro, 1992, 4p.

. NBR 5738: Moldagem e cura de corpos-de-prova cilíndricos ou prismáticos de concreto. Rio de Janeiro, 1994, 9p.

NBR 5739: Concreto - ensaio de compressão de corpos-de-prova cilíndricos. Rio de Janeiro, 1994, 4p.

. NBR 7722: Argamassa e concreto: determinação da resistência à tração por compressão diametral de corpos-de-prova. Rio de Janeiro, 1994, 3p. 
. NBR 7583: Execução de pavimentos de concreto simples por meio mecânico. Rio de Janeiro, 1986, 22p.

. NBR 8802: Concreto endurecido: determinação da velocidade de propagação de onda ultra-sônica. Rio de Janeiro, 1994, 8p.

$\mathrm{ACl}$ Committee 318, Building Code Requirements for Structural Concrete, American Concrete Institute, Farmington Hills, Michigan, 473p., 2008.

Committee 522, Pervious Concrete, 522R-06, American Concrete Institute, Farmington Hills, Michigan, 25p., 2006.

Committee 522, Specification for Pervious Concrete Pavement, 522.1-08, American Concrete Institute, Farmington Hills, Michigan, 7p., 2008.

ALAM, A.; HASELBACH, L.; COFER, W. F. Validation of the performance of pervious concrete in a field application with finite element analysis (FEA), 2011. Disponível em:

<http://wsu.academia.edu/AshrafulAlam/Papers/772589/Validation of the Performa nce of Pervious Concrete in a Field Application with Finite Element Analysis F $\underline{E A}>$

Acesso em: 3 Set. 2011.

ALBUQUERQUE, M. C. F.; BALBO, J. T.; SANSONE, E. C.; PINTO, P. C. Fracture Characterization of Roller Compacted Concrete Mixtures with Blast Furnace Slag and Industrial Sand. International Journal of Pavement Research and Technology. Vol. 04, No. 4, 2011

BALBO, J.T. Pavimentos de concreto. São Paulo: Oficina de Textos, 2009, 472 p.

BEAN, E. Z.; HUNT, W. F.; BIDELSPACH, D. A. Field Survey of Pavement Surface Infiltration Rates. Journal of Irrigation and Drainage Engineering, Vol. 133, No. 3, June, 2007. 
BEELDENS, A. Behaviour of Porous PCC Under Freeze Thaw Cycling. Tenth International Congress on Polymers in Concrete, Honolulu, Hawaii, 2001.

BeEldens, A.; VAN Gemert, D.; CAESTECKER, C. Porous Concrete: Laboratory Versus Field Experience. Proceedings $9^{\text {th }}$ International Symposium on Concrete Roads, Istanbul, Turquia, 2003.

CAPIELLA, K.; BROWN, K. Imprevious Cover and Land-use in the Chesapeak Bay Watershed. Center for Watershed Protection (CWP), Ellicott City, MD, 2001.

Carolinas Ready Mixed Concrete Association (CRMCA). Pervious Concrete Installation Course Information Packet. Carolinas Ready Mixed Concrete Association Inc, 2003.

CERVO, T. C. Estudo de Resistência à Fadiga de Concretos de Cimentos Portland para Pavimentação. Tese (Doutorado em Engenharia) - Departamento de Engenharia de Transportes, Universidade de São Paulo, São Paulo, 2004.

CHINDAPRASIRT, P.; HATANAKA, S.; CHAREERAT, T.; MISHIMA, N.; YUASA, Y. Cement Paste Characteristics and Porous Concrete Properties, Construction and Building Materials 22, Science Direct, p. 894-901, 2008.

CROUCH, L. K.; SMITH, N.; WALKER, A. C.; DUNN T. R.; SPARKMAN, A. Pervious PCC Compressive Strength in the Laboratory and the Field: The Effect of Aggregate Properties and Compactive Effort. Disponível em: http://www.rmc-

foundation.org/images/PCRC\%20Files/Construction\%20Techniques/Pervious\%20PC C\%20Compressive \%20Strength\%20in\%20the\%20Laboratory\%20and\%20the \%20Fie Id.pdf

Acesso: 11 Nov. 2011.

DAVIDS, W. G; WANG, Z.; TURKYYAH, G.; MAHONEY, J. P.; BUSH, D. ThreeDimensional Finite Element Analysis of Jointed Plain Concrete Pavement With 
EverFE2.2. Transportation Research Record: Journal of the Transportation Research Board. Paper N 03/2223, 2003.

DELLATE, N.; MRKAJIC, A.; MILLER, D. I. Field and Laboratory Evaluation of Pervious Concrete Pavements. Transportation Research Record: Journal of the Transportation Research Board. v. 2113, p. 132 - 139, Nov. 2009.

DELLATE, N; CLEARY, J. Developing a Structural Design Method for Pervious Concrete Pavement. Disponível em:

http://www.nssga.org/aftre/Symposium/2006-06.pdf

Acesso: 11 Nov. 2011

\section{ECODESENVOLVIMENTO.}

Disponível em: < http://www.ecodesenvolvimento.org/noticias/asfaltos-permeaveispodem-reduzir-problemas $>$

Acesso em: 24 Set. 2010.

ESTEVES, R. L. Quantificação das Superfícies Impermeáveis em Áreas Urbanas por Meio de Sensoriamento Remoto. 2006, 120p. Dissertação (Mestrado em Engenharia), Departamento de Engenharia Civil e Ambiental da Universidade de Brasília, Brasília, 2006.

FERGUSON, B. K. Porous Pavements - Integrative Studies In Water Management and Land Development, Taylor \& Francis Group CRC Press, 577p., 2005.

GHAFOORI, N.; DUTTA, S. Laboratory Investigation of Compacted No-fines Concrete for Paving Materials. Journal of Materials in Civil Engineering, V.7, No. 3, p. 183-191, 1995.

GOEDE, W. G. Pervious Concrete: Investigation into Structural Performance and Evaluation of the Applicability of Existing Thickness Design Methods. 2009, 198p. Thesis (Master in Engineering), Department of Civil and Environmental Engineering, Washington State University, Washington DC, 2009. 
HENDERSON, V. Pervious Concrete Pavement: An Integrated Laboratory and Field Study. CivE 742. University of Waterloo, Ontário, Canadá. 2008.

HENDERSON, V.; TIGHE, S. L.; NORRIS, J. Pervious Concrete Pavement. Transportation Research Record: Journal of the Transportation Research Board. v. 2095, p. 13-21, Nov. 2009.

HOULE, K. M.; ROSEEN, R. M.; BALLESTERO, T. P.; BRIGGS, J.F.; HOULE, J. J. Examinations of Pervious Concrete and Porous Asphalt Pavements Performance for Stormawater Management in Northern Climates. World Environmental and Water Resources Congress 2009: Great Rivers; Kansas City, MO. v. 342, p. 1105-1122, 2009.

HUANG, B.; WU, H.; SHU, X.; BURDETTE, E. G. Laboratory Evaluation of Permeability and Strength of Polymer-Modified Pervious Concrete, Construction and Building Materials 24, Science Direct, p. 818-823, 2010.

KAJIO, S.; TANAKA, S.; TOMITA, R.; NODA, E.; HASHIMOTO, S. Properties of Porous Concrete with High Strenght, Proceedings $8^{\text {th }}$ International Symposium on Concrete Roads, Lisboa, p. 171-177, 1998.

KEVERN, J. T.; SCHAEFER, V. R.; WANG, K. Temperature Behaviour of Pervious Concrete Systems. Transportation Research Record: Journal of the Transportation Research Board. v. 2098, p. 94-101, Set. 2009.

KIM, J. K.; KIM, Y. Y. Experimental Study of the Fatigue Behavior of High Strength Concrete. Cement and Concrete Research, vol. 26, No 10, p. 56-64, 1996.

KLAIBER, F.W.; LEE, D. Y. The Effects of Air Content, Water-Cement Ratio and Aggregate Type on the Flexural Fatigue Strenght of Plain Concrete. ACI SP-75, American Concrete Institute, Farmington Hills, p. 142-148, 1982. 
KOMLOS, K.; POPOVICS, S.; NIIRNBERGEROH, T.; BABD, B.; POPOVICS, J. S. Ultrassonic Pulse Velocity Test of Concrete Properties as Specified in Various Standards. Cement and Concrete Composities, V. 18, p. 357-364, 1996.

KUANG, X.; KIM, J. Y.; GNECCO I.; RAJE, S.; GAROFALO, G.; SANSALONE, J. J. Particle Separation and Hydrologic Control by Cementiteous Permeable Pavement. Transportation Research Record: Journal of the Transportation Research Board. v. 2025, p. 111-117, Jan. 2007.

LEE, M. G.; CHIU, C. T.; KAN, Y. C.; YEN, T. Experimental Study of Pervious Concrete on Parking Lot. GeoHunan International Conference - Material Design, Construction, Maintenance, and Testinf of Pavements. V. 193, n. 20, p. 125-131, Ago. 2009.

LI, J. Mix Design of Pervious Recycled Concrete. GeoHunan International Conference - Material Design, Construction, Maintenance, and Testinf of Pavements. V. 195, n. 15, p. 103-108, Ago. 2009.

McCUEN, R. H. Hydrologic Analysis and Design. Englewood Cliffs: Prentice-Hall. 1989.

MCCAIN, G.N.; DEWOOLKAR M. M. Strength and Permeability of Porous Concrete Pavements. Transportation Research Record: Journal of the Transportation Research Board. p. 01-13, 2009.

MONTES, F.; HASELBACH, L. Measuring Hydraulic Conductivity in Pervious Concrete. Environmental Engineering Science V. 23, p. 960-969, 2006.

National Ready Mixed Concrete Association (NRMCA). 2004. Freeze-Thaw Resistance of Pervious Concrete. Silver Spring, MD: NRMCA.

NEITHLATH, N. Development and Characterization of Acoustically Efficient Cementitious Materials. 2004, 246p. Thesis (Doctor of Philosophy in Engineering), Faculty of Purdue University, 2004. 
NEVILLE, A. M. Propriedades do Concreto. 3 ed., São Paulo: Pini, 1982, 738 p.

OLEK, J.; WEISS, W. J.; NEITHALATH, N.; MAROLF, A.; SELL, E.; THORNTON, W. D. Development of Quiet and Durable Porous Portland Cement Concrete Paving Materials. Final Report SQDH 2003-5 Center of Advanced Cement Based Materials, Purdue, 2003.

PARK, S.; TIA, M. An Experimental Study on the Water-Purification Properties of Porous Concrete, Cement and Concrete Research, V. 34, p. 177-184, 2004.

PERVIOUS CONCRETE PAVEMENT. Disponível em: $<$ http://www.perviouspavement.org>

Acesso em: 24 Set. 2011.

PINDADO, M. A; AGUADO, A.; JOSA, A. Fatigue Behavior of Polymer Modified Porous Concretes. Universitat Politècnica de Catalunya, School of Civil Engineering (ETESECCPB) Barcelona, Spain, 11p., 1999. Disponível em:

<http://upcommons.upc.edu/e-prints/bitstream/2117/2482/1/aguado cement_1.pdf> Acesso em: 12 Out. 2011.

Portland Cement Association. Thickness Design for Concrete Highway and Street Pavements. Canadian Edition, Ottawa, 1984.

RODDEN, R.; SMITH, T. Structural and Hydrological Design of Sustainable Pervious Concrete Pavements. Annual Conference of the Transportation Association of Canada, Edmonton, Alberta, 2011.

ROSELL, J. J., DOLZ, J., Características Macánicas Del Hormigón Poroso. Ingeniería Civil, 63, p. 82-88, 1987.

SCHAEFER, V.; WANG, K.; SULEIMAN, M.; KEVERN, J. Mix Design Development for Pervious Concrete in Cold Weather Climates. Final Report, Civil Engineering, lowa State University, 2006. 
SCHUELER, T. R. Controlling Urban Runoff: A Practical Manual for Planning and Design Urban BMPs. Washington: Metropolitan Council of Government. 1987.

SULEIMAN, M. T.; KEVERN, J.; SCHAEFER, V. R.; WANG, K. Effect of Compaction Energy on Pervious Concrete Properties, Proceedings of Concrete Technology Forum: Focus on Pervious Concrete, Nashville, TN, May 24-25, 2006.

TAMAI, M.; YOSHIDA, M. Durability of Porous Concrete. Artigo apresentado na Sexta Conferência Internacional sobre Durabilidade do Concreto, American Concrete Institute, 2003.

TENNIS, P.D.; LEMING, M.L.; AKERS, D.J. Pervious Concrete Pavements, EB302, Portland Cement Association, Skokie, Illinois, 36p., 2004.

TSENG, E. Reciclagem Total de Pavimentos de Concreto como Agregados para Construção de Novos Pavimentos de Concreto: O Caso do Rodoanel Metropolitano Mário Covas. 2009, 220p. Dissertação (Mestrado em Engenharia), Departamento de Engenharia de Transportes, Universidade de São Paulo, São Paulo, 2009.

TUCCl, C. E. M.; Parâmetros dos Hidrogramas Unitário para Bacias Urbanas Brasileiras. Revista Brasileira de Recursos Hídricos, Porto Alegre, v. 8, n.2, p. 195199, 2003.

TUCCI, C. E. M.; GENZ, F. Controle do impacto da urbanização In: Drenagem urbana, ABRH, 428p, 1995.

URBONAS, B.; STAHRE, P. Stormwater: Best Management Practices and Detention for Water Quality, Drainage and CSO Management. PTR Prentice Hall, Englewood Cliffs, New, USA, 1993.

U.S. ENVIRONMENTAL PROTECTY AGENCY, 2012. Disponível em: $<$ http://cfpub.epa.gov/npdes/stormwater/menuofbmps/index.cfm?action=browse\&Rbu tton $=$ detail \&bmp $=137 \&$ minmeasure $=5>$ 
Acesso: 26 Dez 2011.

VANCURA, M.; MACDONALD, K.; KHAZANOVICH, L. Microscopic analysis of paste and aggregate distresses in pervious concrete in a wet, hard freeze climate. Science Direct, 06p., 2011.

VIRGILIIS, A. L. C. Procedimentos de Projeto e Execução de Pavimentos Permeáveis Visando Retenção e Amortecimento de Picos de Cheias. 2009. 191p. Dissertação (Mestrado em Engenharia), Departamento de Engenharia de Transportes, Universidade de São Paulo, São Paulo, 2009.

VOLDER, A.; WATSON, T.; VISWANATHAN, B. Potential use of pervious concrete for maintaining existing mature trees during and after urban development. Science Direct, 08p., 2009.

WANG, Y.; WANG, J. Improvement of Porous Pavement. 2011. Disponível em: <https://www.usgbc.org/ShowFile.aspx?Document|D=9915> Acesso: 25 Nov. 2011.

YOUNGS, A. Pervious Concrete: It's for Real. Presentation at the Pervious Concrete and Parking Area Design Workshop, Omaha, NE, 2005.

ZAHARIEVA, R.; BODIN, F. B.; SKOCZYLAS, F.; QIRQUIN, E. Assessment of the Surface Permeation Properties of Recycled Aggregate Concrete, Cement and Concrete Composites 25, Science Direct, p. 223-232, 2003. 